\title{
Biochemical and physiological studies in visceral and vascular smooth muscle during ovine development
}

Citation for published version (APA):

Arens, Y. H. J. M. (2001). Biochemical and physiological studies in visceral and vascular smooth muscle during ovine development. [Doctoral Thesis, Maastricht University]. Universiteit Maastricht. https://doi.org/10.26481/dis.20010125ya

Document status and date:

Published: 01/01/2001

DOI:

10.26481/dis.20010125ya

Document Version:

Publisher's PDF, also known as Version of record

\section{Please check the document version of this publication:}

- A submitted manuscript is the version of the article upon submission and before peer-review. There can be important differences between the submitted version and the official published version of record.

People interested in the research are advised to contact the author for the final version of the publication, or visit the DOI to the publisher's website.

- The final author version and the galley proof are versions of the publication after peer review.

- The final published version features the final layout of the paper including the volume, issue and page numbers.

Link to publication

\footnotetext{
General rights rights.

- You may freely distribute the URL identifying the publication in the public portal. please follow below link for the End User Agreement:

www.umlib.nl/taverne-license

Take down policy

If you believe that this document breaches copyright please contact us at:

repository@maastrichtuniversity.nl

providing details and we will investigate your claim.
}

Copyright and moral rights for the publications made accessible in the public portal are retained by the authors and/or other copyright owners and it is a condition of accessing publications that users recognise and abide by the legal requirements associated with these

- Users may download and print one copy of any publication from the public portal for the purpose of private study or research.

- You may not further distribute the material or use it for any profit-making activity or commercial gain

If the publication is distributed under the terms of Article $25 \mathrm{fa}$ of the Dutch Copyright Act, indicated by the "Taverne" license above, 
Biochemical and physiological studies

in visceral and vascular smooth muscle

during ovine development 
(1) YHJM Arens, Maastricht 2000

ISBN 90-9014468-4

vormgeving en druk: Datawyse bv Maastricht 


\section{Biochemical and physiological studies in visceral and vascular smooth muscle during ovine development}

Proefschrift

ter verkrijging van de graad van doctor

aan de Universiteit Maastricht

op gezag van de Rector Magnificus,

Prof. dr. A.C. Nieuwenhuijzen Kruseman

volgens het besluit van het College van Decanen

in het openbaar te verdedigen

op donderdag 25 januari 2001 om 16.00 uur

door

Yvonne Henrica Johanna Maria Arens

geboren op 5 november 1969 


\section{Promotores}

Prof. dr. J. de Haan

Prof. dr. C.R. Rosenfeld

Co-promotor

Dr. L.L.H. Peeters

\section{Beoordelingscommissie}

Prof. dr. H.A.J. Struijker Boudier (voorzitter)

Prof. dr. C.E. Blanco

Prof. dr. J.P.M. Geraedts

Prof. dr. F. Ramaekers

Prof. dr. G. Visser (Universiteit Utrecht) 


\section{Contents}

Voorwoord

7

List of abbreviations 8

CHAPTER 1

Introduction: Smooth muscle physiology

CHAPTER 2

Introduction: Markers of smooth muscle development

CHAPTER 3

Material and Methods

CHAPTER 4

Maturational differences between aorta and bladder

CHAPTER 5

Umbilical and systemic artery contractile proteins

CHAPTER 6

Ontogeny of uterine smooth muscle proteins

CHAPTER 7

Cytoskeletal proteins in aorta and bladder

CHAPTER 8

Contractile protein alterations in pulmonary hypertensive sheep

CHAPTER 9

General discussion

Summary

Samenvatting

Curriculum vitae 


\section{Voorwoord}

In 1992 werkte ik 5 maanden in de research groep van Dr. Charles Rosenfeld en Dr. Kristine Kamm in het kader van een keuzestage voor mijn doctoraal examen geneeskunde. $\mathrm{Na}$ deze stage nam ik twee besluiten. Ten eerste wilde ik promoveren op het onderwerp waar ik in Dallas aan gewerkt had en ten tweede wilde ik voor langere tijd terug naar de Verenigde Staten. Charles Rosenteld en Louis Peeters waren onmiddellijk enthousiast voor dit plan.

Het zoeken naar een promotor binnen de faculteit en het vinden van financiële steun duurde wat langer. Gelukkig wilden Prof. de Haan en het Termeulen Fonds mij hier de benodigde middelen voor geven en kon ik beginnen aan dit proefschrift.

Vanaf 1995 heb ik met veel plezier in het laboratorium van Charles en Kristine gewerkt en heb ik ingezien dat promoveren met veel ups en downs gepaard gaat: van het maar niet willen lukken van experimenten en het ontdooien van een vriezer met mijn samples tot het winnen van een prijs, the young investigators award, voor mijn onderzoek in 1998.

Behalve een opleiding tot wetenschapper hebben deze jaren in het buitenland bijgedragen aan mijn persoonlijke ontwikkeling. Ik heb geleerd om 4000 mijl van huis mijn eigen boontjes te doppen.

Vervolgens ben ik op mijn plek beland in de genetica, waarin ik sinds 1999 werkzaam ben, mijn proefschrift heb afgerond en nu mijn opleiding tor klinisch geneticus hoop te voltooien.

Zonder jullie steun was dit me nooit gelukt:

Dr. C.R. Rosenfeld en zijn echtgenote Ann-Marie Rosenfeld, Dr. K.E. Kamm en Dr. J.T. Stull en de medewerkers van de laboratoria pediatrie en fysiologie in Dallas.

Prof. dr. J. de Haan en Dr. L.L.H. Peeters van de afdeling gynaecologie in Maastricht.

Dr. C.T.R.M. Schrander-Stumpel, Dr. C.E.M. de Die-Smulders, Mw. F. van der Lubbe en overige collegae van de afdeling klinische genetica in Maastricht.

Mijn ouders en zus.

Allen mijn dank. 


\section{Abbreviations}

$\begin{array}{ll}\text { ANG II } & \text { angiotensin II } \\ \text { ANOVA } & \text { analysis of variance } \\ \text { IP } & \text { inositolphosphate } \\ \text { LC } & \text { light chain } \\ \text { MHC } & \text { myosin heavy chain } \\ \text { MHCI } & \text { myosin heavy chain isoform } \\ \text { MHC-B } & 200 \mathrm{kDa} \text { nonmuscle MHC-isoform } \\ \text { MHC-A } & 196 \mathrm{kDa} \text { nonmuscle MHC-isoform } \\ \text { MLC } & \text { myosin light chain } \\ \text { MLCK } & \text { myosin light chain kinase } \\ \text { PSS } & \text { physiologic saline solution } \\ \text { SDS } & \text { sodium dodecyl sulfate } \\ \text { SM } & \text { smooth muscle } \\ \text { SM1 } & 204 \mathrm{kDa} \text { smooth muscle MHC-isoform } \\ \text { SM2 } & 200 \mathrm{kDa} \text { smooth muscle MHC-isoform } \\ \text { PA } & \text { pulmonary artery } \\ \text { PAH } & \text { pulmonary artery hypertension } \\ \text { PAP } & \text { pulmonary arterial pressure } \\ \text { PVR } & \text { pulmonary vascular resistance } \\ \text { PPHN } & \text { persistent pulmonary hypertension of the newborn }\end{array}$


CHAPTER 1

Smooth muscle contraction 


\section{Morphology of smooth muscle}

Contraction is the primary function of smooth muscle in adult animals. Differentiated smooth muscle expresses a unique assortment of contractile and structural proteins specialized for their function. Two distinct domains are known: the cytoskeletal channel and the contractile domain. In contrast to skeletal muscle, the arrangement of these molecular components still remains unclear. Not only is the conformation of the contractile unit not completely known, but also its organization with respect to the cytoskeleton and mechanisms by which the contractile unit and cytoskeleton are linked remain in debate (1) (Fig 1).

Smooth muscle differs from skeletal muscle and cardiac muscle in that it lacks visible cross-striations. The contraction unit is similar to the contractile unit of skeletal muscle, but is not arranged in regular arrays as in skeletal and cardiac muscle, and therefore, striation is absent. The smooth muscle actins $\alpha$ - and $\gamma$-actin, myosin, caldesmon, calmodulin and myosin light chain kinase are localized in the contractile domain, which forms mini-myotibrils responsible for force development. Actin and myosin are present in the thin and thick filaments, respectively, and slide on each other to produce contraction. The cytoskeleton consists of $\beta$-nonmuscle actin, filamin, calponin and interfilament proteins. Actin is attached to dense bodies by $\alpha$-actinin. In fact dense bodies in smooth muscle serve the sime role as $\mathrm{Z}$ discs in skeletal muscle. Some of the dense bodies are attached to the cell membrane, and others are placed inside the cell and are hold together by a scaffold of structural proteins, which link one dense body to another. Actin and myosin isoforms differ from the skeletal muscle isoforms. Smooth muscle contains fewer mitochondria than skeletal muscle and depends to a large extent on glycolysis for its metabolic needs $(1,2,3)$.

\section{Types}

Smooth muscle lines the wall of vessels and hollow organs. There are six types: vascular, respiratory, urinary, reproductive, gastrointestinal and ocular. In general all but ocular smooth muscle consists of unitary smooth muscle, whereas ocular smooth muscle acts as a multiunit. Unitary smooth muscle consists of a mass of hundreds of muscle fibers that contract together as a single unit. This occurs in large sheets or bundles, and their cell membranes adhere at multiple points as low resistance bridges, so that force can be transmitted from one muscle fiber to the next. The cell membranes are joined by many gap junctions, through which ions can flow from one cell to another so action potentials can travel from one fiber to the next, causing the muscle fibers to contract as one unit. This type of smooth muscle is referred to as syncytial smooth muscle. Multi unit smooth muscle consists of individual units without interconnecting bridges $(4,5,6)$.

The physiology and cell biology has been most extensively studied using vascular smooth muscle (7), whereas smooth muscle biochemistry has been 


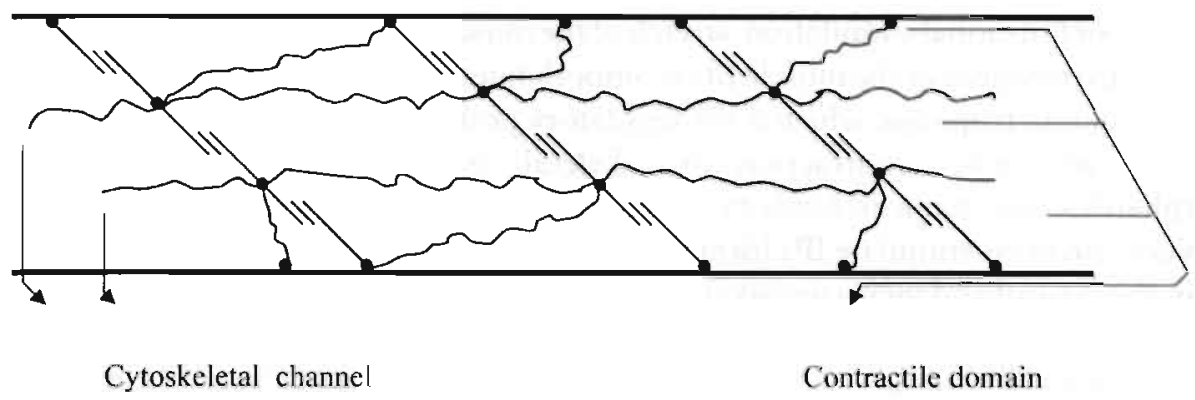

Figure 1. Localization of contractile and cytoskeletal components in smooth muscle cells.

studied using gastrointestinal smooth muscle (8). The discussion in this chapter is confined to the contractile phenotype of differentiated smooth muscle, as smooth muscle cells in culture rapidly dedifferentiate and change their phenotype to a noncontractile state $(8,9,10)$.

\section{Electrical and mechanical activity}

Excitation-contraction coupling is very slow in smooth muscle compared to skeletal or cardiac muscle. Thus less energy is required to sustain a contraction. The economy of energy utilization by smooth muscle is important, because visceral organs must sustain tonic contraction for relatively long periods. The membrane potential in smooth muscle is unstable and shows continuous, irregular contractions. This state of partial contraction is called tone. The resting value of the membrane potentials is low when tissue is active and high when inhibited. Smooth muscle contractions begin $100 \mathrm{~ms}$ after it is excited. Peak contractions occur at $500 \mathrm{~ms}$ and decline within 1 or 2 seconds. This is 30 times slower than a contraction elicited by an average skeletal muscle $(11,12)$.

Smooth muscle is often divided into two types, i.e. phasic and tonic smooth muscle. Generally, phasic muscles maintain tone poorly, have relatively high shortening velocities, and are capable of displaying regenerative action potentials. In contrast, tonic smooth muscles do not display action potentials or regenerative electrical activity under physiological conditions. They also have slower shortening velocities, but can maintain tone more effectively $(13,14)$.

\section{Smooth muscle contraction mechanism}

In smooth muscle two mechanisms are capable of initiating contraction responses, i.e., two forms of excitation-contraction coupling exist: pharmacomechanical and electromechanical coupling. Most smooth muscles contraction responses are initiated by increases in intracellular calcium. This can be caused by 
nerve or hormonal stimulation, stretch of the muscle fiber, or changes in the chemical environment of the muscle fiber. Smooth muscle, unlike skeletal muscle, does not contain troponin, which is the regulatory protein that is activated by calcium ions to cause contraction in skeletal muscle. Instead, an agonist (pharmacomechanical) binds to a receptor on the smooth muscle membrane and via $\mathrm{G}$-proteins stimulate $\mathrm{IP}_{3}$ formation, which then releases intracellular calcium in the cytosol and increases calcium entering the cell $(15,16)$. The membrane can also be depolarized by $\mathrm{KCl}$ (electromechanical), which also causes calcium to enter the cell through calcium channels and calcium to be released from intracellular stores. Calcium then binds to calmodulin, which forms a complex with the enzyme myosin light chain kinase. This catalyzes the phosphorylation of the regulatory light chain of myosin via ATP(adenosinetriphosphate) hydrolysis $(17,18)$ (Fig 2).

The cyclic formation and dissociation of complexes between actin and the myosin heads leads to a sliding of the thin and the thick filaments. It is caused by the ATP-ADP cycle in myosin, which produces a directional movement. In resting muscle the myosin heads are unable to interact with the actin units, because of the stearic interference by tropomyosin, a regulatory protein (Fig 3).

The hydrolysis products $\mathrm{ADP}$ (adenosinediphosphate) and $\mathrm{P}$ (phosphate) remain bound to myosin. When the muscle is stimulated, tropomyosin shifts its position. The myosin heads can than reach out from the thick filament and attach to actin on the thin filament. The binding of myosin-ADP and $\mathrm{P}$ to actin leads to the release of the $P$. The subsequent dissociation of ADP induces a major conformational change in the myosin head. This change in orientation of the myosin head relative to actin constitutes muscle contraction. ADP is released at the end of the contraction. The subsequent binding of ATP to myosin leads to the rapid release of actin and the myosin head is released from the thin filament. Finally, the bound ATP is hydrolyzed by the free myosin head, which resets for the next interaction with actin. When calcium ion concentration falls below a critical level, the process reverses automatically except for the dephosporylation of myosin. Reversal of myosin phosphorylation requires the enzyme myosinphosphatase, which splits the phosphate from the regulatory light chain. This causes the cycling to stop and contraction to cease $(19,20,21,22)$.

\section{Regulation of smooth muscle contraction}

In smooth muscle cells, development of force results from MgATP-dependent cyclic interaction of myosin in the thick filament and actin in the thin filament. The force of contraction is regulated by the concentration of free calcium surrounding the myofilaments (Fig 4). Increases in intracellular calcium result in activation of calcium/calmodulin (CaM)-dependent myosin light chain kinase (MLCK) and phosporylation of the $20 \mathrm{kDa}$ regulatory light chains (LC). This increases myosin ATPase activity and cross-bridge cycling. Phosphorylation of LC facilitates the 

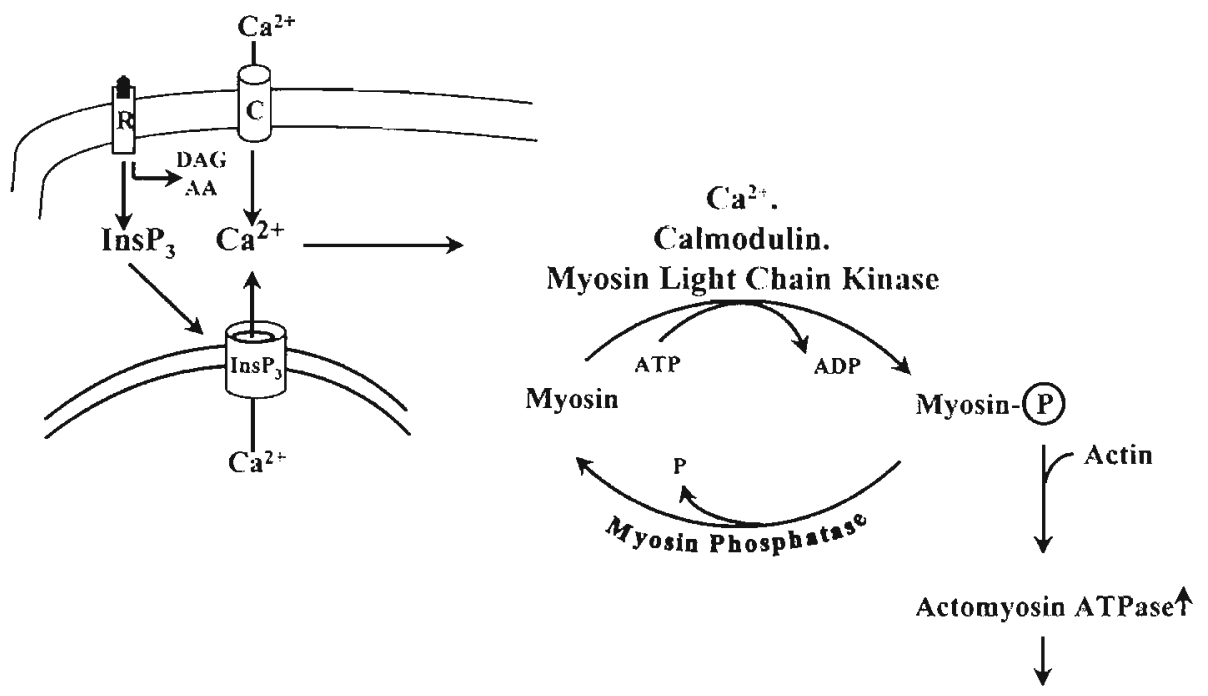

CONTRACTION

Figure 2. Regulation of contraction in smooth muscle.

ability of myosin monomers to assemble into filaments and increases the ATP-ase activity of myosin at least a 100-fold compared to non-phosphorylated myosin. Phosphorylation of the LC, together with free calcium are the regulating factors of the smooth muscle contraction cycle. LC phosphorylation is important for initiating the contraction, since the largest increase in LC phosphorylation occurs in the first 30-60s when tone is developing. Thereafter, phosphorylation drops to much lower levels, suggesting that it does not play a role in sustaining a contraction $(23,24,25)$.

The smooth muscle cell membrane has far more voltage-gated calcium channels than skeletal muscle cells, but has far less sodium channels. Therefore, the flow of calcium inside the cell is more important for generating an action potential. Calcium channels open far more slowly than sodium channels, but remain open much longer. As noted above, calcium acts directly on the contraction mechanism of smooth muscle to cause contraction. Therefore, it is necessary for intracellular calcium concentrations to be strictly regulated (26).

Smooth muscle intracellular calcium levels increase during contraction as a consequence of an influx of calcium from the extracellular space, and/or release of calcium from intracellular stores. Intracellular calcium is stored in the sarcoplasmic reticulum (SR). Calcium influx across the sarcolemna occurs through ion channels, or exchangers. Channel-mediated influxes of extracellular calcium occur through selective calcium-channels or nonselective cation channels, which can be voltage dependent or independent (27). Release from the 


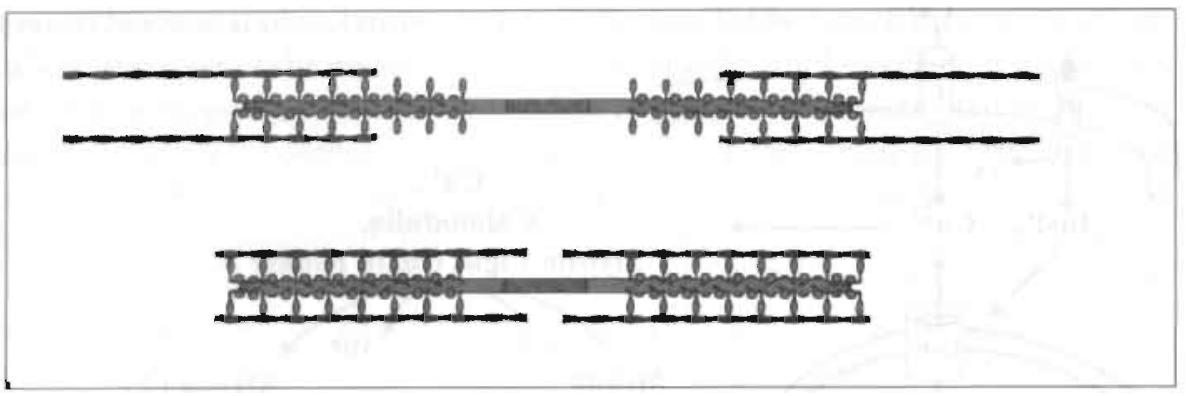

Figure 3. Schematic diagram showing the interaction of thick and thin filaments in smooth muscle contraction. (from Steyer biochemistry $4^{\text {th }}$ ed.)

intracellular stores proceeds through inositol 1,4,5-triphosphate (IP3)-regulated channels or by calcium-induced calcium release, generally via ryanodine receptor-regulated channels.

Relaxation is established by a decrease in intracellular calcium levels to resting values. Intracellular free calcium is extruded from the cell by the sarcolemnal $\mathrm{Ca}^{2+}$-ATPase or the $\mathrm{Na}^{+} / \mathrm{Ca}^{2+}$ exchanger. Intracellular calcium can also be taken up into the intracellular stores by the $\mathrm{Ca}^{2+}$-ATPase pump on the SR membrane. Specific calcium binding molecules are also present both in the myoplasm and in the SR. They act as cell buffers and are therefore reservoirs of bound calcium maintaining a low free calcium concentration in the cell and a large capacity of total calcium in storage.

\section{Latch mechanism}

Once smooth muscle has developed full contraction, the degree of activation can be reduced to less than the initial levels while the muscle maintains its full force of contraction. The energy required to maintain a contraction in smooth muscle is far less than that necessary for skeletal contraction. This mechanism is called the Latch mechanism. The purpose is to permit a tonic contraction for hours with minimal use of energy. Furthermore, minimal neurogenic or hormonal stimulation is required $(6,19,28)$. The cycling frequency of the myosin heads and velocity of contraction are greater when myosin kinase and myosin phosphatase are strongly activated. If activation of the enzymes decreases through dephosphorylation, the cycling frequency decreases, but the myosin heads will remain attached to the actin filament longer and longer, and the number of myosin heads attached to actin filaments remains constant. The number of heads attached determines the static force of contraction. Tension is maintained and energy requirement is low, because ATP is not degraded to ADP, unless a myosin head is detached. 


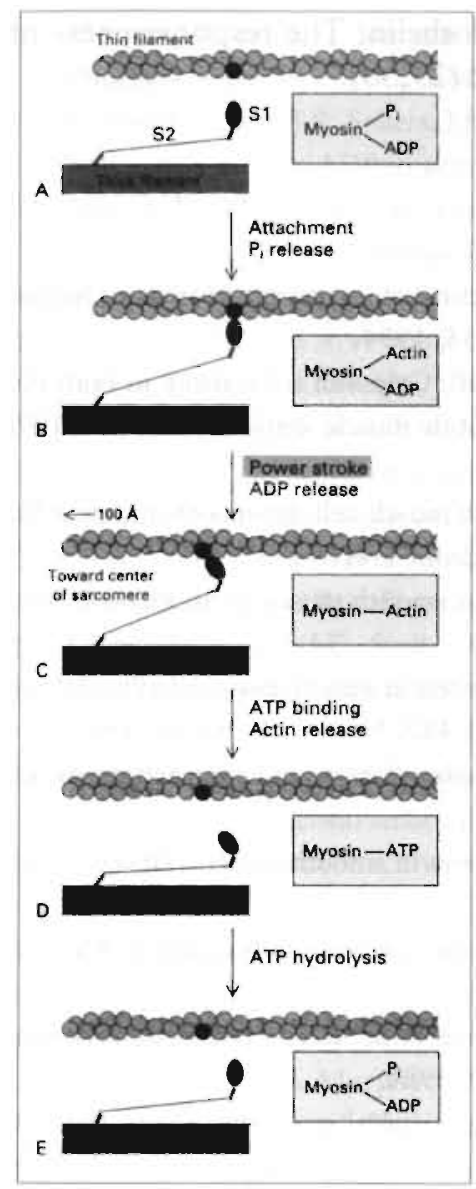

Figure 4. Proposed mechanism for the generation of force by the interaction of the myosin unit with the actin filament. In power stroke, the thin filament moves relative to the thick filament when the myosin unit undergoes conformational changes accompanying the release of ADP. (from Steyer biochemistry $4^{\text {th }}$ ed.)

Another characteristic of smooth muscle is its ability to return to its original force of contraction immediately after it has been elongated or shortened. This can be seen mostly in hollow organs such as, the bladder and uterus, where it is important to maintain the pressure within the lumen regardless of the length of the muscle fibers. This mechanism is closely related to the latch mechanism.

\section{Neuronal and hormonal stimulation}

Unlike skeletal muscle, which is activated only by nerves, smooth muscle is also regulated by many hormonal factors. Many circulating hormones are known to affect smooth muscle contraction. Some are activators of contraction while others are inhibitors, depending on the receptors on the cell membrane. The most important include norepinephrine, epinephrine, acetylcholine, angiotensin II, vaso- 
pressin, oxytocin, serotonin, histamine and endothelin. The responsiveness of smooth muscle to these agonists is tissue specific $(29,30)$.

\section{REFERENCES}

1. North, A.J., M. Gimona, Z. Lando, and J.V. Small. Actin isoform compartments in chicken Gizzard smooth muscle cells. J. Cell. Sci. 107:445-455, 1994.

2. North, A.J., M. Gimona, R. A. Cross, and J.V. Small. Calponin is localized in both the contractile apparatus and the cytoskeleton of smooth muscle cells. J. Cell. Sci. 107: $4.37-444,1994$.

3. Small J.V., and A.J. North. Architecture of the smooth muscle cell. In smooth muscle cells: molecular and cell biology. Ed. S.M. Schwartz. Academic Press 1993.

4. Owens G.K. Regulation of differentiation of vascular smooth muscle cells. Physiol. Rev. 75:487-517,1995.

5. Harsthshorne, D.J. Biochemistry of the contractile process in smooth muscle. In Physiology of the gastrointestinal tract. Ed. L.R. Johnson, 2:423-482. New York: Raven. 1987.

6. Hai C.M., and R.A. Murphy. $\mathrm{Ca}^{2+}$, crossbridge phosphorylation, and contraction. Annu. Rev. Physiol. 51:285-298, 1989.

7. Cabella, G. Structural apparatus for force transmission in smooth muscle. Physiol. Rev. 64:455-477,1984.

8. Hochachka, P.W. muscles as molecular and metabolic machines. Boca Raton, Florida. CRC Press, Inc. 1994.

9. Morgan D.L., and U. Proske. Vertebrate slow muscle: Its structure, pattern of innervation, and mechanical properties. Physiol. Rev. 64:103-169,1984.

10. Spray D.C., and M.V.L. Bennet. Physiology of gap junctions. Annu. Rev. Physiol. 47:281-303, 1985.

11. Homscher E. Muscle enthalpy production and its relationship to actomyosin ATPase. Annu. Rev. Physiol. 49:673-690, 1987.

12. Paul R.J. Smooth muscle energetics. Annu. Rev. Physiol. 51:331-349, 1989.

13. Kitazawa T., B.D. Gaylinn, G.H. Denney, and A.P. Somlyo. G-protein-mediated Ca ${ }^{2+}$ sunsitization of smooth muscle contraction through myosin light chain phosphorylation. J. Biol. Chem. 266:1708-1715, 1991.

14. Himpens B., G. Mathijs, A.V. Somlyo, T.M. Butler, and A.P. Somlyo. Cytoplasmic free calcium, myosin light chain phosphorylation, and force in phasic and tonic smooth muscle. J. Gen. Physiol. 92:713-729, 1988.

15. Brozovich F.V., and K.G. Morgan. Stimulus specific changes in the mechanical properties of vascular smooth muscle. Am. J. Physiol. 261:C497-505, 1991.

16. Brozovich F.V., and M. Yakamawa. Agonist activation modulates cross-bridge states in single vascular smooth muscle cells. Am J. Physiol. 263:C103-108, 1993.

17. Dillon P.F., M.O. Aksoy, S.P. Driska, and R.A. Murphy. Myosin phosphorylation and the cross-bridge cycle in arterial smooth muscle. Science Wash. DC 211:495-497, 1981. 
18. Morgan J.P., and K.G. Morgan. Vascular smooth muscle: the first recorded $\mathrm{Ca}^{2+}$ transients. Pfluegers Arch. 395:75-77, 1982.

19. Greene L.E., and J.R. Sellers. Effect of phosphorylation on the binding of smooth muscle heavy meromyosin.ADP to actin. J. Biol. Chem. 262:4177-4181, 1987.

20. Nishiye E, A.V. Somlyo, K. Torok, A.P. Somlyo. The effects of MgADP on cross-bridge kinetics: a laser flash photolysis study of guinea-pig smooth muscle. J. Physiol. Lond. 460:247-271, 1993.

21. Somlyo, A.P., and A.V. Somlyo. Signal transduction and regulation in smooth muscle. Nature Lond. 372:231-236, 1994.

22. Vyas T.B., S.U. Mooers, S.R. Narayan, J.C. Witherell, M.J. Siegman, and T.M. Butler. Cooperative activation of myosin light chain phosphorylation in permeabilized smooth muscle. Am. J. Physiol. 263:C210-219, 1992.

23. Kamm K.E., and J.T. Stull. Regulation of smooth muscle contractile elements by second messengers. Annu. Rev. Physiol. 51:299-313, 1989.

24. Kamm K.E., and J.T. Stull. Myosin phosphorylation, force and maximal shortening velocity in neurally stimulated tracheal smooth muscle. Am. J. Physiol. 249:C238-247, 1985.

25. Gerthoffer W.T., and R.A. Murphy. Myosin phosphorylation and regulation of crossbridge cycle in tracheal smooth muscle. Am. J. Physiol. 244:C182-187, 1983.

26. O'Donell, M.E., and N.E. Owen. Regulation of ion pumps and carriers in vascular smooth muscle. Physiol. Rev. 74:683-721, 1994.

27. Miller-Hance W.C., K.E. Kamm, J.T. Stull. Role of calcium and myosin phosphorylation in arterial smooth muscle contraction. In Essential hypertension and calcium. Ed. K. Aoki, E.D. Frohlich. Tokyo: Academic.

28. Hai C.M., and R.A. Murphy. Cross-bridge phosphorylation and regulation of latch state in smooth muscle. Am. J. Physiol. 254:C99-106, 1988.

29. White R.P. Pharmadynamic study of maturation and closure of human umbilical arteries. Am. J. Obstet. Gynecol. 160:229-237, 1989.

30. Arens, Y, R.A. Chapados, B.E. Cox, K.E. Kamm, and C.R. Rosenfeld. Differential development of umbilical and systemic arteries. II. Contractile proteins. Am. J. Physiol. 274: R1815-1823, 1998. 
CHAPTER 2

Markers of smooth muscle development 


\section{Background}

Smooth muscle acts to resist an imposed load in the case of large arteries, to propel organ contents in the case of the bladder and gastrointestinal tract, and to adjust organ caliber in the case of vascular and airway muscle. Thus, the primary function of smooth muscle in adult animals is contraction. In fetal sheep the vascular responses to infusion of several pressor agents, e.g., angiotensin II and $\alpha$-agonist, are reported to be less than that observed in the adult ewe (1). For angiotensin II this may be due to the 10 -fold greater metabolic clearance rate in the fetal versus adult sheep $(2,3)$. However, for other agents similarly studied, the explanation is less clear. It is possible that differences in vascular reactivity are accounted for by developmentally - regulated variations in receptor density or subtype and/or associated signal transduction mechanisms. Alternatively, the vascular smooth muscle itself may not be the mature contractile phenotype generally considered necessary for adult smooth muscle function (4). Proteins associated with smooth muscle contractile function are developmentally regulated, and the adult isoforms may not be expressed until late in fetal development or following birth $(4,5)$. However, there is evidence that the fetal bladder has the capacity to contract, thereby inducing micturition or voiding quite early in gestation $(6,7)$; but it is not known if fetal bladder smooth muscle function is similar to or different from that seen in the adult. It is noteworthy that the smooth muscle cell phenotype(s) expressed in vascular and nonvascular smooth muscle has not been compared or clearly defined throughout fetal and neonatal growth and development. Moreover, the relationship between smooth muscle cell phenotype, protein expression and contractile function has not been addressed.

\section{Differentiation}

Relatively little is known regarding the cellular and molecular function of differentiation of smooth muscle. Cellular differentiation is the process by which multipotential cells in the developing organism acquire those specific functions and properties that distinguish them from other cell types. It is widely assumed that the general principles governing the transition from multi-potential cells to committed cells (determination), committed cells to a cell-specific phenotype (differentiation) and the acquisition of the mature phenotype (maturation) will be applicable to smooth muscle. Maturation refers to the later stages of differentiation and is characterized by acquisition of further cell-specific properties ultimately resulting in the cellular phenotype characteristics of a mature phenotype. Determination is the process by which multi potential cells in the developing embryo become committed to a particular cell lineage. These stages represent a continuum and are only to be distinguished from each other by the cellular markers that characterize that stage and the molecular processes that control progression from one stage to another. Differentiation has been most extensively 
studied in skeletal muscle, where studies have shown that maintenance of the differentiated phenotype involves continuous activation or inactivation of genes $(8,9)$. For skeletal muscle several groups of regulatory genes have been identified; however, no such factors have yet been identified for smooth muscle (4). Studies in other cell types, principally skeletal muscle, have established general principles of differentiation may be applicable to other cell types, including smooth muscle $(9,10,11)$. Smooth muscle cells like most cells contain a complete set of genetic material, but express only a small amount of the genes present. It is not clear what determines the expression of which genes. In smooth muscle cells the major function is contraction. On the other hand, smooth muscle cells are capable of a multitude of other functions that vary at different developmental stages, during vascular repair, and in certain disease states (12). Fully differentiated smooth muscle cells differentiate at a very low rate, and they produce only small amounts of extracellular matrix proteins. These processes can be remarkably accelerated during development, injury or atherogenesis. It is important that during these stages the smooth muscle cell can maintain its major function, contraction, while at the same time recruit cells for repair.

\section{Markers of smooth muscle maturation}

Differentiated smooth muscle cells express a unique assortment of contractile and structural proteins specialized for their contractile function. Two distinct structural domains have been defined by immunohistochemical techniques $(13,14)$ (Fig 1).

A cytoskeletal channel and a contractile domain have been described. Myosin II (conventional filamentous myosin), smooth muscle actins $(\alpha+\gamma)$, h- and l-caldesmon, calponin, calmodulin and myosin light chain kinase are co-localized in the contractile domain, which forms myofibrils responsible for force development and/or shortening.

The cytoskeletal channel consists of colocalized $\beta$-nonmuscle actin, filamin, calponin and the intermediate protein desmin; it probably functions to provide tensile strength for the cell and as a scaffold for $\alpha$-actin containing dense bodies to which contractile elements attach. Smooth muscle isoforms of actin, myosin heavy chain (MHC), caldesmon and calponin are expressed in differentiated smooth muscle cells (14). The cytoskeletal and contractile proteins of nonmuscle cells and smooth muscle cells in culture are more plastic in that contractile assemblies can form transiently to perform specific functions and then dissemble, as illustrated by the contractile ring, which is composed of actin and myosin in dividing cells. Smooth muscle cells in culture express nonmuscle isoforms of the above proteins (4). However, quantitative and qualitative characterization of the temporal patterns of expression of smooth muscle and nonmuscle cytoskeletal proteins in smooth muscle during development is presently lacking. 


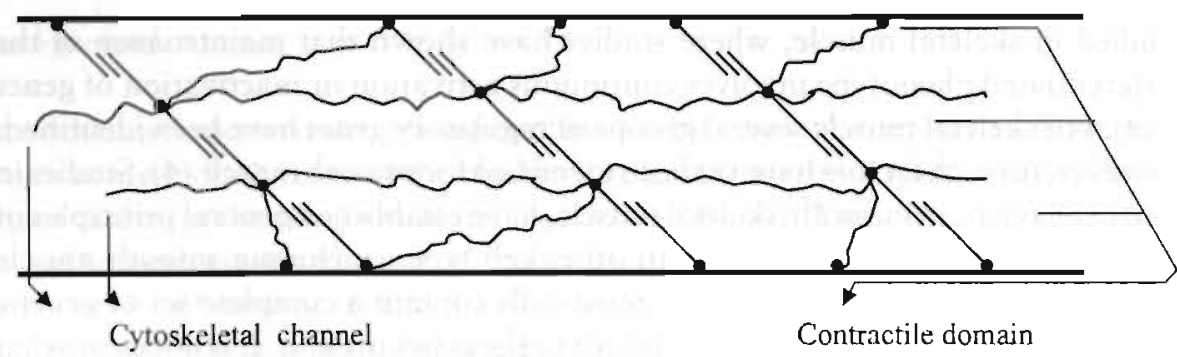

Figure 1. Localization of contractile and cytoskeletal components in smooth muscle cells.

As noted earlier, smooth muscle contraction results from the interaction of myosin in thick filaments with actin in thin filaments, but this may be dependent upon the expression of adult or mature isoforms of these and other smooth muscle proteins $(4,5)$.

\section{Actin}

Smooth muscle $\alpha$-actin was the first known marker of differentiated smooth muscle cells expressed during vasculogenesis. It is one of six isoactins expressed in mammalian cells. All are products of separate genes, although they share a high degree of homology in the protein coding regions. Mature fully differentiated smooth muscle cells express only four actin isoforms: smooth muscle $\alpha$-actin, non-muscle $\beta$-actin, non-muscle $\gamma$-actin and smooth muscle $\gamma$-actin. The most abundant of the actin isoforms is smooth muscle $\alpha$-actin, which accounts for $70 \%$ of actin content. The functional relevance for isoform diversity in actin proteins might be related to the differential affinity of actin isoforms for actin binding proteins. However, there are no major functional differences presently known between the different isoforms, although high smooth muscle $\alpha$-actin content is required for high force generating capacity $(4,15)$. Smooth muscle $\alpha$-actin is not exclusively expressed by smooth muscle. It is transiently expressed by mesodermally derived cells during development, tissue repair, and neoplastic growth.

Expression of isoactins is developmentally regulated in rats and humans. $\beta$-non-muscle actin is gradually replaced by $\alpha$-smooth muscle actin. There is marked species variability in degree of expression of these two proteins. In the newborn rat the predominant actin isoform is $\beta$-non-muscle actin, while $\alpha$-actin fractional content is approximately $27 \%$. In contrast, $\alpha$-actin in aortic smooth muscle cells from the 20 week old human fetus, accounts for $41 \%$ of total actin content $(4,16,17)$. 
The thick filament is an assembly of hundreds of individual myosin II molecules, each composed of six polypepride chains, two heavy chains and two pairs of light chains. The carboxy-terminal ends of two MHC wrap around each other, forming a coiled-coiled tail involved in filament assembly. The amino-terminal end is folded in a globular head containing the binding sites for actin and $\mathrm{Mg}^{2+}$-ATP, as well as for each of the light chains. The head domain is the site of chemomechanical transduction associated with actin-activation of Mg-ATPase activity (Fig 2). Smooth and nonmuscle myosin II heavy chains are derived from three distinct genes: one for smooth muscle (SMMHC,18) and two for nonmuscle (MHC-A and MHC-B,19). The smooth and nonmuscle myosin compose a class referred to as non-sarcomeric myosins that are distinct from myosins in striated muscles as they are regulated by $\mathrm{Ca}$-dependent phosphorylation of the regulatory light chain subunit. Products of all non-sarcomeric MHC genes have been reported to exist in vertebrate smooth muscle: SM1 $(204 \mathrm{kDa})$, SM2 (200 kDa), MHC-B (200 kDa), MHC-A (196 kDa) (20,21). SM1 and SM2 are alternatively spliced products of the SMMHC gene differing in the carboxyl-terminal portion of the molecule $(20,22)$ and are considered to be "mature" smooth muscle MHC isoforms. They account for nearly all MHC found in vascular smooth muscle of adult animals and humans and are co-expressed in a single smooth muscle cell. An additional spliced variant of smooth muscle that is not resolved by electrophoretic mobility occurs by the insertion of 7 amino acids in the $\mathrm{Mg}^{2+}$ - ATP binding site (23). Expression of the non-muscle MHC-A and MHC-B appears to be regulated in a tissue-dependent manner, with MHC-A expressed most abundantly in spleen and intestinal cells and MHC-B in brain and testes (24). While there is no evidence for splice variants of MHC-A, several alternatively spliced isoforms of MHC-B can occur due to inserts of 10-21 amino acids in the head region. Expression of the non-muscle isoforms, in particular MHC-B, is observed in smooth muscle cells undergoing growth and/or cell division and may be representative of cells of the synthetic phenotype $(19,25)$.

The expression of the various MHC isoforms as well as other contractile and cytoskeletal proteins appears to be developmentally regulated $(5,16,26,27)$, and the patterns of expression are both species and tissue specific. Although it is possible that each of these isoforms may exist within a single smooth muscle cell at various stages of development, thereby modifying smooth muscle function, this has not been clearly defined. While the SM1 isoform is expressed in varying amounts in smooth muscle tissues from the fetus and the neonate of several species $(22,26,27,28)$, including the human, the expression of SM2 is quite variable, and it is unclear when in development it is first present. For example, SM2 mRNA and protein are not detectable in fetal aorta and barely detectable in the neonate, but are seen in the human fetal rabbit aorta as early as 14 to 31 weeks gestation, with 


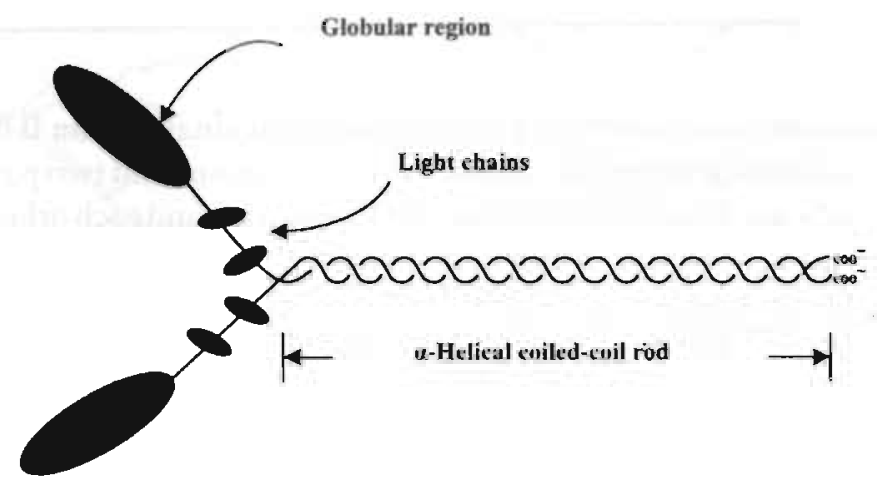

Figure 2. Schematic diagram of a myosin molecule.

values increasing after birth $(26,27)$. Further studies in a single species are needed in order to clarify this issue.

MHC-B, which also has been referred to as bovine brain MHC, chicken fibroblast MHC and SM embryonic (Smemb), is expressed most predominantly in rabbit and humin fetal aorta and decreases after birth $(22,27)$. It is also found transiently in proliferating smooth muscle cells within arteriosclerotic neointimas and cultured vascular smooth muscle cells $(19,22)$. During development MHC-B expression is reported to decrease, and in human tissues it is associated with a disappearance of MHC-B mRNA by adulthood (27). The fall in MHC-B expression is associated with increasing amounts of $S M 2$ protein and $\mathrm{mRNA}$ after birth, suggesting that this switch may serve as a marker for smooth muscle maturation. What orchestrates these synchronous changes in protein expression within the smooth muscle cell is not known. It has been observed that aortic smooth muscle MHC-B expression falls during development, and this is associated with a rise in SM2. In contrast, MHC-B was not expressed in ovine fetal bladder smooth muscle during the same period of development. If the repression of MHC-B expression is a marker of smooth muscle maturation, this suggests that bladder smooth muscle is more mature than vascular smooth muscle at similar times in development.

MHC-A was initially identified in human platelets and subsequently in aortic smooth muscle from neonatal rats and the bovine fetus (28). It was reported to decrease with increasing age. Its presence in the fetal rabbit aorta, however, remains questionable (22). While existing studies have provided insight into the ontogeny of $\mathrm{MHC}$ isoform expression in smooth muscle, they are limited by large gaps in time between tissue samples, the study of relative few tissue samples at each time period of development, and in general, little or no parallel data regarding the tissue contents of these proteins. Moreover, previous studies have provided no information regarding the impact of expression of these various 
isoforms, and in particular MHC-B, on smooth muscle function during development.

Although there is substantial homology between MHC-B and both SM1 and SM2, the function of MHC-B appears to be different. As noted earlier, it is found in cultured vascular smooth muscle cells and transiently in proliferating smooth muscle cells in damaged intimas (22). Thus, it may be integrated in smooth muscle proliferation, growth or migration. In support of this, antisense nonmuscle MHC oligonucleotides have been reported to suppress smooth muscle proliferation in vitro (19). There also is a phenotypic change in proliferating smooth muscle cells in culture, which express the MHC-B isoform, from spindle-shaped cells capable of contraction to polygonal cells with an increased amount of subcellular organelles involved with protein synthesis. These cells lose their thick filaments and have decreased capacity to contract, which may be proportionate to the expression of nonmuscle MHC (29). Therefore, the expression of MHC-B may constitute a marker for the synthetic state of smooth muscle cells, and its suppression during development may signal maturation of smooth muscle cell function. Studies defining the regulation of non-sarcomeric MHC gene expression are in their early stages. The promotor and flanking region of the SMMHC (18) and MHC-A, but not the MHC-B gene have been cloned, sequenced and analyzed. While the $5^{2}$-flanking region of the SMMHC contains a canonical TATA box sequence, MHC-A does not, which is typical of a housekeeping gene (18). Further analysis of the SMMHC promotor and flanking regions will continue with the aim of defining transcriptional activation factors that may yield insight into the regulation of differentiation of smooth muscle (18). Studies of the MHC-B gene promotor and flanking regions will provide novel insights into smooth muscle differentiation by revealing repressors of nonmuscle genes

\section{Caldesmon and calponin}

Caldesmon and calponin are thin-filament binding proteins found in smooth muscle cells that have been attributed a role in modulating the interaction of actin and myosin.

Caldesmon is considered a part of the contractile domain and is a major calmodulin- and actin-binding protein in smooth muscle and non-muscle cells (30). It inhibits superprecipitation and actomyosin $\mathrm{Mg}^{2+} \mathrm{ATP}$-ase activity (31). When added to permeabilized smooth muscle, it causes relaxation $(30,31)$. Two isoforms exist: h-caldesmon a $150 \mathrm{kDa}$ protein and $\mathrm{l}$-caldesmon a $70 \mathrm{kDa}$ protein. They are derived from a single gene by alternative splicing. (30,32). h-Caldesmon is abundantly expressed in differentiated smooth muscle, whereas l-caldesmon is predominantly expressed in non-muscle and immature smooth muscle cells $(30,33)$. Neither isoform is detectable in adult skeletal or cardiac muscle. Expression of caldesmon is developmentally regulated (34). 1-Caldesmon is detected in chicken gizzards at 10 days of gestation, while h-caldesmon is first expressed 
between 10 and 13 days. From day 13 there is a progressive increase in $\mathrm{h}$-caldesmon, that parallels increases in desmin, myosin and $\beta$-tropomyosin. In contrast, 1-caldesmon decreases progressively to undetectable levels 3 days posthatching (33).

Calponin is an actin-binding protein, which interacts with actin and tropomyosin in a $\mathrm{Ca}^{2+}$-dependent manner and with calmodulin in a $\mathrm{Ca}^{2+}$-independent manner. It inhibits the $\mathrm{Mg}^{2+}$-ATPase activity of myosin and therefore regulates smooth muscle contraction (35); but the mechanism remains unclear. Calponin is expressed in both the contractile and the cytoskeletal domain, but is predominantly located in the cytoskeletal compartment (14), where it is localized in the cytoplasmic dense bodies and the adhesion plaques at the cell surface. Calponin like caldesmon is not unique to smooth muscle cells.

\section{Myosin light chain kinase and Myosin light chain}

Myosin light chain kinase (MLCK) is activated by calcium and calmodulin and catalyzes the transfer of phosphate from MgATP to a serine residue near the $\mathrm{N}$-terminal of the myosin regulatory light chain. Phosphorylation is more important for regulation in smooth muscle compared to skeletal muscle. Phosphorylation of the regulatory light chain results in a marked increase in actin-activated myosin ATPase activity (36). There are two primary forms of MLCK; smooth muscle and skeletal, which are derived from two distinct gene products. The smooth muscle isoform is also present in nonmuscle cells.

Besides the two heavy chains, the myosin molecule consists of two pairs of light chains: the essential $17 \mathrm{kDa}$ light chains and the $20 \mathrm{kDa}$ regulatory light chains. Two smooth muscle isoforms of the essential $17 \mathrm{kDa}$ light chain have been identified $(37,38)$. They are derived from the same gene and are the products of alternative splicing $(39,40)$. LC17a is the most acidic one and LC17b the more basic $(37,38)$. Gastrointestinal smooth muscle and fibroblasts predominantly expresses the L.C17a form, while vascular smooth muscle expresses both. The 17 $\mathrm{kDa}$ light chains are necessary for modulating the affinity of myosin for actin and actomyosin ATPase activity. The ratio of the $17 \mathrm{kDa}$ isoforms might affect the functional and enzymatic activity. Tissues high in LC17b have a lower actomyosin ATPase activity compared to those with more abundant LC17a (37).

Multiple isoforms of the regulatory $20 \mathrm{kDa}$ myosin light chain exist. LC.20a is a smooth muscle light chain, whereas LC20b is a nonmuscle isoform, although both are expressed in smooth muscle and nonmuscle. It is not known if the different isoforms have different functional effects.

\section{Desmin and filamin}

The cytoskeleton of smooth muscle contains structural filaments of the intermediate class $(10 \mathrm{~nm})$, that are composed primarily of desmin and vimentin, with 
desmin being a muscle specific form. However, the relative portion differs between smooth muscle tissues. The function of the intermediate filaments (IF) remains unclear, although they are thought to constitute a part of the cellular skeleton in smooth muscle (41). Desmin is developmentally regulated in skeletal and cardiac muscle $(42,43,44)$. There is, however, a relative paucity of information regarding developmental regulation of desmin in vascular and visceral smooth muscle. It is expressed in developing smooth muscle from gastrointestinal and urogenital tracts $(42,43)$, but does not appear to be expressed in the developing vasculature of the mouse (45).

According to structural data, filamin is considered to be associated with the intermediate filaments and actin (46). It is a $280 \mathrm{kDa}$ protein, which dimerizes at the extreme c-terminal of the protein. The function of filamin in the cell is presently unknown. The contractile function might be less clear regarding its association with the structural proteins. Filamin has shown to inhibit actomyosinphosphatase in vitro at low concentrations and potentiate it in high concentrations.

\section{CONCLUSION}

Substantial studies have been performed in intact fetal animals, and in particular in fetal sheep over the past 20 years. These studies have been performed to determine the ability of the fetal cardiovascular system to adapt to various stress states, e.g, severe hypoxemia or hypovolemic shock as might occur during acute fetal-maternal hemorrhage. Still, our understanding of the development and the function of fetal smooth muscle remained cursory. What regulates smooth muscle growth and differentiation during development? The proteins that govern smooth muscle contractility are developmentally regulated and tissue specific. For example fetal bladder, which is mature very early in gestation, and aorta, which becomes mature predominantly after birth. The studies described in this thesis will provide a detailed characterization of the ontogeny of expression of both the smooth muscle contractile and cytoskeletal proteins, and importantly the relation that exists between these proteins and smooth muscle function. The potential impact rests not only in understanding smooth muscle development and what orchestrates these alterations, but also in understanding how smooth muscle growth is regulated, thereby potentially impacting this knowledge about smooth muscle responses to various insults as well as repair.

The aim of this project is to examine the proteins associated with smooth muscle function and proliferation during development and pregnancy, the specific goals of this project are to: 
1. Complete the descriptive studies of the expression of smooth muscle and non-muscle $\mathrm{MHC}$ isoforms in ovine fetal and neonatal bladder and vascular smooth muscle;

2. Compare ontogeny of the expression of contractile proteins with organ function by measuring stress generating capacity of bladder and vascular smooth muscle;

3. Determine if differences in vascular smooth muscle protein expression exist between umbilical and systemic arteries and if these differences are associated with different capacities to generate stress;

4. Characterize the contractile protein expression in myometrium of fetal and postnatal sheep and describe the effect that having been pregnant has on the expression of contractile proteins; and

5. Examine the hypothesis that cytoskeletal proteins a re expressed in coordination with actin during development in aortic and bladder smooth muscle.

\section{REFERENCES}

1. Yoshimura T., R.R. Magness, and C.R. Rosenfeld. Angiotensin II and alpha-agonist. I. Responses of ovine fetoplacental vasculature. Am. J. Physiol. 259:H464-472, 1990.

2. Rosenfeld C.R., A. Gresores, T.A. Roy, and R.R. Magness. Comparison of ANG II in fetal and pregnant sheep: metabolic clearance and vascular sensitivity. Am. J. Physiol. 268: E237-247, 1995.

3. Robillard J.E., R.A Gomez, J.G. Meernik, W.D. Kuehl, and D. VanOrden. Role of angiotensin II on the adrenal and vascular responses to hemorrhage during development in fetal lambs. Circ. Res. 50:645-650, 1982.

4. Owens G.K. Regulation of differentiation of vascular smooth muscle cells. Physiol. Rev. $75: 487-517,1995$.

5. Chern J., K.E. Kamm, and C.R. Rosenfeld. Smooth muscle myosin heavy chain isoforms are developmentally regulated in male fetal and neonatal sheep. Pediatr. Res. 38:697-703, 1995.

6. Ohel G., S. Haddad, and A. Samueloff. Fetal Urine Production and micturition and fetal behavioral state. Am J Perinatol 12:91-92, 1995.

7. Kogan BA, and H.S. Iwamoto. Lower urinary tract function in the sheep ferus: studies of autonomic control and pharmacologic responses of the fetal bladder. J. Urol. 141: 1019-1024, 1989.

8. Blau H., and D. Baltimore. Differentiation requires continuous regulation. J. Cell. Biol. 112:781-783, 1991.

9. Blau H, G. Pavlath, E. Hardeman, C. Chiu, L. Siberstein, S. Webester, S. Miller, and C. Webster. Plasticity of the differentiated state. Science Wash. DC 230:758-766, 1985.

10. Olson E.N. Interplay between proliferation and differentiation within the myogenic lineagc. Dev. Biol. 154:261-272, 1992. 
11. Weintraub $\mathrm{H}$. The MyoD family and myogenesis: redundancy, networks, and thresholds. Cell 75:1241-1244, 1993.

12. Schwartz S.M., G.R. Campbell, and J.H. Campbell. Replication of smooth muscle cells in vascular disease. Circ. Res. 58:427-444, 1986.

13. North, A.J., M. Gimona, Z. Lando, and J.V. Small. Actin isoform compartments in chicken Gizzard smooth muscle cells. J. Cell. Sci. 107:445-455, 1994.

14. North, A.J., M. Gimona, R. A. Cross, and J.V. Small. Calponin is localized in both the contractile apparatus and the cytoskeleton of smooth muscle cells. J. Cell. Sci. 107: 437-444, 1994.

15. Murphy R.A., C.M. Rembold, and C.M. Hai. Contraction in smooth muscle: What is latch? Prog. Clin. Biol. Res. 327:39-50, 1990.

16. Kocher O., and G. Gabbiani. Expression of actin mRNAs in rat aortic smooth muscle cells during development, experimental intimal thickening, and culture. Differentiation 32: 245-251, 1986.

17. Nikkari S.T., I. Rantala, P. Pystynen, and T. Nikkari. Characterization of the phenotype of smooth muscle cells in human fetal and aorta on the basis of ultrastructure, immunofluorescence, and the composition of skeletal and cytucontractile proteins. Artheresclerusis 74: 33-40, 1988.

18. Katoh Y., E. Loukianov, E. Kopras, A. Zilberman, and M. Periasamy. Identification of functional promotor elements in the rabbit smooth muscle heavy chain gene. J. Biol. Chem. 269:30538-30545, 1994.

19. Simons M., M. Wang, W. Mc.Bride, S. Kawamoto, K. Yamakawa, D. Gdula, R.S. Adelstein, and L. Weir. Human nonmuscle myosin heavy chains are encoded by two genes located on different chromosomes. Circ. Res. 69:530-539, 1991.

20. Nagai R., M. Kuro-o, P. Babij, and M. Periasamy. Identification of two types of smooth muscle myosin heavy chain isoforms by cDNA cloning and immunoblots analysis. ]. Biol. Chem. 264:9734-9797, 1989.

21. Kuro-o M. R. Nagai, K. Nakahara, H. Katoh, R. Tsai, H. Tsuchimochi, Y. Yazaki, A. Ohkubo, and F. Takaku. cDNA cloning of a myosin heavy chain isoform in embryonic smooth muscle and its expression during vascular development and in arteriosclerosis. J. Biol. Chem. 266:3768-3773, 1991.

22. Eddinger T.J., and J.A. Wolf. Expression of four myosin heavy chain isoforms with development in mouse uterus. Cell Motil. Cytoskeleton 25:358-368, 1993.

23. Kelley C.A., R.S. Adelstein. Characterization of isoform diversity in smooth muscle myosin heavy chains. Can. J. Physiol. Pharmacol. 72:1351-1360, 1994.

24. Kawamoto S., and R.S. Adelstein. Chicken nonmuscle myosin heavy chains: differential expression of two mRNAs and evidence for two different polypeptides. J. Cell. Biol. 112:915-924, 1991.

25. Seidel C.L., D. Rickman, H. Steuckrath, J.C. Allen, and A.M. Kahn. Control and function of alterations in contractile protein isoform expression in vascular smooth muscle. In: Regulation of Smoorh Muscle Contraction, edired by RS Moreland. New York: Plenum, p.315-325, 1991. 
26. Frid M.G., O.Y. Prinesva, A. Chiavegato, E. Faggin, M. Scatena, V.E. Koteliansky, P. Pauletto, M.A. Glukhova, and S. Satore. Myosin heavy-chain isoform composition and distribution in developing and adult human aortic smooth muscle. J. Vasc. Res. 30: 279-292, 1993.

27. Aikawa M., P.N. Sivan, M. Kuro-o, K. Nakahara, S. Takewaki, M. Ueda, H. Yamaguchi, Y. Yakazi, M. Periasamy, and R. Nagai. Human smooth muscle myosin heavy chain isoforms as molecular marker for vascular development and atherosclerosis. Circ. Res. 73:1000-1012, 1993.

28. Eddinger T.J., R.A. Murphy. Developmental changes in actin and myosin heavy chain isoform expression in smooth muscle. Arch. Biochem. Biophys. 284:2232-2237, 1991.

29. Chamley-Campbell J., G.R. Campbell, and R. Ross. Smooth muscle cell in culture. Physiol. Rev. 59:1-61, 1979.

30. Sobue K., and J.R. Sellers. Caldesmon, a novel regulatory protein in smooth muscle and non-muscle actomyosin systems. J. Biol. Chem. 266:12115-12118, 1991.

31. Nagai P.K., and M.P. Walsh. Inhibition of smooth muscle actin activated $\mathrm{Mg}^{2+}$ ATPase activity by caldesmon. J. Biol. Chem. 259:13656-13659, 1984.

32. Humphrey M.B., H. Herrera Sosa, G. Gonzalez, R. Lee, J. Bryan. Cloning of cDNAs encoding human caldesmons. Gene 112:197-204, 1992.

33. Ueki N., K. Sobue, K. Kanda, T. Hada, K. Higashino. Expression of high and low molecular weight caldesmons during phenotypic modulation of smooth muscle cells. Proc. Natl. Acad. Sci. USA 84:9049-9053, 1987.

34. Duband J.L., M. Gimona, M. Scatena, S. Sartore, J.V. Small. Calponin and SM22 as differentiation markers of smooth muscle: spatiotemporal distribution during avian embryonic development. Differentiation 55:1-11, 1993.

35. Winder S.J., and M.P. Walsh. Smooth muscle calponin: Inhibition of actomyosin MgATPase and regulation by phosphorylation. J. Biol. Chem. 265:10148-10155, 1990.

36. Sellers J.R. Mechanisms of phosphorylation-dependent regulation of smooth muscle heavy meromyosin. J. Biol. Chem. 260:15815-15819, 1985.

37. Helper D.J., J.A. Lash amd D.R. Hathaway. Distribution of isoelectric variants of the 17,000 dalton myosin light chain in mammalian smooth muscle. J. Biol. Chem. 263: 15748-15753, 1988.

38. Kamm K.E., and J.T. Stull. Myosin phosphorylation, force and maximal shortening velocity in neurally stimulated tracheal smooth muscle. Am. J. Physiol. 249:C238-247, 1985.

39. Hasegawa Y., Y. Ueda, M. Watanbe, and F. Morita. Studies on aminoacid sequences of two isoforms of $17-\mathrm{kDa}$ essential light chain of smooth muscle myosin porcine aorta media. J. Biochem. 111:798-803, 1992.

40. L.enz S., P. Loshe, U. Seidel, and H. Arnold. The alkali light chains of human smooth muscle and nonmuscle myosins are encoded by a single gene. J. Biol. Chem. 264:9009-9015, 1989.

41. Lazarides $\mathrm{E}$. Intermediate filaments: a chemically hererogeneous, developmentally regulated class of proteins. Annu. Rev. Biochem. 51:219-250, 1982. 
42. Franke W.W., E. Schmid, C. Freudenstein, M. Appelhans, M. Osborn, K. Weber, and T.W. Keenan. Intermediate-sized filaments of the prekeratin type in myoepithelial cells. J. Cell. Biol. 84:633-654, 1980.

43. Bennett G.S., S.A. Fellini, J.M. Croop, J.J. Otto, J. Bryan, and H. Holtzer. Differences among 100-angstrom filament subunits from different cell types. Proc. Natl. Acad. Sci. USA $75: 4364-4368,1978$.

44. Li Z.L., A. Lilienbaum, G. Butler-Browne, and D. Paulin. Human desmin-coding gene: complete nucleotide sequence, characterization and regulation of expression during myogenesis and development. Gene 78:243-254, 1989.

45. Schaart G., C. Viebahn, W. Langmann, and F. Ramaekers. Desmin and titin expression in early postimplantation mouse embryos. Development 107:585-596, 1989.

46. Small J.V., D.O. Fürst, and J. De Mey Localization of filamin in smooth muscle. J. Cell. Biol. 102:210-220, 1986. 


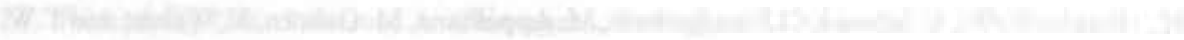

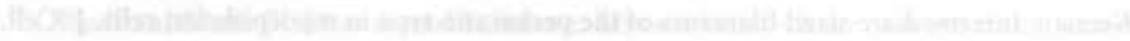

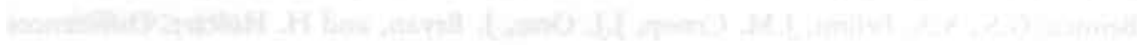

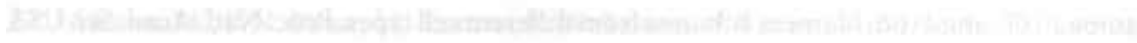

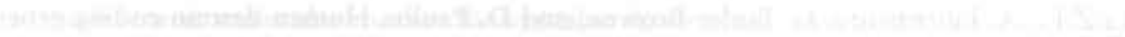

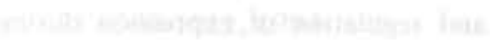


(:HAPTER 3

Materials and methods 


\section{Characterization of smooth muscle proteins}

During ovine development there are substantial tissue specific alterations that occur in the expression and contents of several important contractile proteins and the nonmuscle MHC isoforms in smooth muscle of a number of arteries and visceral tissues. In this thesis we studied animals before 80 days of gestation and after 3 mon postnatally, which had not been done before. We studied in detail the smooth muscle proteins associated with the development of smooth muscle cytoskeleton, e.g. $\alpha$-actin, desmin, filamin and calponin. Furthermore, the expression of other contractile protein has been extensively studied. They play an important role in the contractile properties of smooth muscle cells and possibly their maturation, e.g. caldesmon, $\alpha$-actin, myosin, calponin, calmodulin, and myosin light chain kinase.

\section{Tissue preparation}

Female fetal ( $72-140 d$ of gestation, $n=19$; term $145 d$ ), postnatal sheep ( $1 \mathrm{~d}-3 \mathrm{mo}$, $n=21)$ and maternal sheep $(n=4-6)$ were euthanized by rapid intravenous injection of pentobarbital sodium $(50 \mathrm{mg} / \mathrm{kg}$ ) to the mother or neonate via the external jugular vein. Segments of abdominal aorta, bladder and myometrium were quickly obtained from fetal, postnatal and adult animals and placed into iced physiological buffed solution containing (in mm): $137.0 \mathrm{NaCl}, 2.7 \mathrm{KCl}, 10$ $\mathrm{Na}_{2} \mathrm{HPO}_{4}, 1.76 \mathrm{KH}_{2} \mathrm{PO}_{4} .0 .1 \%$ diethyl pyrocarbonate, $\mathrm{pH}$ 7.4. Adventitia and epithelium from the myometrium were removed with sharp dissection and a soft cotton swab. Strips of tissue were cut, hlotted dry to remove of excess water and capillary blood, frozen in liquid nitrogen, and stored at $-80^{\circ} \mathrm{C}$ until studied. Additional segments were obtained in order to measure stresses. These studies were approved by the Institutional Review Board for Animal Research.

Female near-term fetal sheep $(n=12 ; 130-145$ days of gestation, term $145 \pm 5$ days) and maternal sheep $(n=8)$ were killed by rapid intravenous injection of pentobarbital sodium $(50 \mathrm{mg} / \mathrm{kg})$ to the mother via the external jugular vein. Segments of abdominal aorta, femoral artery and external and internal umbilical artery in case of the fetus were removed from each animal and placed into iced physiologic buffered solution ( $137.0 \mathrm{mM} \mathrm{NaCl}, 2.7 \mathrm{mM} \mathrm{KCl}, 10 \mathrm{mM} \mathrm{Na}_{2} \mathrm{HPO}_{4}$, $1.76 \mathrm{KH}_{2} \mathrm{PO}_{4}, 0.1 \%$ diethyl pyrocarbonate, $\mathrm{pH}$ 7.4). Endothelium and adventitia were removed from the arteries by sharp dissection. Strips of tissue were cut, blotted dry to remove excess water and capillary blood, frozen in liquid nitrogen, and stored at $-80^{\circ} \mathrm{C}$ until studied.

\section{Tissue preparation in model of pulmonary bypertension}

Eight pregnant mixed-breed western ewes with twin gestations were operated upon at the Universiry of California, San Francisco at $\sim 140 \mathrm{~d}$ of gestation under 
sterile condition with epidural anesthesia and intravenous sedation. One twin fetus $(n=8)$ was partially exposed through a hysterotomy, and a thoracotomy was performed as previously described (6). Briefly, the arterial truck and the main pulmonary artery were dissected, and an aortotomy and pulmonary arteriotomy were performed. Between these two arteries, an $8.0-\mathrm{mm}$ expanded polytetrafluoroethylene vascular graft ( $2 \mathrm{~mm}$ length) (Gore-tex; W.L. Goré and Assoc) was placed to provide an aortopulmonary shunt. The other twin $(n=7)$ served as a control and was not operated upon. The thoracotomy incision was closed, and the fetus was returned into the uterus. Amniotic fluid was replaced by warm saline before closure of the uterine incision. Postoperative, the ewes recovered and the fetuses were allowed to deliver spontaneously at term. Following delivery, lambs were maintained in a holding area until one month of age when they were killed with lethal doses of intravenous pentobarbital sodium, and tissue was collected. These protocols were approved by the Committee on Animal Research of the University of California, San Francisco.

The lungs were removed in block and third and fourth generations of PA and femoral arteries were collected. Adventitia and adjacent lung tissue were removed by blunt dissection and endothelium was removed with a soft cotton swab. Strips of arteries were cut, frozen in liquid nitrogen, and stored at $-80^{\circ} \mathrm{c}$ until studied.

\section{Protein analysis and contents}

Sodium dodecyl sulfate (SDS) homogenates were prepared from $10-20 \mathrm{mg}$ samples of frozen tissue as previously reported. Briefly, homogenates were divided into two aliquots. One was subjected to centrifugation at $10,000 \mathrm{x} g$ for 2 min and the supernatant removed to determine the soluble or cellular protein in each sample. The other sample was not centrifuged and was used to determine the total homogenate protein. Aliquots of both samples were analyzed for protein content by BCA reagent (Pierce, Rockford, III.). Aliquots of the supernatant containing bromphenol blue and 2-mercaptoethanol were subjected to SDS-Page, using $3-20 \%$ and $4 \%$ polyacryla mide gels to determine the contents of total actin, $\mathrm{MHC}$ and MHC-isoforms. For each tissue mini-gels were loaded with 20-40 $\mu \mathrm{g}$ of soluble protein and subjected to electrophoresis at $200 \mathrm{~V}$ until the dye front reached the bottom of the gel. Gels were stained with Coomassie Brilliant Blue overnight and appropriately destained to remove background staining. Stained gels were scanned, each lane in duplicate, with a laser densitometer (LKB Instruments, Inc., Stockholm, Sweden) to estimate the relative amounts of actin, MHC. Differences between measurements were $<5 \%$, and values for each band were averaged. The fraction of stained protein accounted for by actin, MHC was converted to micrograms using the total protein quantified by BCA reagent in each sample. Values are expressed as $\mu \mathrm{g} / \mathrm{mg}$ of wet weight. The band corresponding to filamin was previously identified by immunoblotting. Interfilament proteins in smooth muscle can be estimated from whole muscle preparations 
owing to their relative abundance. In addition, we confirmed by immunoblotting that this band contained desmin in both aortic and bladder samples. Values for each band were averaged, and the fractional content of filamin or IF protein was converted to micrograms using the total protein quantified by $\mathrm{BCA}$ reagent. Values are expressed as $\mu \mathrm{g} / \mathrm{mg}$ of wet weight.

\section{Western analysis}

MHC: Tissue extracts were subjected to electrophoresis in $4 \%$ polyacrylamide gels. Proteins were electrophoretically transferred to nitrocellulose paper at 80 $\mathrm{mA}$ overnight. Blots were incubated overnight with an antibody against SM2 (1:4000) or MHC-B (1:20,000). Following $2 \mathrm{~h}$ incubation with goat anti-mouse IgG conjugated with horseradish peroxidase $(1: 15,000)$, immunoreactive protein was visualized by chemiluminescence (ECL Amersham).

Caldesmon and calponin: Tissue extracts $(2.5 \mu \mathrm{g}$ of soluble protein) were subjected to electrophoresis in 3-20\% gradient polyacrylamide gels. Proteins were electrophoretically transferred to nitrocellulose paper at $100 \mathrm{~V}$ for $1 \mathrm{~h}$. The membranes were cut according to molecular weight markers. The top half of these blots were incubated overnight with antiserum against caldesmon $(1: 10,000)$, which detects the $h$ - and the l-form of caldesmon, and with goat anti-rabbit IgG conjugated with horseradish peroxidase $(1: 15,000)$. Immunoreactive protein was visualized by enhanced chemiluminescence (ECL, Amersham). The bottom half of the membranes were incubated overnight with an antibody against calponin $(1: 10,000)$. The next day they were incubated with goat anti-mouse IgG conjugated with horseradish peroxidase $(1: 15,000)$ and were visualized by ECL.

MLCK: Tissue extracts ( $5 \mu \mathrm{g}$ of soluble protein) were subjected to electrophoresis in $5 \%$ polyacrylamide gels. Proteins were electrophoretically transferred to nitrocellulose paper at $100 \mathrm{~V}$ for $\mathrm{lh}$. Blots were incubated overnight with an antibody against myosin light chain kinase $(1: 7500)$. The next day they were incubated with goat anti-mouse IgGconjugated with horseradish peroxidase (1:3000) and were visualized by enhanced chemiluminescence (ECL, Amersham).

MLC: These same samples (15 $\mu \mathrm{g}$ of soluble protein) were loaded and separated on $15 \%$ polyacrylamide gels. Proteins were transferred to $0.2 \mu \mathrm{m}$ nitrocellulose paper at $100 \mathrm{~V}$ for $1 \mathrm{~h}$. The membranes were incubated overnight with antiserum against the regulatory light chain $(1: 5000)$ and with goat anti-rabbit $\operatorname{IgG}$ conjugated with horseradish peroxidase $(1: 15,000)$ and visualized by ECL.

\section{Myosin light chain phosphorylation}

Strips of aorta and bladder were mounted for measurement of isometric force and quick-frozen with tongs precooled in liquid nitrogen either at rest or at the time of maximum contraction, using $10^{-3} \mathrm{M}$ phenylephrine for the aorta and femoral 
artery, $10^{-3} \mathrm{M}$ carbachol for the bladder and $10^{-5} \mathrm{M}$ seretonin for the umbilical artery. The frozen muscle was weighed, placed in frozen slurry of trichloroacetic acid $(10 \%, w t / v o l)$ in acetone that contained DTT $(10 \mathrm{mM})$, and allowed to thaw in order to denature cellular proteins. Thereafter the muscle was placed in $60 \mathrm{vol}$ of trichloroacetic acid $(10 \%$, wt,vol) and DTT $(10 \mathrm{mM})$ and homogenized. The precipitated protein was washed with diethyl ether and then suspended in urea-glycerol buffer for electrophoretic analysis of light chain phosphorylation by immunoblotting $(24,27)$. Samples were subjected to electrophoresis for $1 \mathrm{~h}$ at $400 \mathrm{~V}$ in a gel containing $10 \%$ polyacrylamide and $40 \%$ ( $\mathrm{vol} / \mathrm{vol}$ ) glycerol. Protein was transferred to nitrocellulose paper and nonphosphorylated and phosphorylated forms of the light chain $(1: 10,000)$ and peroxidase-conjugated goat anti-rabbit $\operatorname{IgG}(1: 15,000)$ with ECL. Relative amounts of nonphosphorylated light chain were quantified by laser densitometry.

\section{Force measurements}

Tissues were quickly placed in physiologic saline solution (PSS) containing (in mM) $120.5 \mathrm{NaCl}, 4.8 \mathrm{KCl}, 1.2 \mathrm{MgSO}_{4}, 1.2 \mathrm{NaH}_{2} \mathrm{SO}_{4}, 20.4 \mathrm{NaHCO}_{3}, 1.6$ $\mathrm{CaCl}_{2}, 10$ dextrose and 1 pyruvate. The endothelium was dissected away and strips of equal width were cut with a double blade cutting-tool in the circular direction of the muscle.

The strips were tied at both ends with 6.0 silk; the bottom was hooked to a stainless steel rod attached to a calibrated mechanical drive to adjust muscle length and the top part was tied to a Grass FT.03C force transducer. Force was recorded on a Grass model 7D polygraph. The strips were suspended in a $25-\mathrm{ml}$ jacket-organbath containing PSS at $37 \mathrm{C}$ and bubbled with $95 \% \mathrm{O}_{2}-5 \% \mathrm{CO}_{2}$ to maintain a $\mathrm{pH}$ of 7.4. Length-force relationships were determined as follows. Each strip was stretched to $0.5 \mathrm{~g}$ initially and length was measured; this was followed by equilibration for $1 \mathrm{~h}$. The PSS was emptied from each bath and replaced with $65 \mathrm{mM} \mathrm{KCl}(\mathrm{KCl}$ isotonically replaced $\mathrm{NaCl}$ in PSS). Maximal force obtained in response to $\mathrm{KCl}$ depolarization at a given length was taken as the total force. Passive force contributed by connective tissue in the strip was obtained after the tissue was placed in calcium-free PSS containing $2 \mathrm{mM}$ ethylene glycol-bis(-aminoethylether)- $N, N, N^{\prime}, N^{\prime}$-tetraacetic acid, eliminating force contributed by contraction of smooth muscle cells. After obtaining a value for passive force, calcium-free PSS was removed and replaced with regular $\mathrm{Ca}^{2+}$-containing PSS. Normal spontaneous activity was allowed to return, the tissue was stretched to a new length, and the stimulation-relaxation protucul was repeated. Active force generated by the arteries was obtained by subtracting the passive from total force at the respective length. The length at which maximal active force $\left(F_{o}\right)$ occurred was defined as the optimal length $\left(L_{o}\right)$ for each muscle strip. After this procedure, tissues were blotted and weighted. Tissue cross-sectional area was calculated based on the weight, density, and length of the tissue at $\mathrm{L}_{0}$. Stress 
$\left(\mathrm{N} / \mathrm{m}^{2}\right)$ was calculated by dividing the active force at optimal length by the cross-sectional area.

\section{Multiple agonists}

Strips of internal and external umbilical arteries were cut and hang in the muscle bath as for the optimal length-tension measurements. The strips were stretched to their optimal length as determined by length-force calculations, within three stretches of 20 minutes each. The strips were then stimulated twice with $65 \mathrm{mM}$ $\mathrm{KCL}$. All strips were relaxed with $\mathrm{Ca}^{2+}$-free PSS after each contraction. The strips of external and internal umbilical arteries were subsequently stimulated with phenylephrine $10^{-5} \mathrm{M}$, histamine $10^{-4} \mathrm{M}$, serotonin $10^{-5} \mathrm{M}$, carbachol $10^{-5} \mathrm{M}$, bradykinin $10^{-5} \mathrm{M}, \mathrm{PGF}_{2} 10^{-4} \mathrm{M}, \mathrm{PGE}_{2} 10^{-5} \mathrm{M}$, angiotensin II $10^{-7} \mathrm{M}$, endothelin $10^{-8} \mathrm{M}$. Concentration of agonist was determined by the maximal contraction given by a certain concentration of agonist in human umbilical cords.

\section{STATISTICS}

Data was analyzed using polynomial regression analysis to obtain estimates for significance of fit to functions indicating non-zero slope (Sigma Stat 1.0). Significance between groups was determined by Student's t-test and one-way analysis of variance (ANOVA) with Newman-Keuls correction for multiple comparisons. Grouped data are reported as means \pm SEM. Significance was taken as $p<0.05$. In addition animals were divided in 7 groups in the first study: fetal at $<100 \mathrm{~d}$, 101-130d, and 131-145d gestation; postnatal at 1-7d, 8-21d, 22-30d, and $>85 \mathrm{~d}$ after birth. 
CHAPTER 4

\section{Maturational differences between vascular and bladder smooth muscle during ovine development}

Yvonne H.J.M. Arens, Charles R. Rosenfeld, Kristine E. Kamm

Departments of pediatrics and physiology

University of Texas southwestern medical center, Dallas, Texals 


\section{A BSTRACT}

Maturation rates of vascular and visceral smooth muscle during ovine development were compared by quantifying contractile protein, myosin heavy chain (MHC) isoform contents and contractile properties in aorta and bladder from female fetal $(n=19)$ and postnatal $(n=21)$ sheep. Actin, myosin, and protein contents rose progressively throughout development in both tissues $(p<0.003$ ); however, expression patterns differed. During the last trimester, i.e. 101-130d (term $\sim 145 \mathrm{~d}$ ), bladder actin and MHC contents were $\sim 2$-fold greater $(\mathrm{p}<0.04$ ) than those in aorta. While the fractional content of $204 \mathrm{kDa}$ smooth muscle MHC (SM1) in bladder decreased from $74 \pm 3 \%$ at midgestation to $48 \pm 2 \%$ 3 mon postnatal, aorta exhibited an increase from $30 \pm 2 \%$ to $65 \pm 2 \%$. Bladder MHC migrating at $200 \mathrm{kDa}$ contained only smooth muscle SM2 throughout development. In contrast, $200 \mathrm{kDa} \mathrm{MHC}$ in aorta was predominantly nonmuscle MHC-B at mid-gestation, which was gradually replaced by SM2 as development progressed. Along with its early expression of SM2, bladder muscle obtained maximal stress generating capacity $\left(1.7 \times 10^{5} \mathrm{~N} / \mathrm{m}^{2}\right)$ by term gestation, whereas aorta exhibited no contractions until after birth. We conclude that whereas aortic smooth muscle maturation is delayed until after birth, bladder smooth muscle matures biochemically and funcrionally during prenaral devclopment, thus supporting early requirements for micturition.

Index terms: Actin, myosin, aorta, bladder 


\section{INTRODUCTION}

Rapid growth and maturation of the smooth muscle-containing organ systems are hallmarks of fetal development. Internal organs are formed in the mid to late stages of embryogenesis, with differentiation-specific smooth muscle protein markers seen first in the vascular outflow tract, followed by bronchial buds, gut, peripheral vasculature and bladder (1). Subsequent increases in contractile protein content, as well as muscle-specific composition, during fetal and postnatal development should accompany the need for increasing contractile capacity during maturation brought about by growing demands for organ function. In support of this, we found that, within the vasculature of near-term fetal sheep, umbilical arteries were both biochemically and functionally comparable to systemic vessels from adults, whereas fetal systemic vessels exhibited an immature phenotype (2) consistent with the relatively minor contribution of the systemic circulation as compared to the umbilical circulation to alterations in fetal vascular resistance $(3,4)$. Likewise in a preliminary study comparing protein compusition of visceral and vascular smooth muscles from late fetal gestation and neonatal male sheep (5), we noted that the bladder expressed only smooth muscle isoforms of myosin heavy chain (MHC), whereas the aorta expressed both smooth and non-muscle isoforms, suggesting that among organ systems there may also be differential rates of smooth muscle maturation.

Smooth muscle differentiation and maturation are distinguished by the gradual and sequential induction of tissue-specific protein markers (reviewed in Owens, 1995) (6). Smooth muscle myosin heavy chain (SM-MHC) is a key marker of the differentiated phenotype in that it appears exclusively in the smooth muscle cell lineage during development (1). Mature, "contractile" smooth muscles express smooth muscle and to a minor extent non-muscle isoforms of $\mathrm{MHC}(6,7)$. The four SM-MHC isoforms arise from a single gene through alternative splicing (reviewed in Kelley and Adelstein, 1994) (8). SM1 (204 kDa) and SM2 (200 kDa) differ in their carboxyl-terminal tail region, and additional splice variants of these forms contain a small insert in the amino-terminal head region. Non-muscle MHC isoforms MHC-A (196 kDa) and MHC-B (200 kDa) are the products of two distinct genes (9). They are expressed in all cell types and implicated in actin-based motile functions such as cytokinesis and cellular locomotion (10). Developmental patterns of MHC isoform expression in smooth muscle are largely understood from studies of blood vessels and exemplified by the presence of SM1 and non-muscle MHC in the late gestation fetus and neonate, with a gradual onset of SM2 expression after birth accompanied by reciprocal declines in non-muscle MHC (6). Expression patterns of MHC markers have been evaluated as qualitative assessments of differentiation; however, functionally consequential quantitative increases in content of these with maturation have received limited attention. 
In the present study we further investigate the proposal that smooth muscle maturation parallels requirements for organ function. Amounts and patterns of actin and $\mathrm{MHC}$ isoform expression as well as stress generating capacity were compared between the bladder, a visceral tissue known to be active in fetal sheep $(11,12)$, and the aorta, a vascular smooth muscle tissue extensively described in other species $(13,14,15,16,17,18)$ and known to be less reactive in fetal than adult sheep $(2,4)$. The sheep offers certain advantages as a model for studying aspects of fetal physiology, owing to the experimental ability to modify the hormonal milieu while studying physiologic responses in vivo $(19,20,21)$. Moreover, significant quantities of smooth muscle tissues can be obtained from fetal and neonatal sheep to perform protein analysis and contractile measures, thus providing a model system for relating contractile protein phenotype to contractile function over extended periods of development. The present results indicate that bladder smooth muscle undergoes accelerated maturation of contractile protein phenotype accompanied by the early onset of force development, as compared to the vascular smooth muscle of the aorta.

\section{METHODS}

\section{Tissue Preparation}

Female fetal (72-140d of gestation, $n=19$; term $\sim 145 \mathrm{~d}$ ) and postnatal (1-120d, $\mathrm{n}=25$ ) sheep were euthanized by a bolus infusion of sodium pentobarbital via the external jugular vein $(50 \mathrm{mg} / \mathrm{kg})$ of the mother in case of the fetus or of the newborn. Segments of abdominal aorta and the entire bladder were quickly removed and placed into iced phosphate buffered saline $(137.0 \mathrm{mM} \mathrm{NaCl}, 2.7$ $\mathrm{mM} \mathrm{KCl}, 10 \mathrm{mM} \mathrm{Na}_{2} \mathrm{HPO}_{4}, 1.76 \mathrm{KH}_{2} \mathrm{PO}_{4}, 0.1 \%$ diethyl pyrocarbonate, $\mathrm{pH}$ 7.4), which was bubbled with oxygen. Tissues for contraction measures were transported within $30 \mathrm{~min}$ to another laboratory and transferred to oxygenated physiological salt solution (22) for dissection as described below. Endothelium and adventitia were removed from the aorta with a soft cotton swab and blunt dissection, respectively, and the epithelium was removed from the bladder by sharp dissection. Strips of tissue were cut, blotted dry to remove excess fluid and capillary blood, frozen in liquid nitrogen, and stored at $-60^{\circ} \mathrm{C}$ until studied. Some strips were reserved unfrozen for measurements of isometric force.

\section{Protein Analysis and Content}

Samples of frozen tisue (10-20 mg) were homogenized in 40 volumes of sodium dodecyl sulfate (SDS) buffer containing $2 \%$ SDS, $20 \%$ sucrose and $0.4 \mathrm{M}$ Tris (pH 6.8) $(22,5,23)$. The homogenates were divided into two aliquots. The first was used to determine the total homogenate protein content. The second was 
subjected to centrifugation at $10,000 \times \mathrm{g}$ for $2 \mathrm{~min}$, and the supernatant was removed in order to determine the soluble or cellular protein in each sample. Densitometric analysis of supernatant and pellet fractions subjected to SDSpolyacrylamide gel electrophoresis (PAGE) showed that $>90 \%$ of myosin and $>85 \%$ of actin were recovered in the supernatant. Aliquots were analyzed for protein content by BCA reagent (Pierce). To the remaining homogenate and supernatant samples were added 2-mercaptoethanol and bromophenol blue to achieve final concentrations of $5 \%$ and $0.04 \%$ respectively. Samples of soluble protein [20-40 $\mathrm{g}$ based on loading curves determined for each tissue type (22)] were then subjected to PAGE in 3-20\% and $4 \%$ polyacrylamide gels to determine the contents of actin and $\mathrm{MHC}$ and the relative amounts of $\mathrm{MHC}$ isoforms, respectively. Gels contained molecular mass standards used to confirm relative mobility (Bio-Rad Laboratories). Positive identification of the positions of MHC and actin bands was confrimed by western blotting with antibodies generated in this laboratory (smooth muscle MHC) and purchased from Sigma ( $\alpha$-actin). The fractions of Coomassie blue-stained protein accounted for by actin and MHC in $3-20 \%$ gels and $\mathrm{MHC}$ isoforms in $4 \%$ gels were estimated by scanning laser densitometry to obtain a profile of peaks followed by area integration of the absorbency signal for each peak (Model 2202/2220, LKB Instruments). Lanes were scanned in duplicate. The fraction of protein accounted for by actin and MHC was converted to micrugrams knowing the amount of protein loaded. Values are expressed as $\mu \mathrm{g} / \mathrm{mg}$ of wet weight.

\section{Western Blot Analysis}

Tissue extracts were subjected to electrophoresis in $4 \%$ polyacrylamide gels, and proteins were electrophoretically transferred to nitrocellulose paper at $80 \mathrm{~mA}$ overnight. Blots were incubated overnight with antiserum. Antisera to SM2 (1:4000) or MHC-B (1:20,000) were raised in this laboratory against synthetic peptides specific to each form and characterized as described previously (5). Antisera against MHC-A (1:20,000) were generously provided by Drs. N. Murakami and J.R. Sellers. Purified bovine brain MHC-B was the gift of Dr. Barbara Barylko. Antibodies to MLCK (1:3000) were raised in this laboratory against purified bovine tracheal smooth muscle MLCK. Following $2 \mathrm{~h}$ incubation with goat anti-rabbit IgG conjugated with horseradish peroxidase (1:15,000), immunoreactive protein was visualized by chemiluminescence (ECL Amersham).

\section{Contractile Measurements}

Muscle strips (1.4 $\mathrm{mm}$ wide) from aorta and bladder were prepared using a double-bladed cutting tool $(22,24)$. Strips of a orta were open rings with endothelium removed by gently rolling a moist cotton swab over the lumenal surface. Bladder strips were cut from muscle in the longitudinal orientation and dissected 
clean as described above. Strips were mounted in organ baths for measurement of isometric force no more than two hours after being removed from the animals. Baths contained oxygenated $\left(95 \% \mathrm{O}_{2}, 5 \% \mathrm{CO}_{2}\right)$ physiological salt solution (PSS) [120.5 mM NaCl, $4.8 \mathrm{mM} \mathrm{KCl}, 1.2 \mathrm{mM} \mathrm{MgCl}, 1.6 \mathrm{mM} \mathrm{CaCl}, 1.2 \mathrm{mM}$ $\mathrm{NaH}_{2} \mathrm{PO}_{4}, 20.4 \mathrm{mM} \mathrm{NaHCO}_{3}, 10 \mathrm{mM}$ dextrose, $1 \mathrm{mM}$ pyruvate, $\left.\mathrm{pH} 7.4,37^{\circ} \mathrm{C}\right]$ (22). Length-force relations were determined for each tissue type at each gestational age. Stresses in response to phenylephrine $\left(10^{-6} \mathrm{M}\right)$ or PSS containing 65 $\mathrm{mM} \mathrm{KCl}$ (replacing $\mathrm{NaCl}$ ) were determined in strips stretched to the optimal length $\left(\mathrm{L}_{\mathrm{o}}\right)$ for maximal force $\left(\mathrm{F}_{\mathrm{o}}\right)$. Tissue cross-sectional area was calculated based on weight, density, and length of the tissue at $\mathrm{L}_{\mathrm{o}}$. Stress $\left(\mathrm{N} / \mathrm{m}^{2}\right)$ was calculated by dividing active force at $\mathrm{L}_{\mathrm{o}}$ by the cross-sectional area $(25,26)$.

\section{Myosin light chain phosphorylation}

The ability of contractile proteins to be activated by myosin light chain phosphorylation was assesed by comparing values in strips relaxed in calcum-free buffer with those maximally activated. Strips of aorta and bladder mounted for measurement of isometric force were quick frozen with tongs precooled in liquid nitrogen either relaxed or at the time of maximum contraction, using $10^{-3} \mathrm{M}$ phenylephrine for the aorta or $10^{-3} \mathrm{M}$ carbachol for the bladder. The frozen muscle was weighed, placed in a frozen slurry of trichloroacetic acid $(10 \%$, $\mathrm{wt} / \mathrm{vol})$ in acetone that contained DTT $(10 \mathrm{mM})$ and allowed to thaw. Following a $10 \mathrm{~min}$ incubation the liquid was decanted and the strip was homogenized in 60 volumes of trichloroacetic acid $(10 \%, \mathrm{wt} / \mathrm{vol})$ and DTT $(10 \mathrm{mM})$. Precipitated protein was washed with diethyl ether and then suspended in urea-glycerol buffer for electophoretic analysis of regulatory light chain phosphorylation by immunoblotting with antiserum raised against light chain purified from bovine tracheal smooth muscle (27). Separated proteins were transferred to nitrocellulose paper and light chain was detected by immunoblotting with specific antibodies using the ECL detection system (Amersham). Relative amounts of nonphosphorylated and phosphorylated light chain were quantified by scanning laser densitometry.

\section{STATISTICS}

Data were analyzed using polynomial regression analysis to obtain estimates for significance of fit to functions indicating non-zero slope (Sigma Stat 1.0). The variables used were protein contents ( $y$-axis) versus gestational age in days ( $x$-axis). This type of analysis is particularly useful when changes over time are gradual and not detected by analysis of variance of grouped samples. In addition, animals were divided into 8 groups. Fetal stages represent 1) midgestation $(<100 \mathrm{~d}), 2)$ the period of rapid growth preceding increases in estrogen and cortisol (101-130d), 
and 3) preparation for parturition (131-145d gestation). Postnatal stages represent 1) adaptation immediately following birth (1-7d),2) intermediate postnatal adaptation (8-21d), 3) completion of postnatal adaptation (22-30d), 4) 3-4mon or late postnatal, and 5) adult (>1yr). Significance between groups was determined by one-way analysis of variance (ANOVA) with Newman-Keuls correction for multiple comparisons. Grouped data are reported as means \pm SEM.

\section{RESULTS}

\section{Protein Contents}

In both aorta and bladder, total and soluble protein contents increased during development. Regression analysis in aortic smooth muscle demonstrated gradual increases from $<100 \mathrm{~d}$ gestation to $>3$ mon after birth $(R=0.40$ and $0.48 ; p=0.007$ and 0.001 , respectively; first order). Because of the gradual nature of these increases, significant differences between agegroups were detected only at 3 months after birth (Table 1). In contrast, bladder smooth muscle total and soluble protein increased around the time of birth, as evidenced by highly significant polynomial regressions $(\mathrm{R}=0.62$ and $0.83 ; \mathrm{p}<0.001$ each; second order) and pronounced differences occurring after $130 \mathrm{~d}$ gestation (total) or $7 \mathrm{~d}$ postnatal (soluble; Table 1). Additional but modest increases in soluble protein occurred after week one postnatal (Table 1).

Differences between tissues were also observed. Prior to $100 \mathrm{~d}$ gestation aortic total protein exceeded that of bladder $(p<0.02$, ANOVA), whereas after that age values did not differ. In contrast, soluble protein contents were similar at $<100 \mathrm{~d}$ gestation, but after that, bladder contents always exceeded aorta $(\mathrm{p}<0.03$, ANOVA).

\section{Actin and Myosin Heavy Chain Contents}

Actin and $\mathrm{MHC}$ contents in aortic smooth muscle also increased during development (Fig 1). Actin contents rose abruptly after $100 \mathrm{~d}$ gestation (Fig 1), increasing $-75 \%$, and then rose gradually, resulting in a nearly 4 -fold increase by 3 mon postnatal. In contrast, $\mathrm{MHC}$ contents rose gradually, levels doubling during development. The pattern in bladder smooth muscle was quite different. Actin contents rose rapidly in the last third of gestation, increasing $\sim 4$-fold by term, and remained stable thereafter (Fig 1). The rise in MHC contents paralleled that of actin, increasing 2 -fold by term and 3.3 -fold by $30 \mathrm{~d}$ postnatal.

The most striking differences between tissues were seen for MHC contents. At $<100 \mathrm{~d}$ gestation aorta MHC contents were similar to bladder. Beyond $100 \mathrm{~d}$ gestation, values in bladder were $\sim 2$-fold greater $(\mathrm{p}<0.004)$ than those in aorta. This difference continued throughout the remainder of development. Differences 
Table 1. Analysis of Variance for Age-grouped Data Comparing Total and Soluble Protein Contents in Aorta and Bladder Smooth Muscle During Ovine Development

\begin{tabular}{|c|c|c|c|c|c|c|c|c|c|}
\hline \multirow[b]{2}{*}{ Days } & \multicolumn{3}{|c|}{ Fetal Age } & \multicolumn{4}{|c|}{ Postnatal Age } & \multirow{2}{*}{$\begin{array}{l}\text { Aduit } \\
>1 y r\end{array}$} & \multirow[b]{2}{*}{$\mathrm{P}$-value } \\
\hline & $<100$ & $101-130$ & 131.145 & $1-7$ & $8-21$ & $22-30$ & $86-120$ & & \\
\hline Aorta (n) & (8) & (9) & (6) & (8) & (5) & (3) & (6) & (3) & \\
\hline Prot & $65 \pm 4^{4}$ & $75 \pm 6^{=1}$ & $86 \pm 9^{50}$ & $68 \pm 9^{a}$ & $78 \pm 12^{-\infty}$ & $82 \pm 5^{a b}$ & $100 \pm 9^{b}$ & $102 \pm 6^{\circ}$ & 0.025 \\
\hline Prot, & $40 \pm 3^{a}$ & $40 \pm 3^{a}$ & $41 \pm 4^{4}$ & $42 \pm 6^{*}$ & $47 \pm 7^{20}$ & $55 \pm 6^{4, b}$ & $61 \pm 7^{b}$ & ط1士 & 0.073 \\
\hline
\end{tabular}

\begin{tabular}{|c|c|c|c|c|c|c|c|c|c|}
\hline Bladder & (8) & (9) & (6) & (8) & (5) & (3) & (6) & (5) & \\
\hline Prot:e & $55 \pm 7^{\circ}$ & $74 \pm 5^{2 i}$ & $81 \pm 7^{\prime \prime}$ & $86 \pm 5^{\circ}$ & $90 \pm 7^{\circ}$ & $89 \pm 3^{b}$ & $86 \pm 5^{b}$ & $112 \pm 7^{*}$ & 0.004 \\
\hline Protssauto & $50 \pm 7^{\circ}$ & $56 \pm 4^{*}$ & $68 \pm 3^{\circ 0}$ & $69 \pm 6^{\circ 5}$ & $78 \pm 5^{\circ}$ & $86 \pm 3^{b c}$ & $72 \pm 5^{\circ}$ & $92 \pm 8^{c}$ & 0.001 \\
\hline
\end{tabular}

Values shown are means \pm SEM with units of $\mu \mathrm{g} / \mathrm{mg}$ weight. Results of ANOVA comparing groups are shown by letter superscripts indicating significant differences where no overlap occurs. P-values for ANOVA are shown.

between tissues for actin contents were more variable. Nonetheless, between $131 \mathrm{~d}$ gestation and $21 \mathrm{~d}$ postnatal, bladder actin contents exceeded those in aorta $(p<0.04)$.

\section{Myosin Heavy Chain Isoforms}

MHCs separated by electrophoresis in gels containing $4 \%$ polyacrylamide yielded two protein species at relative mobilities 204 and $200 \mathrm{kDa}$. No species of lower relative mass (196 kDa) were observed for any tissue studied. The relative amounts of the 204 and $200 \mathrm{kDa}$ bands were quantified by densitometry and expressed as percent of total. Changes in species content during development were determined as the product of the measured total myosin content and the percent mass of each species. Subsequently, identification of $\mathrm{MHC}$ isoforms within the $200 \mathrm{kDa}$ species was performed by Western analysis.

The predominant MHC species in aortas from mid-gestation fetal sheep ( $<100 \mathrm{~d}$ ) was the $200 \mathrm{kDa}$ form, which composed $70 \pm 3 \%$ of total MHC (Fig 2). The percentage of $200 \mathrm{kD}$ a species declined rapidly thereafter $(\mathrm{R}=0.61, \mathrm{p}<0.001$; second order) to $35 \pm 2 \%$ at $>3$ mon. The relative amount of the $204 \mathrm{kDa}$ isoform rose reciprocally $(\mathrm{R}=0.64, \mathrm{p}<0.001$; second order $)$ over the period studied from $30 \pm 2 \%$ to $65 \pm 2 \%$, respectively. Significant differences in the amount of each 


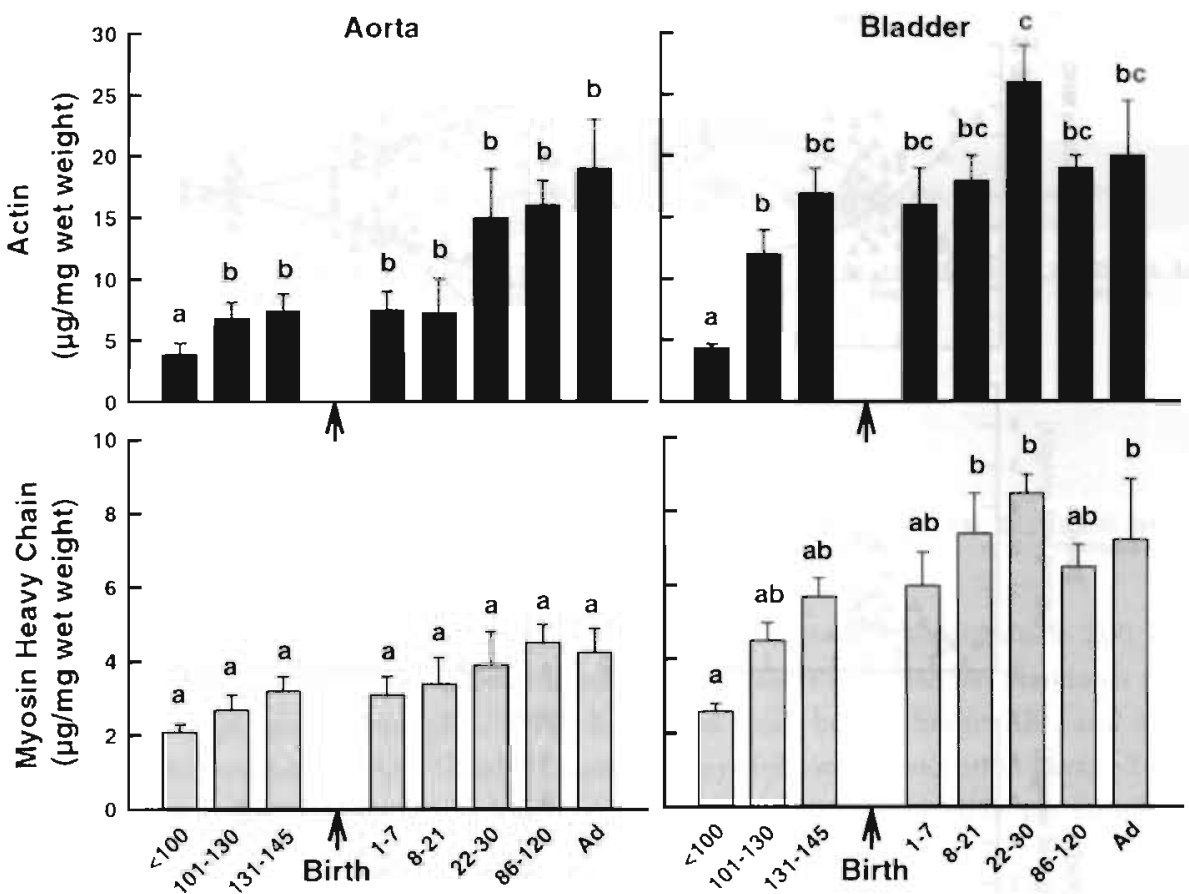

Figure 1. Alterations in actin and myosin heavy chain contents $(\mu \mathrm{g} / \mathrm{mg}$ of wet weighr) in aorta and bladder during ovine fetal and postnatal development. Actin and MHC contents include all isoforms. Each time interval represents $n$ values shown in Table 1 . Average time of birth $(\sim 145 \mathrm{~d}$ gestation $)$ is indicated by the arrow. Significant polynomial regression analyses were obrained for changes in actin and MHC contents, respectively, with aorta $(R=0.62$ and 0.52 , $\mathrm{p}<0.001$ each; first order) and bladder ( $R=0.70$ and $0.67, p<0.001$ each; second order). Groups not different as determined by ANOVA are indicated by the same letrer.

species were detected between fetuses at $<100 \mathrm{~d}$ gestation and animals $>1 \mathrm{wk}$ postnatal ( $\mathrm{p}<0.001 \mathrm{ANOVA}$ ). In striking contrast to the aorta, the predominant MHC species in bladder muscle from mid-gestation fetuses was the $204 \mathrm{kDa}$ form, which composed $74 \pm 3 \%$ of total MHC (Fig 2 ). This gradually declined ( $R=0.84$, $\mathrm{p}<0.001$; first order) to $48 \pm 2 \%$ at $3 \mathrm{mon}$, while the $200 \mathrm{kDa}$ species increased $(\mathrm{R}=0.84, \mathrm{p}<0.001$; first order) from $26 \pm 3 \%$ to $51 \pm 2 \%$. Values at $<100 \mathrm{~d}$ gestation significantly differed ( $\mathrm{p}=0.003$, ANOVA) from those at $>21 \mathrm{~d}$ postnatal.

Calculation of the tissue content of these $\mathrm{MHC}$ species $(\mu \mathrm{g} / \mathrm{mg}$ wet weight) resulted in a pattern distinct from that seen for the relative amounts (Fig 2). In aorta the $204 \mathrm{kDa}$ isoform content increased 4.3 -fold by 3 mon postnatal $(\mathrm{p}<0.01$ ANOVA). The $200 \mathrm{kDa}$ isoform content, however, was unchanged throughout development (Fig 2). In contrast, amounts of both 204 and $200 \mathrm{kDa}$ species in 

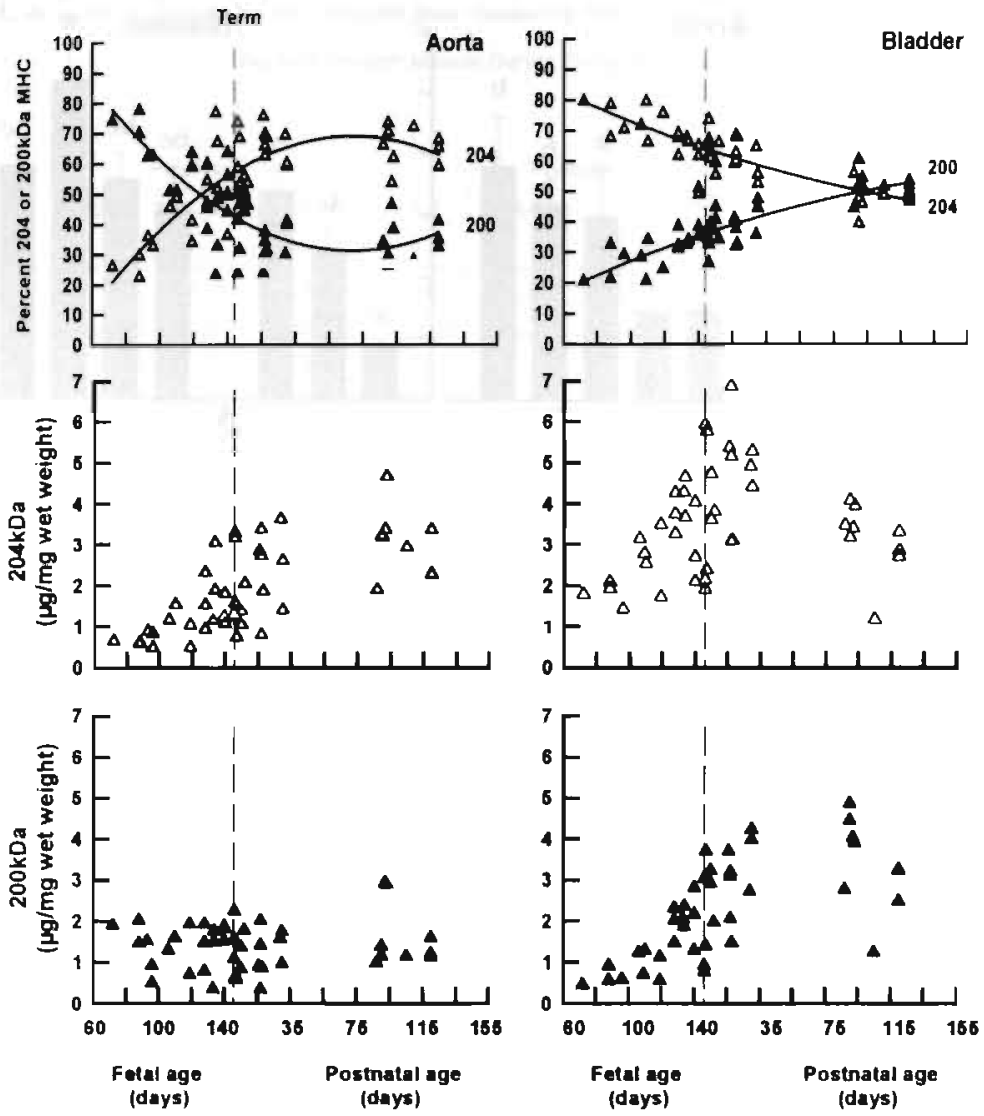

Figure 2. Relative and absolute changes in $204 \mathrm{kDa}$ and $200 \mathrm{kDa} \mathrm{MHC}$ isoforms in aorta and bladder during ovine development. (Top panels) Values were derived by calculating the percent of total staining MHC $(204+200 \mathrm{kDa})$ comprised of each form. Polynomial regression curves are shown as solid lines through the data to distinguish the two groups. (Middle and lower panels) Absolute changes in contents of the $204 \mathrm{kDa}$ and $200 \mathrm{kDa}$ MHC isoforms ( $\mu \mathrm{g} / \mathrm{mg}$ of wet weight) in aorta and bladder during ovine development. Graph properties as described in Figure 1. Significant polynomial regression analyses for $204 \mathrm{kDa}$ protein were obtained for aorta ( $R=0.68, \mathrm{p}<0.001$; first order) and bladder ( $\mathrm{R}=0.58, \mathrm{p}<0.001$; second order) as well for $200 \mathrm{kDa}$ protein in bladder $200 \mathrm{kDa}$ protein $(R=0.65, p<0.001$; first order). The $200 \mathrm{kDa}$ isoform content of aorta was unchanged, averaging $1.4 \pm 0.1 \mu \mathrm{g} / \mathrm{mg}$ wet weight. 
SM2

Aorta

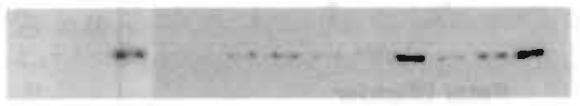

Std Std Std $88 \quad 93 \quad 110128140 \quad 2 d \quad 15 d \quad 29 d 3 m 4 m$ Plt B8 SH2 Fotal Postratal

\section{Bladder}

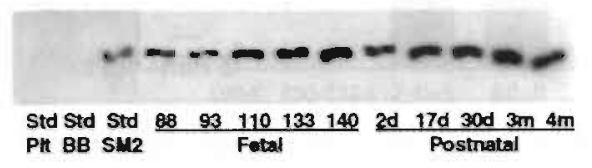

MHC B
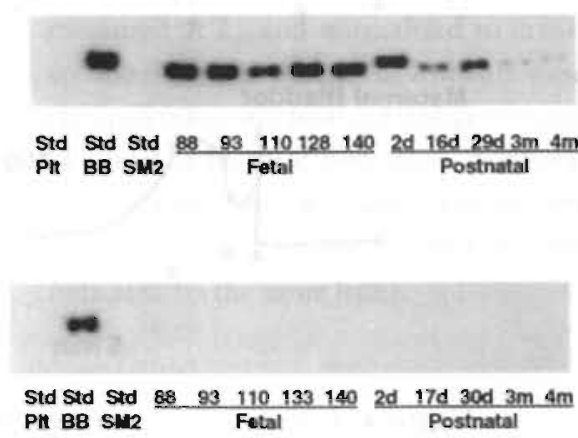

Figure 3. Representative immunoblots illustrating the change in smooth muscle $200 \mathrm{kDa}$ isoforms SM2 and MHC-B during ovine development in aorta and bladder. Standards (Std) included sheep platelet lysates (PIt), MHC-B purified from bovine brain (BB), and adult myometrial homogenate (SM2). Numbers represent days following conception (term $~ 145 \mathrm{~d}$ ) and birth. Separating gels were loaded with protein to yield $200 \mathrm{ng}$ total MHC per sample, as calculated from MHC contents assessed above.

bladder, increased rapidly and in parallel, with increases of 2.7 - and 6 -fold respectively ( $\mathrm{p}<0.02$ and $=0.002$, ANOVA).

The $200 \mathrm{kDa}$ MHC species may contain SM2 and/or MHC,-B. The developmental dependence of expression of each was determined by immunoblotting with antibodies specific for SM2 and MHC-B (7). This analysis was used to qualitatively assess patterns of isoform expression (Fig 3). Each blot was loaded with three standards: sheep platelets as a marker for MHC-A, purified bovine brain myosin as a marker for MHC-B, and adult ovine myometrium as a marker for SM2. Although we never detected a protein species at $196 \mathrm{kDa}$, it is possible that ovine MHC-A may migrate at a different position. We were not able to rule out the presence of MHC-A in these samples because antibodies against human platelet MHC-A peptide did not cross-react with sheep platelet protein and polyclonal antibodies against human platelet MHC-A showed cross-reactivity with MHC-B. The specificities of anti-MHC-B and anti-SM2 are illustrated on immunoblots in Fig 3. Although there was no change in aortic total $200 \mathrm{kDa}$ MHC content during development (Fig 2), the isoform distribution changed dramatically (Fig 3). MHC-B was abundant prenatally and declined rapidly after birth, while SM.2 was barely detected at early time points prenatally and increased most dramatically after birth. In striking contrast to the aorta, bladder muscle showed no detectable expression of MHC-B, even at mid-gestation, whereas SM2 was abundant throughout development and increased prior to and after birth (Fig 3). 

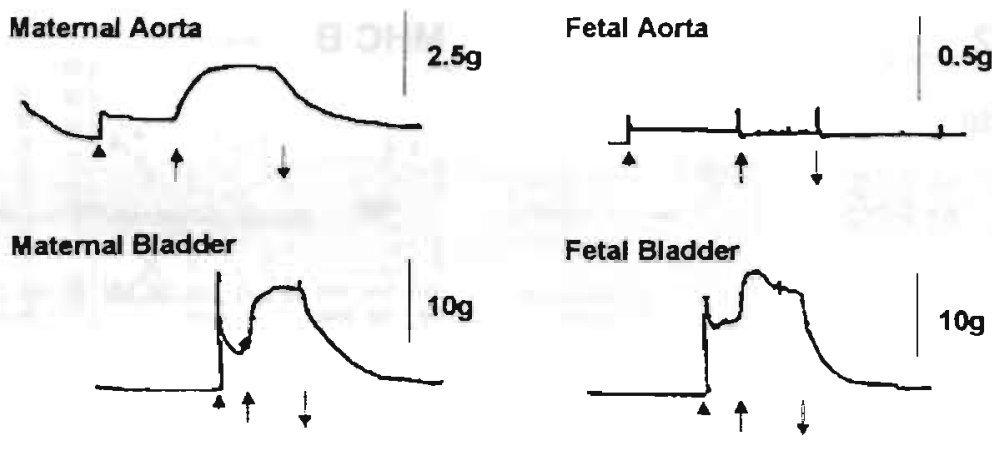

\section{$5 \overline{\min }$}

$5 \overline{\min }$

Figure 4. Isometric force tracings from maternal and fetal smooth muscle tissues collected near term (130-145d gestation). Indicated tissues were mounted for force measurements as described. Strips were stretched $(\boldsymbol{\Delta})$, then stimulated ( $\uparrow$ ) with $10^{-6} \mathrm{M}$ phenylephrine (aorta) or $65 \mathrm{mM} \mathrm{KCl-PSS}$ (bladder), followed by relaxation $(\downarrow)$ in $\mathrm{Ca}^{2+}$-free PSS containing $2 \mathrm{mM}$ EGTA.

\section{Isometric Force Development}

We compared contractile responses of aorta and bladder smooth muscle strips from $100 \mathrm{~d}$ gestation and near-term fetal sheep with $2-4 \mathrm{wk}$ neonates and adults. Strips of fetal aorta showed no contractile response (Fig 4) to any agent tested $\left(\mathrm{KCl}\right.$, phenylephrine, histamine, serotonin, $\mathrm{PGF}_{2 \alpha}$, ATP, carbachol, angiotensin II, or endothelin), whereas strips of bladder muscle gave robust contractions with $\mathrm{KCl}$ depolarization and carbachol. All strips of adult aorta and bladder contracted in response to $\mathrm{KCl}$ and other agents. Maximal active stress was determined from the results of the length-force relations. Strips were stretched in calcium-containing PSS, stimulated with $65 \mathrm{mM} \mathrm{KCl} \mathrm{PSS,} \mathrm{then} \mathrm{relaxed} \mathrm{in}$ calcium-free PSS containing $2 \mathrm{mM}$ EGTA. Active force was calculated as the difference between peak force and the resting (passive) force following relaxation in calcium-free PSS. Bladder muscle exhibited significant tone following stretch, which was removed after incubation in calcium-free PSS (Fig 4). Values of maximal active stress are shown in Fig 5. Contraction responses in $100 \mathrm{~d}$ and term fetal aortic strips were markedly attenuated compared to vessels from neonates and adults. Although responses of aortas from fetal animals were unmeasurable, aortic stress increased to near-adult values soon after birth. In contrast, bladder muscle generated significant stress at $100 \mathrm{~d}$ gestation and values increased 7 -fold during the late fetal period (Fig 5). This was followed by a progressive decline postnatally. 


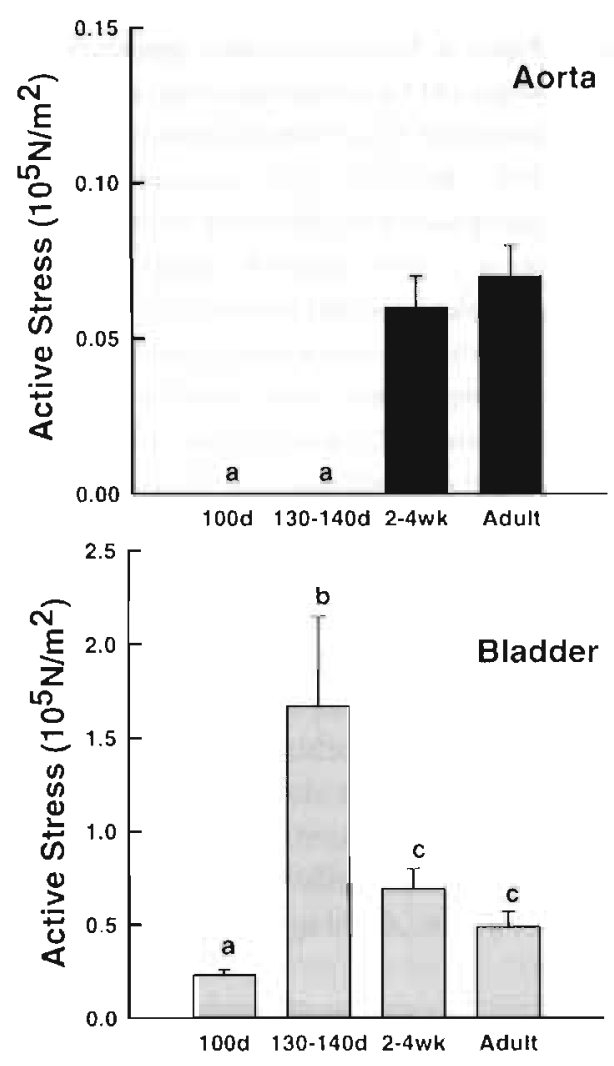

Figure 5. Maximal stress generation by aorta and bladder strips in response to $\mathrm{KCl}$ depolarization. Isometric forces were measured at $\mathrm{L}_{\mathrm{o}}$ and normalized to crosssectional area as described. Animals were grouped into early fetal (<100d gestation); late fetal (130-140d gestation); postnatal (2-4wk after birth) and adult. Groups not different as determined by ANOVA are indicated by the same letter.

\section{Myosin Light Chain Phosphorylation}

In order to determine whether failure of aortic smooth muscle to contract in the prenatal period arises from a deficit in the excitation process, we measured regulatory light chain (RLC) phosphorylation in response to high concentration of agonist as an index of activation. In the passive state achieved with calcium-free conditions no phosphorylation was observed in aorta or bladder strips collected at any age. Consistent with the results of contraction experiments, all muscles that contracted exhibited about $0.5 \mathrm{~mol}$ phosphate $/ \mathrm{mol}$ RLC at the time of maximal stress development in response to high concentrations of agonist (Fig 6). These included neonatal and adult aorta stimulated with $10^{-3} \mathrm{M}$ phenylephrine as well as bladder from any developmental stage stimulated with $10^{-3} \mathrm{M}$ carbachol. In fetal aortic smooth muscle strips, however, no RLC phosphorylation was observed in response to $10^{-3} \mathrm{M}$ phenylephrine consistent with a failure to contract.

To test the possibility that a deficiency in myosin light chain kinase may account for a lack of phosphorylation, we performed immunoblotting analysis on 


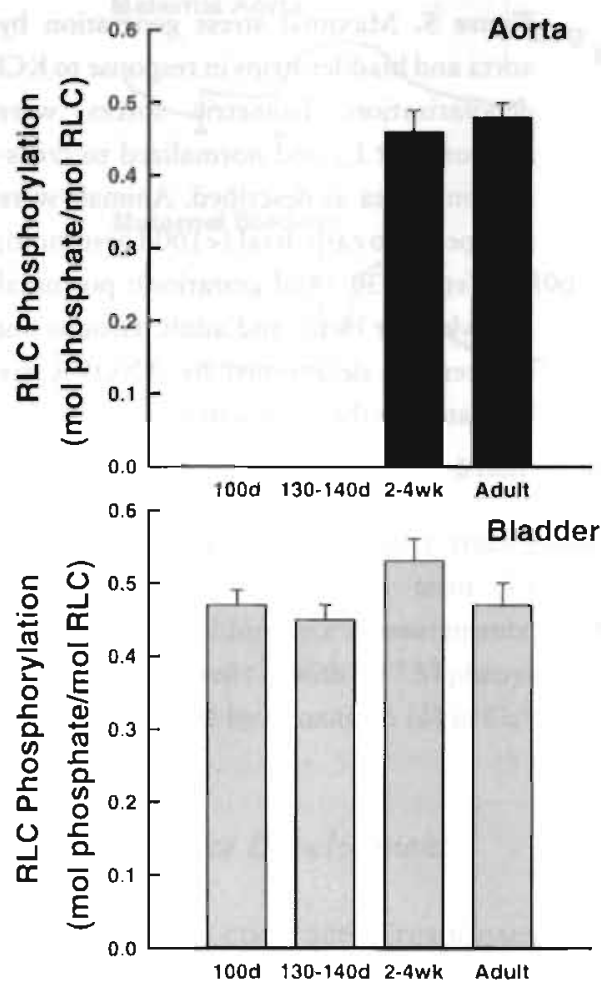

Figure 6. Values of myosin regulatory light chain (RLC) phosphorylation in response to agonist Muscles treated with calcium-free PSS showed no measurable RLC phosphorylation (data not shown). Aortic strips were treated with $10^{-3} \mathrm{M}$ phenylephrine and bladder strips with $10^{-3}$ $\mathrm{M}$ carbachol. Values for both early fetal and term fetal aortic strips were $0.0 \mathrm{~mol}$ phosphate/mol RLC with $n=8$ for each. $N$ values for other conditions range from 4 to 8 .

tissues. Aortic and bladder smooth muscles expressed MLCK throughout development. Relative amounts of MLCK were determined by densitometry and followed by normalization to adult values as $100 \%$. MLCK increased in the aorta from $79 \pm 10 \%$ at $100 \mathrm{~d}$ gestation, peaked at two weeks postnatal $(136 \pm 13 \%)$ and then declined to $100 \%$ in adult ( $p=0.04$, ANOVA). In contrast, no significant differences in MLCK amount were found with ANOVA among bladder tissues from the different developmental stages.

\section{DISCUSSION}

Fetal and postnatal development are marked by rapid growth accompanied by an orderly sequence of maturational changes. The maturation of smooth muscle cells in the walls of hollow organs would be expected to parallel growth and requirements for organ function. Results of the present study reveal that in a large mammal maturation of vascular and visceral smooth muscle tissues, as assessed by increases in contractile protein content, occurs continuously from early mid-gestation through the first month of life. Nevertheless, distinct differences are 
seen between the tissues with regard to absolute contents of contractile proteins, the interconversion of $\mathrm{MHC}$ isoforms, and the early onset of contractile function, leading to the conclusion that bladder smooth muscle matures far in advance of the vascular smooth muscle of the aorta.

Increases in MHC and particularly actin contents exceed those of total or soluble protein for both tissues, demonstrating specific up-regulation of the contractile component of smooth muscle after mid-gestation and providing evidence of cellular maturation. Comparison between tissues reveals that bladder contents of soluble protein, actin and MHC exceed those in aorta after $100 \mathrm{~d}$ gestation, leading to the conclusion that bladder muscle growth and maturation is initiated early in development and proceeds rapidly thereafter. We previously measured actin and $\mathrm{MHC}$ contents in aorta and bladder from inale animals over a more limited developmental period ( $119 \mathrm{~d}$ gestation to $33 \mathrm{~d}$ postnatal) (5). Values for actin, $\mathrm{MHC}$ and soluble protein are similar in respective tissues from female and male animals during this period; thus, sex per se does not appear to exert significant effects on processes regulating normal maturation of aorta or bladder muscle. Previous studies of quantitative increases in contractile protein content during smooth muscle maturation have focused on late fetal or postnatal periods $(5,10,28,29)$. By extending our observations to much earlier times in gestation $(72 \mathrm{~d})$, we have identified the time around $100 \mathrm{~d}$ as an important transition point for smooth muscle growth, and particularly for increases in contractile protein content.

MHC isoform expression clearly illustrates the differences in maturational patterns between the bladder and the smooth muscle of aorta. For example, the ratio of $204 / 200 \mathrm{kDa} M H C$ species increases between $<100 \mathrm{~d}$ gestation and 3 mon after birth in aorta, but decreases in bladder over the same period. While plots of percent MHC species show dramatic relative changes, they provide a limited picture of alterations occurring during development because the total amount of MHC varies and because the composition of isoforms within a band of given molecular mass may be heterogeneous. We therefore analyzed the total contents of each $\mathrm{MHC}$ species and the changes in isoform expression within the $200 \mathrm{kDa}$ species. Amounts of SM1 (204 kDa MHC) increase throughout development in both tissues, and in bladder values exceed those of aorta by 3 - to 5 -fold at all times. SM1 is an exclusive marker of smooth muscle differentiation (1), and its presence in both tissues confirms that each contains differentiated smooth muscle cells at mid-gestation. The succeeding increases in SM1 content illustrate an important quantitative attribute of smooth muscle maturation not previously described. Immunohistochemical studies will be required to determine whether maturation of all cells within a tissue occurs gradually and in parallel, or whether individual cells mature more rapidly but in gradual succession. Distinct populations of cells have been shown to exist within different tissues $(17,30,31)$, thus the latter cannot be ruled out. Abundant $\mathrm{SM}-\mathrm{MHC}$, as well as actin and other contractile proteins, may arise from transcriptional, translational or post-translational regulatory 
processes that constitute a significant facet of the mature smooth muscle phenotype. Mechanisms regulating contractile protein quantities require future investigation.

Qualitative analysis of isoforms within the $200 \mathrm{kDa} \mathrm{MHC}$ species demonstrates further dramatic differences between aorta and bladder. Where MHC-B predominates before birth in aorta, no MHC-B was detected in bladder at any stage. In ovine aorta $\mathrm{MHC}$ - $\mathrm{B}$ was gradually replaced by $\mathrm{SM} 2$ after birth. These results are consistent with those of others in which postnatal increases in SM2 fraction lead to adult values in human $(13,16)$, rabbit $(14,18)$, and mouse $(15)$ aorta, as well as swine carotid artery (32), accompanied by reciprocal declines in MHC-B $(13,18)$. The replacement of non-muscle isoforms of cytoskeletal proteins, such as $l$-caldesmon, $\alpha$-tropomyosin- $2 b$ and $\mathrm{MHC}-\mathrm{B}$, with smooth muscle isoforms constitutes a maturational transition in smooth muscle $(33,34)$. Striking in the present study was the observation that no MHC-B was expressed in bladder after $90 \mathrm{~d}$ gestation, supporting the conclusion that maturational transitions are accelerated in bladder smooth muscle. Postnatal alterations in rat and mouse bladder 204 and $200 \mathrm{kDa}$ proteins are modest and resemble those seen in postnatal sheep $(15,32)$. While the specific contributions of $\mathrm{MHC}$ isoforms to muscle function are not fully defined, SM1 and SM2 are associated with a contractile phenotype, whereas MHC-B is associated with growth conditions either during development, disease or cell culture $(9,34,35,36)$. The present finding that little or no $\mathrm{MHC}-\mathrm{B}$ is expressed in bladder muscle during fetal maturation suggests that this muscle has a fully expanded population of mature smooth muscle cells at an early stage as compared to aorta.

Maturation of contractile protein content and phenotype should be reflected in an increased contractile capacity during development. This tenet is well-illustrated in the bladder muscle, where active stress increases some seven-fold between 100 and 140 days gestation reflecting significant increases in actomyosin content over the same period. Moreover, the increase in stress generation does not appear to result from changing responsiveness to stimulation during fetal growth because both MLCK content and the fraction of myosin phosphorylated in response to maximal agonist were similar at 100 and 140 days gestation. Stress generation has also been reported to increase with fetal development in pig tracheal smooth muscle (37). In contrast, aortic muscle from fetal sheep was unresponsive to a host of agonists and failure to contract was associated with a lack of myosin phosphorylation, in spite of significant expression of MLCK. We previously found contraction and myosin phosphorylation to be inhibited in near-term femoral arteries (2). These results, in combination with generally lesser sensitivity of the fetal ovine systemic vasculature to vasoconstrictors as compared to the placental circulation $(4,10)$, support the notion that some components of systemic vascular smooth muscle are functionally immature up to the time of birth. This immaturity is reflected in the expression of the nonmuscle MHC-B in these vessels, which decreases following birth. However, the lack of 
contractile responsiveness in these vascular muscles appears less likely to result from immaturity of the contractile apparatus than from deficits in the excitation pathway. This tentative conclusion is based on following: 1) agonists do not elicit myosin phosphorylation indicating failure to elevate intracellular calcium required to activate MLCK; 2) vascular muscle contains amounts of smooth muscle MHC and actin prior to birth that are comparable to amounts found in the contractile bladder muscle at $100 \mathrm{~d}$ gestation; and 3) contractile responsiveness is observed within a week after birth at which time changes in the contractile protein profile are minimal. Further investigations will be required to determine whether maturation associated with the onset of contractility involves the induction of receptor expression, coupling pathways, ion channels or other regulatory proteins.

Following birth, aortic stress increased to near-adult values. A similar pattern was seen in second generation pulmonary arteries from sheep (28); however others have noted increases in maximum contractile response between neonatal and adult aortas from rat (29), gastric myocytes from rabbit (38), and carotid artery from sheep (39). More surprising in the present study was the decline in stress generation observed in bladder muscle with postnatal maturation. This could not be attributed to differences in actomyosin contents, nor levels of activation as assessed by myosin phosphorylation. No references to postnatal changes in bladder stress were found in the literature. Declines in stress generation might be accounted for by age-dependent changes in cellular density or orientation in the bladder wall.

The advanced maturation and growth of bladder smooth muscle as compared to that from aorta supports the notion that demands for organ function may influence the developmental course. The aorta is a conduit vessel, thus the need for rapid maturational changes before birth may be minimal. In contrast, the bladder is functional early in the midtrimester, excreting urine at a rate of $7-10 \mathrm{ml} / \mathrm{kg} \cdot \mathrm{h}$, which increases to $30-40 \mathrm{ml} / \mathrm{kg} \cdot \mathrm{h}$ at term $(11,12)$. It has been established that the differentiation of smooth muscle in the bladder is dependent upon interactions with the epithelium (40). It remains to be determined whether the accelerated maturation of the bladder is also dependent upon epithelial signals that may be influenced by bladder filling and/or distension. In addition, bladder smooth muscle cells may be independently influenced by these mechanical forces. Contractile responses of the fetal aortic and bladder smooth muscle tissues were consistent with the above notion in that only the bladder muscle exhibits robust force generation in response to stimulation.

\section{Perspectives}

The period of fetal development supports growth and maturation of organ systems essential for survival to birth and independent life thereafter. Owing to the relatively large size of the fetus, the ovine model allows analysis of functional 
properties of smooth muscle tissues during development. These and our previous results demonstrate a relation between early onset of organ function and accelerated maturation of its smooth muscle component during ovine fetal development $(2,5)$. Whether maturation is brought about by neuronal, hormonal, paracrine and/or mechanical factors remains to be investigated. Smooth muscle differentiation is a complex process that involves the orderly activation of genes encoding smooth muscle-specific proteins such as SM1. In quantifying SM1 protein contents (as well as those of total MHC and actin) at multiple points through development, this study distinctively illustrates that maturation following differentiation includes increases in contractile protein content over the last third of ovine gestation and through the first month postnatally, laying the foundation for increasing contractile capacity $(29,38,41)$. Further studies will be required to determine threshold conditions leading to contractile function, as well as specific queues promoting maturation during development.

\section{REFERENCES}

1. Miano, J.M., P. Cserjesi, K.L. Ligon, M. Periasamy, and E.N. Olson. Smooth muscle myosin heavy chain exclusively marks the smooth muscle lineage during mouse embryogenesis. Circ. Res. 75: 803-812, 1994.

2. Arens, Y., R.A. Chapados, B.E. Cox, K.E. Kamm and C.R. Rosenfeld. Differential development of umbilical and systemic arteries. II. Contractile proteins. Am. J. Physiol. 275: R1815-R1823, 1998.

3. Dawes, G. S. The umbilical circulation. Am. J. Obstet. Gynecol. 84:1634-1648, 1962.

4. Kaiser, J.R., B.E. Cox, T.A. Roy and C.R. Rosenfeld. Differential development of umbilical and systemic arteries. I. ANG II receptor subtype expression. Am. J. Physiol. 274: R797-R807, 1998.

5. Chern, J., K.E. Kamm, and C.R. Rosenfeld. Smooth muscle myosin heavy chain isoforms are developmentally regulated in male fetal and neonatal sheep. Pediatr. Res. 38: 697-703, 1995 .

6. Owens, G.K. Regulation of differentiation of vascular smooth muscle cells. Physiol. Rev. 75: 487-517, 1995 .

7. Somlyo, A.P. Myosin isoforms in smooth muscle: how may they affect function and structure? J. Muscle Res. Cell Motil. 14: 557-563, 1993.

8. Kelley, C.A. and R.S. Adelstcin. Characterization of isoform diversity in smooth muscle myosin heavy chains. Can. J. Phỵsiol. Pharmacol. 72: 1351-1360, 1994.

9. Simons, M., M. Wang, W. McBride, S. Kawamoto, K. Yamakawa, D. Gdula, R.S. Adelstein, and $\mathrm{L}$. Weir. Human nonmuscle myosin heavy chains are encoded by two genes located on different chromosomes. Circ. Res. 69: 530-539, 1991.

10. Warrick, H.M. and J.A. Spudich. Myosin structure and function in cell motility. Annu. Rev. Cell Biol. 3: 379-421, 1987. 
11. Takeuchi, H., T. Koyanagi, T. Yoshizato, T. Takashima, S. Satoh, and H. Nakano. Fetal urine production at different gestational ages: Correlation to various compromised fetuses in utero. Early Hum. Dev. 40: 1-11, 1994.

12. Van Otterlo, L.C., J.W. Wladimiroff, and H.C.S. Wellenburg. Relationship between fetal urine production and amniotic fluid volume in normal pregnancy and pregnancy complicated by diabetes. Br. J. Obstet. Gynecol. 84: 205-209, 1977.

13. Aikawa, M., PN. Sivam, M. Kuro-o, K. Kimura, K. Nakahara, S. Takewaki, M. Ueda, H. Yamaguchi, Y. Yazaki, M. Periasamy, and R. Nagai. Human smooth muscle myosin heavy chain isoforms as molecular markers for vascular development and atherosclerosis. Circ. Res. 73: 1000-1012, 1993.

14. Borrione, A.C., A.M.C. Zanellato, G. Scannapieco, P. Pauletto, and S. Satore. Myosin heavy-chain isoforms in adult and developing rabbit vascular smooth muscle. J. Biochem. 183: 413-417, 1989.

15. Eddinger, T.J. and J.A. Wolf. Expression of four myosin heavy chain isoforms with development in mouse uterus. Cell Motil.Cytoskeleton 25: 358-368, 1993.

16. Frid, M.G., E.P. Moiseeva, and K. Stenmark. Multiple phenotypically distinct smooth muscle cell populations exist in the adult and developing bovine pulmonary arterial media in vivo. Circ. Res. 75: 669-681, 1994.

17. Frid, M.G., O.Y. Printesva, A. Chiavegato, E. Faggin, M. Scatena, V.E. Koteliansky, P. Pauletto, M.A. Glukhova, and S. Satore. Myosin heavy-chain isoform composition and distribution in developing and adult human aortic smooth muscle. J. Vasc. Res. 30: 279-292, 1993.

18. Kuro-o, M., R. Nagai, H. Tsuchimochi, H. Katoh, Y. Yazaki, A. Ohkubo, and F. lakaku. Developmentally regulated expression of vascular smooth muscle myosin heavy chain isoforms. J. Biol. Chem. 264: 18272-18276, 1989.

19. Iwamoto, H.S. and A.M. Rudolf. Effects of angiotensin II on the blood flow and its distribution in fetal lambs. J. Dev. Physiol. 1: 283-293, 1981.

20. Nathanielsz, D.W. Animal Models in Fetal Medicine. Ithaca: Perinatology Press, 1984, p. 1-216.

21. Yoshimura, T., R.R. Magness, and C.R. Rosenfeld. Angiotensin II and alpha-agonist. I. Responses of ovine fetoplacental vasculature. Am. J. Physiol. 259: H464-H472, 1990.

22. Annibale, D.J., C.R. Rosenfeld, J.T. Stull, and K.E. Kamm. Protein content and mycsin light chain phosphorylation in uterine arteries during pregnancy. Am. J. Physiol. 259: C484-( 489, 1990.

23. Rovner, A.S., M.M. Thompson, and R.A. Murphy. Two different heavy chains are found in smoorh muscle myosin. Am. J. Physiol. 250: C861-C870, 1986.

24. Ipson, M.E., C.R. Rosenfeld, R.R. Magness, and K.E. Kamm. Alterations in myometrial stress during ovine pregnancy and the puerperium. Am. J. Physiol. 271: R446-R454, 1996.

25. Annibale, D.J., C.R. Rosenfeld, and K.E. Kamm. Alterations in vascular smooth muscle contractility during ovine pregnancy. Am. J. Physiol. 256: H1282-H1288, 1989.

26. Herlihy, J.T., and R.A.Murphy. Length-tension relationship of smooth muscle of the hog carotid artery. Circ. Res. 33: 275-283, 1973. 
27. Persechini, A., K.E. Kamm and J.T. Stull. Different phosphorylated forms of myosin in contracting tracheal smooth muscle. J. Biol. Chem. 261: 6293-6299, 1986.

28. Belik, J., A. Halayko, K. Rao, and N. Stephens. Pulmonary vascular smooth muscle: Biochemical and mechanical developmental changes. Am. J. Physiol. 71: 1129-1135, 1991.

29. Seidel, C.L. and J.C. Allen. Pharmacologic characteristics and actomyosin content of aorta from neonatal rats. Am. J. Physiol. 237: C81-C86, 1979.

30. Madsen, C.S., C.P. Regan, J.E. Hungerford, S.L. White, I. Manabe and G.K. Owens. Smooth muscle-specific expression of the smooth muscle myosin heavy chain gene in transgenic mice requires 5'-flanking and first intronic DNA sequence. Circ. Res. 82:908-917, 1998.

31. Meer, D.P. and T.J. Eddinger. Heterogeneity of smooth muscle myosin heavy chain expression at the single cell level. Am. J. Physiol. 270: C1819-C1824, 1996.

32. Eddinger, T.J. and R.A. Murphy. Developmental changes in actin and myosin heavy chain isoform expression in smooth muscle. Arch. Biochem. Biophys. 284: 2232-2237, 1991.

33. Kashiwada, K., W. Nishida, K. Hayashi, K. Ozawa, Y. Yamanaka, H. Saga, T. Yamashita, M. Tohyama, S. Shimada, K. Sato, and K. Sobue. Coordinate expression of alphatropomyosin and caldesmon isoforms in association with phenotypic modulation of smooth muscle cells. J. Biol. Chem. 272: 15396-15404, 1997.

34. Kuro-o, M., R. Nagai, K. Nakahara, H. Katoh, R. Tsai, H. Tsuchimochi, Y. Yazaki, A. Ohkubo, and F. Takaku. cDNA cloning of a myosin heavy chain isoform in embryonic smooth muscle and its expression during vascular development and in arteriosclerosis. J. Biol. Chem. 266: 3768-3773, 1991.

35. Chamley-Campbell, J., G.R. Campbell, and R. Ross. The smooth muscle cell in culture. Physiol. Rev. 59: 1-61, 1979.

36. Simons, M. and R.D. Rosenberg. Antisense nonmuscle myosin heavy chain and c-myb oligonucleotides suppress smooth muscle cell proliferation in vitro. Circ. Res. 70: 835-843, 1992.

37. Booth, R.J., M.P. Sparrow, and H.W. Mitchell. Early maturation of force production in pig tracheal smooth muscle during fetal development. Am. J. Respir. Cell Mol. Biol. 7: 590-597, 1992.

38. Tomomasa, T., Y. Xie, A. Morikawa, T. Kuroume, and P.E. Hyman. Postnatal changes in size and actomysin content of rabbit gastric myocytes. Reprod. Fertil. Dev. 7: 1305-1310, 1995 .

39. Belik, J., and N.L. Stephens. Developmental differences in vascular smooth muscle mechanics in pulmonary and systemic circulations. J. Appl. Physiol. 74: 682-687, 1993.

40. Baskin, L.S., S.W. Hayward, P. Young and G.R. Cunha. Role of mesenchymal-epithelial interactions in normal bladder development. J. Urol. 156: 1820-1827, 1996.

41. Murphy, R.A., J.T. Herlihy, and J. Megerman. Force-generating capacity and contractile protein content of arterial smooth muscle. J. Gen. Physiol. 64: 691-705, 1974. 
CHAPTER 5

\section{Differential development of umbilical and systemic arteries: II. contractile proteins}

Yvonne Arens, Rene A. Chapados, Blair E. Cox,

Kristine E. Kamm, Charles R. Rosenfeld

Departments of Pediatrics and Physiology

University of Texas southwestern medical center, Dallas, Texas 


\section{A B S T R A C T}

In fetal sheep, umbilical responsiveness to angiotensin II exceeds systemic vascular responsiveness. Fetal systemic vascular smooth muscle (VSM) exhibits an immature phenotype with decreased contractile protein contents, low 200 $\mathrm{kDa}$ myosin heavy chain (MHC) SM2, and significant nonmuscle MHC-B expression, whereas umbilical VSM phenorype is incompletely described. We tested the hypothesis that differences in vascular responsiveness could reflect dissimilarities in VSM phenotype. Actin, MHC, MHC-isoforms and active stresses were compared in strips of femoral arteries and aorta from near-term fetal $(n=12)$ and adult $(n=12)$ sheep to those in external and intra-abdominal umbilical arteries. Actin contents in fetal femoral artery and aorta were less $(p \geq 0.006)$ than in external umbilical artery $(7.37 \pm 1.4$ and $7.53 \pm 0.7$ vs $21.6 \pm 2.2$ $\mu \mathrm{g} / \mathrm{mg}$ wet weight, respectively) as were $\mathrm{MHC}$ contents $(3.17 \pm 0.4$ and $2.84 \pm 0.3$ vs $7.16 \pm 0.7$, respectively). Whereas 204 and $200 \mathrm{kDa}$ MHC were expressed equally in fetal systemic arteries, umbilical and adult arteries predominantly expressed the $204 \mathrm{kDa}$ isoform (SM1); only fetal systemic VSM expressed MHC-B. Fetal systemic artery stresses and myosin light chain phosphorylation were less those that in umbilical and adult arteries $(p<0.001)$. Compared to umbilical and adult arteries, fetal systemic VSM is biochemically and funcrionally immature; thus umbilical VSM demonstrates precocious maturation resembling adult VSM in protein expression and funcrion.

Key words: Fetal sheep, myosin heavy chain isoforms, smooth muscle phenotype, active stresses, myosin light chain phosphorylation. 


\section{INTRODUCTION}

The maintenance and regulation of the umbilicial-placental circulation is crucial for fetal growth and well-being. In fetal sheep this vascular bed is sensitive to several vasoconstrictors, especially angiotensin II $(1,2,3,4)$. This responsiveness has also been observed in human umbilical arteries studied in vitro $(5,6,7)$. In intact fetal sheep the umbilical circulation is more sensitive to angiotensin II than the systemic vasculature $(1,2,3,4)$. However, the mechanisms responsible for these differences in vascular reactivity are unclear. One explanation is that the contractile protein composition and therefore the contractile capacity of vascular smooth muscle (VSM) in umbilical and systemic arteries differ.

In the adult, systemic VSM modulates arterial pressure and mediates responses to numerous stimuli. These differentiated VSM cells express a unique assortment of contractile and structural proteins, reflecting a mature "contractile" phenotype $(8,9)$. In these cells contraction results from the interaction of actin in the thin filaments and myosin in the thick filaments. Myosin molecules are composed of six subunits: two heavy chains, two regulatory and two essential light chains. The carboxyl-terminal ends of the myosin heavy chains (MHC) form a coiled-coil tail that polymerizes to form thick filaments. The amino-terminal end is folded in a globular head containing binding sites for actin and $\mathrm{Mg}^{2+}$-ATP as well as for each of the light chains and is the site of chemo-mechanical transduction associated with $\mathrm{Mg}^{2+}$-ATPase activity. Smooth muscle contraction is triggered by a rise in cytosolic calcium leading to phosphorylation of the myosin regulatory light chains, which permits actin to activate myosin $\mathrm{Mg}^{2+}$-ATPase $(10,11)$. In mature VSM these components of the contractile mechanism are present and functional.

In several species, including fetal sheep, a model widely used to study cardiovascular development, the expression of contractile proteins in VSM is developmentally regulated in a tissue specific manner $(12,13,14,15,16)$. In fetal sheep actin and MHC contents in systemic arteries are quite low throughout the majority of gestation, increasing just prior to term and during the immediatc. postnatal period $(12,13)$. There also are changes in expression of the MIIC: isoforms, at least 4 of which are expressed in vertebrate smooth muscle $(17,18,19,20)$. The smooth muscle MHC isoforms, SM1 (204 kDa) and SM2 $(200 \mathrm{kDa})$, are alternatively spliced products of a single gene and are exclusively expressed in cells of smooth muscle lineage (21). They differ in their carboxyl-terminal tail sequence and exhibit different patterns of expression during VSM development, with SM2 expression increasing in mature or "contractile" tissues $(22,12,13,14,18,23,9)$. MHC-B, also $200 \mathrm{kDa}$, is derived from a separate gene, and its expression is associated with the "synthetic" phenotype of smooth muscle cells (18). It is found in nonmuscle cells (24), smooth muscle cells in culture $(24,25)$, and developing fetal VSM $(12,13,17,18,26)$. Its expression declines during development $(12,13,18)$. MHC-A, also a nonmuscle 
isoform, is $196 \mathrm{kDa}$ and is derived from a third gene $(17,27)$. It is primarily expressed in platelets (26), but also in some fetal tissues, where it is developmentally regulated $(14,28)$, and in cultured smooth muscle cells $(17,25)$. The relationship between the patterns of VSM protein expression and function during development are unclear; however, we (12) have recently observed that stress generation may be attenuated when MHC. B is present and SM2 content is low. This pattern of protein expression may also differ amongst arteries in the developing fetus, but this has not been fully explored.

To the best of our knowledge, contractile phenotype and VSM contractile function in umbilical and systemic arteries have not been compared. Therefore, the purpose of the present study was to determine: 1) if differences in VSM protein expression exist in umbilicil and systemic arteries from near-term fetal sheep, 2 ) if differences in protein expression are associated with different capacities to generate stress, and 3) whether umbilical artery VSM resembles adult VSM and thus is highly specialized in the fetal vasculature.

\section{METHODS}

\section{Tissue preparation}

Near-term fetal ( $\mathrm{n}=12 ; 130-145 \mathrm{~d}$ of gestation, term $\sim 145 \mathrm{~d}$ ) and maternal $(\mathrm{n}=12)$ sheep were killed by rapid intravenous injection of pentobarbital sodium (50 $\mathrm{mg} / \mathrm{kg}$ ) to the mother via the external jugular vein. Segments of abdominal aorta and femoral artery were quickly obtained from fetal and adult animals as well as segments of external and intra-abdominal umbilical arteries from fetuses and placed into iced physiologic buffered solution containing (in $\mathrm{mM}$ ): $137.0 \mathrm{NaCl}$, $2.7 \mathrm{KCl}, 10 \mathrm{Na}_{2} \mathrm{HPO}_{4}, 1.76 \mathrm{KH}_{2} \mathrm{PO}_{4}, 0.1 \%$ diethyl pyrocarbonate, $\mathrm{pH} 7.4$. We obtained segments of both external (from the mid-third of the umbilical cord) and intra-abdominal umbilical artery since they represent a continuum of this vessel and we (29) recently observed differences in angiotensin II receptor expression in these two portions of the umbilical circulation. Arteries from pregnant ewes were used since we $(30,31)$ previously reported that neither the protein contents in nor the stresses generated by systemic blood vessels are altered during ovine pregnancy. Endothelium and adventitia were removed from the arteries with a soft cotton swab and sharp dissection, respectively. Strips of tissue were cut, blotted dry to remove excess water and capillary blood, frozen in liquid nitrogen, and stored at $-80^{\circ} \mathrm{C}$ until studied. Additional segments were obtained in order to measure stresses (see below). These studies were approved by the Institutional Review Board for Animal Research. 


\section{Protein analysis and content}

Sodium dodecyl sulfate (SDS) homogenates were prepared from $10-20 \mathrm{mg}$ samples of frozen tissue as previously reported $(13,31)$. Briefly, homogenates were divided into two aliquots. One was subjected to centrifugation at $10,000 \mathrm{xg}$ for $2 \mathrm{~min}$ and the supernatant removed to determine the soluble or cellular protein in each sample. The other sample was not centrifuged and was used to determine the total homogenate protein. Aliquots of both samples were analyzed for protein content by BCA reagent (Pierce, Rockford, Ill.). Aliquots of the supernatant containing bromphenol blue and 2-mercaptoethanol were subjected to SDSPAGE, using 3-20\% and 4\% polyacrylamide gels to determine the contents of total actin and $\mathrm{MHC}$ and the relative a mounts of $\mathrm{MHC}$ isoforms, respectively. For each tissue mini-gels were loaded with $20-40 \mu \mathrm{g}$ of soluble protein and subjected to electrophoresis at $200 \mathrm{~V}$ until the dye front reached the bottom of the gel. Gels were stained with coomassie Brilliant Blue overnight and appropriately destained to remove background staining. Stained gels were scanned, each lane in duplicate, with a laser densitometer (LKB Instruments, Inc., Stockholm, Sweden) to estimate the relative amounts of actin, $\mathrm{MHC}$ and $\mathrm{MHC}$ isoforms. Differences between measurements were $<5 \%$, and values for each band were averaged. The fraction of stained protein accounted for by actin and MHC was converted to micrograms using the total protein quantified by BCA reagent in each sample. Values are expressed as $\mu \mathrm{g} / \mathrm{mg}$ of wet weight.

\section{SDS-PAGE and immunoblotting}

Using the supernatant extracts of fetal and maternal aorta and femoral artery as well as external and internal umbilical artery, $-200 \mathrm{ng}$ of total MHC were loaded and separated on $4 \%$ polyacrylamide gels. Proteins were electrophoretically transferred to nitrocellulose paper at $80 \mathrm{~mA}$ overnight in the presence of methanol $(20 \%)$ and SDS $(0.1 \%)$. Blots were then blocked for $1 \mathrm{~h}$ in a buffer that contained powdered milk $(0.3 \% \mathrm{wt} / \mathrm{vol})$, incubated for $4 \mathrm{~h}$ with blocking buffer containing specific antiserum against either SM2 or MHC-B, $(1: 4000$ and 1:20,000 respectively), and then incubated with goat anti-rabbit IgG conjugated with horseradish peroxidase $(1: 15,000)$. Antibodies to $\mathrm{MHC}$ isoforms were generated against short peptides derived from sequences unique to the carboxyl-terminal tail of each isoform as described by Chern et al (13). Regions containing MHC isoforms were visualized by enhanced chemiluminescence (ECL, Amersham International PLC, England). The blots were kept in the ECL-developing solution for $1 \mathrm{~min}$, exposed on film for $5 \mathrm{sec}$ and then developed. 


\section{Histologic evaluation}

Immediately following dissection, segments of external umbilical artery and fetal and adult femoral artery were fixed in $10 \%$ neutralized formalin, paraffinembedded, and stained with hematoxylin-eosin or elastin van Gieson for imaging by light microscopy.

\section{Stress measurements}

Segments of arteries were placed in chilled physiologic saline solution (PSS) containing (in mM): $120.5 \mathrm{NaCl}, 4.8 \mathrm{KCl}, 1.2 \mathrm{MgSO}_{4}, 1.2 \mathrm{NaH}_{2} \mathrm{PO}_{4}, 20.4$ $\mathrm{NaHCO}_{3}, 1.6 \mathrm{CaCl}_{2}, 10$ dextrose and 1 pyruvate. The adventitia was removed, and the arteries were opened along the long axis of the vessel. The endothelium was removed by gently swabbing with a cotton swab; the efficiency of this method has been confirmed using histochemistry. Strips of equal width were cut parallel to the cellular long axis (i.e., parallel to the vessel circumference) with a double bladed cutting tool as previously described (30). Strip widths were fixed at 1.3 $\mathrm{mm}$.

The strips were tied at one end with 6-0 silk that was attached to a Grass FT. $03 \mathrm{C}$ force transducer; the bottom of the strip was clamped in a plexiglass holder attached via a stainless steel rod to a calibrated mechanical drive to adjust muscle length. Isometric force was recorded on a Grass model 7D polygraph. The strips were suspended in $25 \mathrm{ml}$ jacketed muscle baths containing PSS bubbled with a $95 \% \mathrm{O}_{2}-5 \% \mathrm{CO}_{2}$ gas mixture to maintain a $\mathrm{pH}$ of 7.4 at $37^{\circ} \mathrm{C}$. Length-force relationships were determined using methods previously reported in order to compare maximal active force $\left(F_{0}\right)$ at comparable muscle lengths $\left(L_{0}\right)(30,32)$. Strips were stretched $0.5 \mathrm{~g}$ initially and length was measured; this was followed by equilibration for $1 \mathrm{~h}$. The PSS was then removed from each bath and replaced with $65 \mathrm{mM} \mathrm{KCl}(\mathrm{KCl}$ isotonically replaced $\mathrm{NaCl}$ in PSS). Maximal force obtained in response to $\mathrm{KCl}$ depolarization at a given length was taken as the total force. Passive force contributed by connective tissue in the strip was obtained after the tissue was placed in $\mathrm{Ca}^{2+}$-free PSS containing $2 \mathrm{mM}$ ethylene glycolbis $(\beta$ aminoethyl ether)- $N, N, N^{\prime}, N^{\prime}$-tetra-acetic acid, eliminating force contributed by contraction of smooth muscle cells. After obtaining a value for passive force, $\mathrm{Ca}^{2+}$-free PSS was removed and replaced with $\mathrm{Ca}^{2+}$-containing PSS. After re-equilibration, the tissue was stretched to a new length, and the stimulation-relaxation protocol was repeared. There were no observable effects of EGTA on responses to repeated contractions. Active force generated by the arteries was obtained by subtracting the passive from total force at the respective length. The length at which $\mathrm{F}_{\mathrm{o}}$ occurred was defined as the optimal length $\left(\mathrm{L}_{\mathrm{o}}\right)$ for each muscle strip. After this procedure, tissues were blotted and weighed. Tissue crosssectional area was calculated based on the weight, density, and length of the tissue 
at $\mathrm{L}_{\mathrm{o}}$. Stress $\left(\mathrm{N} / \mathrm{m}^{2}\right)$ was calculated by dividing the active force at optimal length by the cross-sectional area $(30,32)$.

\section{Myosin light chain phosphorylation}

Strips of umbilical artery and fetal and adult femoral artery were mounted for measurement of isometric force and quick-frozen with tongs precooled in liquid nitrogen either at rest or at the time of maximum contraction, using $10^{-3} \mathrm{M}$ phenylephrine for femoral arteries and $10^{-5} \mathrm{M}$ 5-hydroxytryptamine, respectively. The frozen muscle was weighed, placed in frozen slurry of trichloroacetic acid $(10 \%, \mathrm{wt} / \mathrm{vol})$ in acetone that contained DTT $(10 \mathrm{mM})$, and allowed to thaw in order to denature cellular proteins. Thereafter the muscle was placed in $60 \mathrm{vol}$ of trichloroacetic acid $(10 \%, \mathrm{wt} / \mathrm{vol})$ and DTT $(10 \mathrm{mM})$ and homogenized. The precipitated protein was washed with diethyl ether and then suspended in urea-glycerol buffer for electrophoretic analysis of light chain phosphorylation by immunoblotting (31,32). Samples were subjected to electrophoresis for $1 \mathrm{~h}$ at 400 $\mathrm{V}$ in a gel containing $10 \%$ polyacrylamide and $40 \%$ (vol/vol) glycerol. Protein was transferred to nitrocellulose paper and nonphosphorylated and phosphorylated forms of the light chain were localized by western blotting with antibodies against bovine tracheal myosin light chain $(1: 10,000)$ and peroxidase-conjugated goat anti-rabbit IgG $(1: 15,000)$ with ECL. Relative amounts of nonphosphorylated and phosphorylated light chain were quantified by laser densitometry.

\section{Umbilical artery responses}

Human umbilical arteries have been extensively studied in vitro and shown to respond differently to several constrictors $(5,6,7)$. Similar studies of ovine umbilical arteries, however, are rare (33). We, therefore, characterized ovine umbilical artery responses to several agonists. Strips of external and internal umbilical artery were cut and hung in muscle baths as earlier described. The strips were stretched to their optimal length as determined by length-force calculations, using three stretches of $1.5 \mathrm{mg}$ for $20 \mathrm{~min}$ each. The strips were then stimulated twice with $65 \mathrm{mM} \mathrm{KCl}$. All strips were relaxed with $\mathrm{Ca}^{2+}$-free PSS after each contraction. The strips of external and internal umbilical artery were subsequently stimulated with $10^{-6} \mathrm{M}$ phenylephrine (PE), $10^{-4} \mathrm{M}$ histamine (Hist), $10^{-5} \mathrm{M}$ 5-hydroxytryptamine (5-HT; serotonin), 10-5 $\mathrm{M}$ carbachol (Cch), $10^{-5} \mathrm{M}$ bradykinin (BK), $10^{-4} \mathrm{MPGF}_{2 \alpha}$ (PGF), $10^{-5} \mathrm{MPGE}_{2}$ (PGE), $10^{-8} \mathrm{M}$ angiotensin II (ANG), and $10^{-9} \mathrm{M}$ endothelin (ET). These concentrations have been shown to cause maximal contraction in human umbilical arteries (7). 


\section{Statistics}

All data are reported as means \pm SEM. Data were analyzed using Student's t-test and one-way analysis of variance (ANOVA) with Newman-Keuls correction for multiple comparisons. Significance was taken as $\mathrm{p}=0.05$.

\section{RFSUI.TS}

\section{Total and soluble protein}

Total protein contents did not differ significantly amongst the fetal and adult arteries studied (Table 1). Although soluble protein contents in feral femoral artery and aorta were similar, values were $-40 \%$ less than that measured in either the external or internal umbilical artery ( $\mathrm{p}<0.0001$, ANOVA), but did not differ from that seen in adult femoral artery (Table 1). Furthermore, the soluble/total protein ratio was greatest in the external umbilical artery when compared to all other vessels, averaging 0.92 , while the internal umbilical artery was similar to the adult and fetal aorta, demonstrating an intermediate position between fetal systemic vessels and the external umbilical artery.

\section{Histology}

To further assess the differences in cellular and noncellular protein contents, samples of each vessel were prepared for histologic evaluation using hematoxylin-eosin to examine smooth muscle contents and van Gieson stain for elastin contents. As seen in Figures 1A, C and E, the smooth muscle content of the external umbilical artery is substantially greater than that in either the fetal or adult femoral arteries. In contrast, the femoral vessels contain relatively greater contents of elastin, a nonsoluble noncellular protein, than the umbilical artery (Fig 1B, D and F). It also is notable that the structural pattern of the fetal femoral artery differs from that of the adult, with more orderly layering of smooth muscle cells and elastin fibers, and an apparent greater nuclear density. Thus, differences in vessel architecture are evident.

\section{Actin and $M H C$ contents}

Actin contents in the fetal femoral artery and aorta did not differ, averaging 7.5 $\mu \mathrm{g} / \mathrm{mg}$ wet weight, but were $\sim 65 \%$ less $(\mathrm{p}=0.006)$ than those measured in either umbilical artery (Fig 2A), which averaged $20 \mu \mathrm{g} / \mathrm{mg}$ wet weight. Actin contents in the fetal systemic arteries were also significantly less than those measured in the respective adult vessels, which more closely resembled that seen in umbilical arteries (Fig 2A). 
Table 1. Total and soluble protein contents ( $\mu \mathrm{g} / \mathrm{mg}$ wet weight) in fetal and adult arteries.

\begin{tabular}{llll}
\hline & Total protein & Soluble protein & Soluble/Total ratio \\
\hline Fetal aorta $(\mathrm{n}=6)$ & $85.8 \pm 9.0^{\mathrm{a}}$ & $40.9 \pm 4.2^{\mathrm{a}}$ & $0.49 \pm 0.05^{\mathrm{a}}$ \\
Fetal femoral $(\mathrm{n}=7)$ & $85.0 \pm 5.4^{\mathrm{a}}$ & $37.1 \pm 3.6^{\mathrm{a}}$ & $0.43 \pm 0.02^{\mathrm{a}}$ \\
Internal umbilical $(\mathrm{n}=5)$ & $98.1 \pm 11.0^{\mathrm{a}}$ & $63.6 \pm 5.2^{\mathrm{b}}$ & $0.68 \pm 0.09^{\mathrm{b}}$ \\
External umbilical $(\mathrm{n}=5)$ & $73.8 \pm 14.3^{\mathrm{a}}$ & $63.2 \pm 5.8^{\mathrm{b}}$ & $0.92 \pm 0.11^{\mathrm{c}}$ \\
Adult aorta $(\mathrm{n}=5)$ & $104 \pm 3.8^{\mathrm{a}}$ & $57.3 \pm 5.7^{\mathrm{b}}$ & $0.55 \pm 0.04^{\mathrm{ab}}$ \\
Adul femoral $(\mathrm{n}=7)$ & $92.2 \pm 7.5^{\mathrm{a}}$ & $35.0 \pm 3.1^{\mathrm{a}}$ & $0.38 \pm 0.03^{\mathrm{a}}$
\end{tabular}

Values are means \pm SEM. Different letters within columns denote significant differences between tissues with $p<0.0001$ by ANOVA, while the same letter denotes values that are not significantly different.

Although MHC contents did not differ between fetal and adult systemic arteries (Fig 2B), the MHC contents in the external and internal umbilical arteries were $>2$-fold higher than those measured in all other vessels studied $(\mathrm{p}<0.0001$, ANOVA).

\section{MHC-isoforms}

The relative and absolute contents of the 204 and $200 \mathrm{kDa}$ MHC-isoforms present in samples of fetal and adult VSM were determined from densitometric scans of the proteins separated on $4 \%$ polyacrylamide gels. Only $2 \mathrm{MHC}$ bands were observed for each artery studied, confirming our prior observations for ovine fetal aorta that the $196 \mathrm{kDa}$ protein could not be identified (13). The 204 $\mathrm{kDa}$ protein accounted for $-50 \%$ of the total $\mathrm{MHC}$ in the fetal femoral artery and aorta. In contrast, it accounted for $>62 \%(\mathrm{p}=0.0001$, ANOVA) of MHC in the external umbilical artery and both adult arteries; the internal umbilical artery was intermediate at $57 \%$. Therefore, the relative amount of the $200 \mathrm{kDa}$ protein in fetal systemic VSM $(45-50 \%)$ exceeded that in the external umbilical artery and adult VSM, (27-36\%; $<<0.0001$, ANOVA); again the internal umbilical artery was intermediate with $45 \%$ of MHC protein the $200 \mathrm{kDa}$ isoform. When we determined the absolute contents of the 204 and $200 \mathrm{kDa}$ proteins, which take into account differences in total MHC content, the values were similar in the fetal systemic arteries, averaging $\sim 1.5 \mu \mathrm{g} / \mathrm{mg}$ wet weight (Fig 3). In contrast, the content of the $204 \mathrm{kDa}$ MHC-isoform exceeded that of the $200 \mathrm{kDa}$ protein in both umbilical and adult arteries, a value that was $>2$-fold higher than the 200 $\mathrm{kDa}$ protein in both external umbilical artery $(\mathrm{p}=0.001)$ and adult femoral artery $(\mathrm{p}=0.0009$; Fig 3$)$. Compared to all systemic arteries, the contents of both the 204 

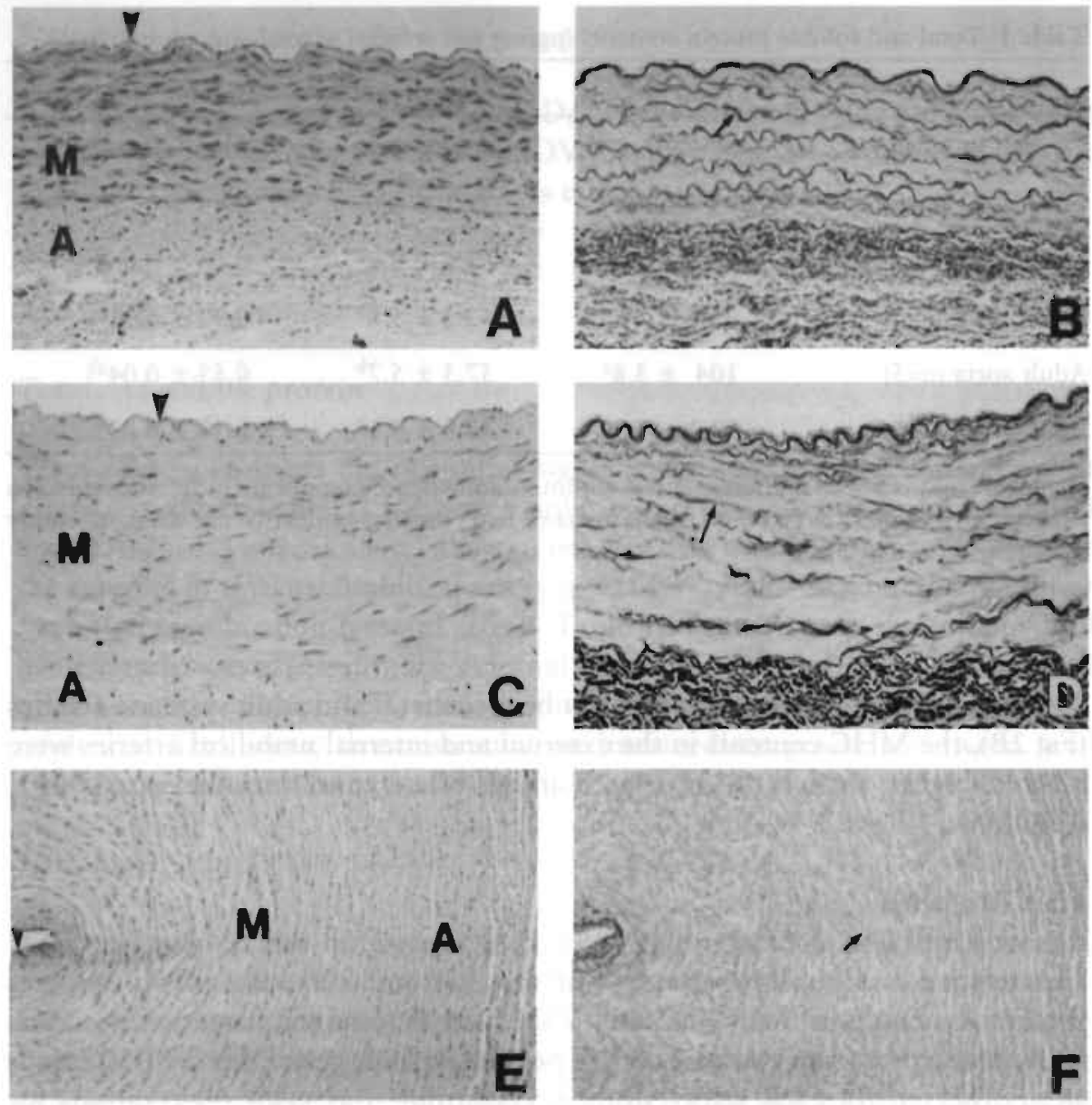

Figure 1. Representative examples of fetal femoral artery ( $A$ and B), adult femoral artery (C and $D)$ and external umbilical artery ( $E$ and $F$ ) stained with hematoxylin-eosin ( $A, C$ and $E$ ) to assess smooth muscle content and van Gieson stain to assess elastin content (B, D and F). Femoral artery photomicrographs are at $20 \mathrm{x}$ in order to permit a comparison of size, cell distribution and architecture, whereas umbilical histology is shown at $10 \mathrm{x}$ because of vessel size. Arrow heads denote vascular endothelium, arrows elastin fibers, $m$ the media, and a the vascular adventitia.

and $200 \mathrm{kDa}$ proteins were greater in umbilical arteries, reflecting the greater total MHC content (Fig 2B).

Since the $200 \mathrm{kDa}$ protein could consist of either the smooth muscle isoform SM2, the fetal nonmuscle isoform MHC-B, or both, we performed western immunoblot analyses to determine the expression of these two isoforms in each artery studied using specific antisera (13). All of the arteries expressed SM2 (Fig 4); 


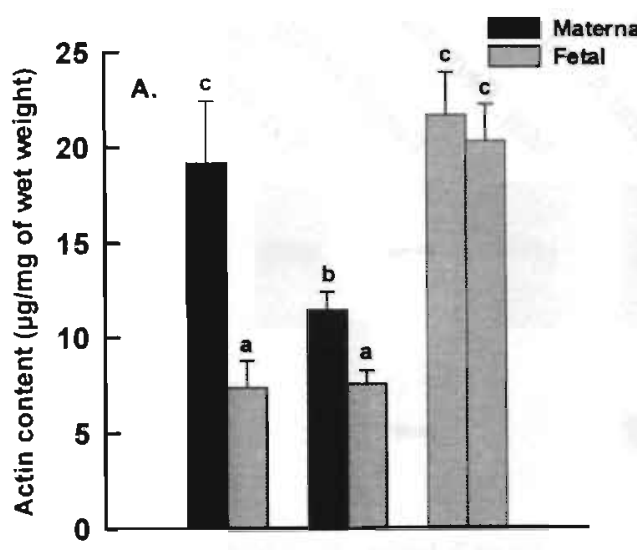

Figure 2. Total acrin (A) and total myosin heavy chain (B) contents in arteries obtained from near-term fetal and adult sheep. Different letters denote significant differences between tissues $(p=0.006$ by ANOVA), while groups not significantly different from each other are noted by the same letters. See the Table for the number of animals within each tissue group. Values are means \pm SEM.
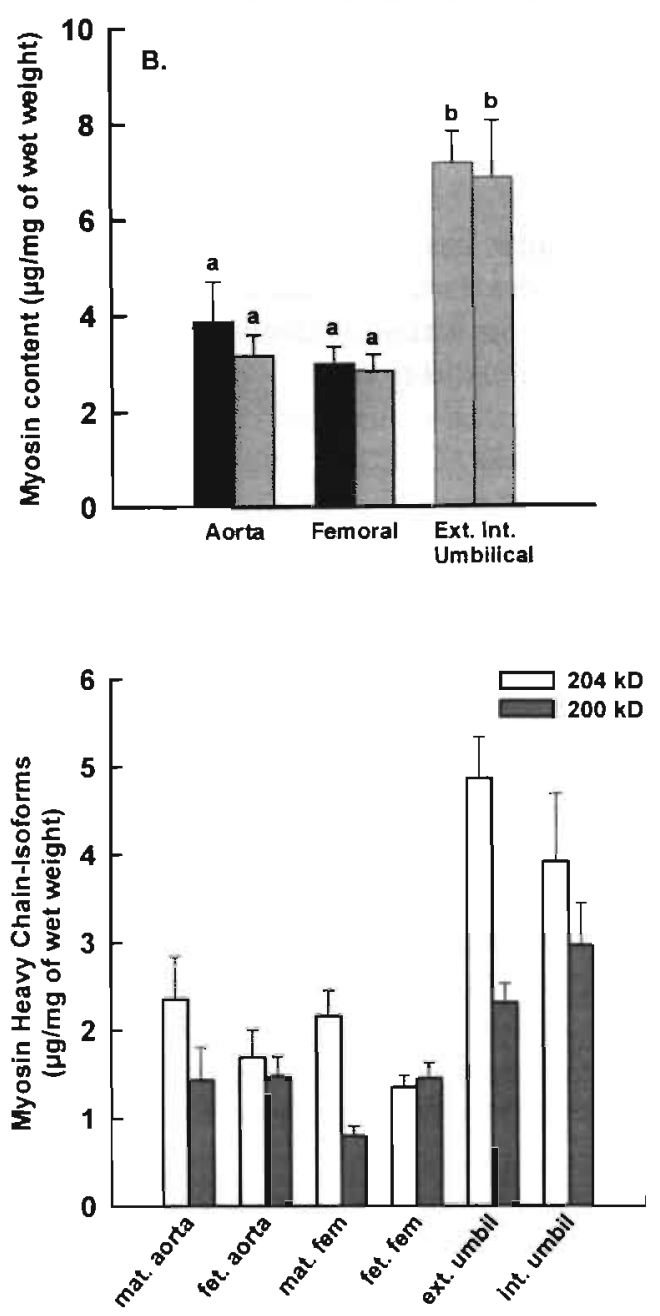

Figure 3. Contents of 204 and $200 \mathrm{kDa}$ myosin heavy chain species in arteries obtained from near-term fetal and adult sheep. Values are means \pm SEM. Numbers of animals studied is noted in Table 1. 


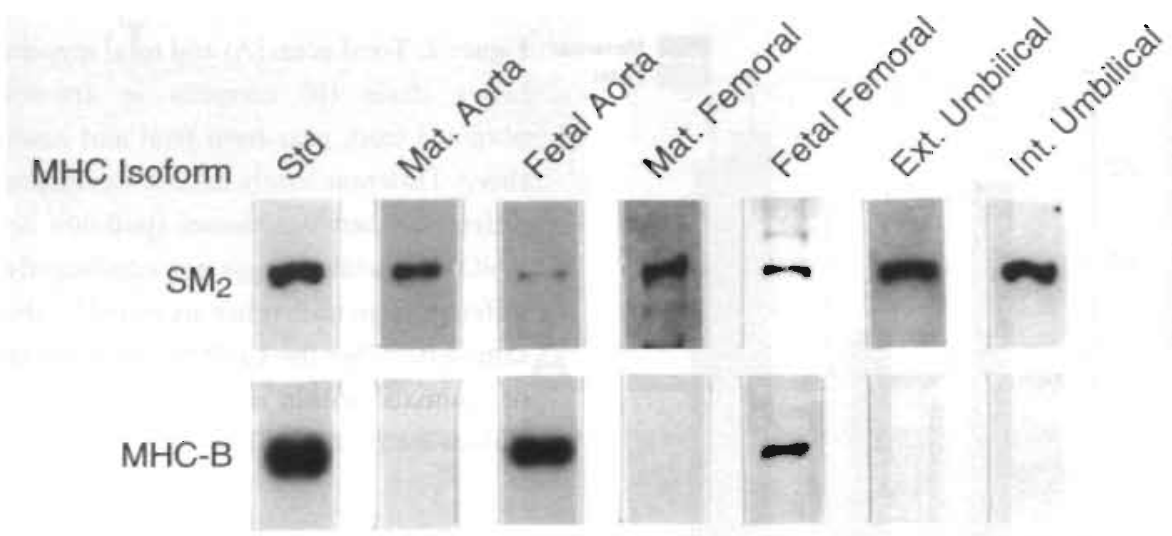

Figure 4. Representative immunoblots of $200 \mathrm{kDa}$ myosin heavy chain-isoforms in fetal and adult arteries. The standards ( $\mathrm{Std}$ ) for the SM2 and MHC-B were adult ovine myometrium and purified bovine brain myosin (8), respectively. Approximately $200 \mathrm{ng}$ of total myosin heavy chain were loaded in each lane.

however, SM2 expression was substantially less in fetal systemic arteries compared to either umbilical artery or the adult arteries. In contrast, only the fetal femoral artery and aorta expressed MHC-B; there was no evidence of this isoform in any of the umbilical or adult arteries examined (Fig 4).

\section{Contraction responses}

Active stresses were determined for each artery with vascular strips obtained from four additional near-term animals and performed in duplicate. Although contraction responses could be elicited by vascular strips obtained from both umbilical arteries and either adult vessel with $65 \mathrm{mM} \mathrm{KCl}$ or $10^{-6} \mathrm{M}$ phenylephrine, responses by strips of fetal aorta and femoral artery were greatly attenuated to both $\mathrm{KCI}$ and $\alpha$-stimulation as well as several other agonists, including histamine, serotonin, $\mathrm{PGF}_{2 \alpha}, \mathrm{ATP}$, angiotensin II, and endothelin (data not shown). As summarized in Figure 5, stress generated by fetal systemic arteries in response to $\mathrm{KCl}$, which by-passes potential maturational differences in receptor densities or coupling, were significantly less than those observed with the external umbilical artery ( $\mathrm{p}<0.0001$, ANOVA), which, in contrast, generated active stresse's similar to those measured for both adult arteries. It is notable that responses by the internal umbilical artery were again intermediate between the exrernal umbilical artery and fetal systemic vessels. 


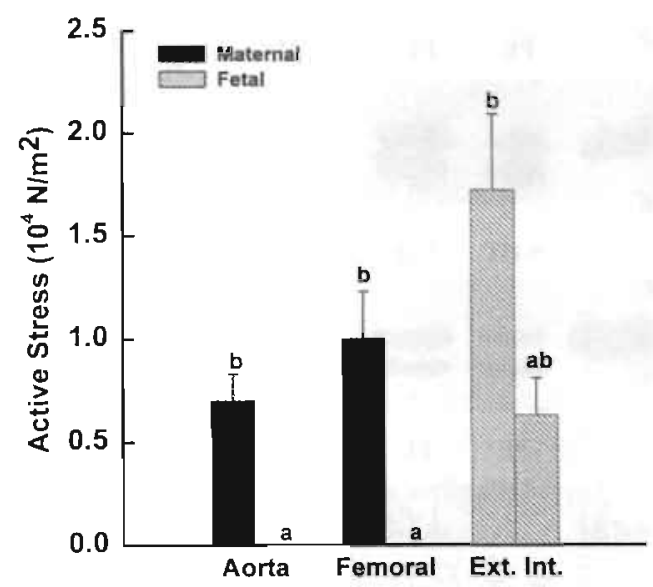

Figure 5. Summary of active stresses obtained with strips of fetal and adult arteries using $65 \mathrm{mM} \mathrm{KCl}$ at optimal length. Tissues were obtained from 4 animals, each studied in duplicate. Different letters denote significant differences between groups $(p<0.0001$, ANOVA), while the same letrer signifies that groups are not significantly different. Values are means \pm SEM.

\section{Myosin light chain phosphorylation}

The primary regulation of force in smooth muscle occurs via $\mathrm{Ca}^{2+}$-dependent phosphorylation of the myosin regulatory light chain $(10,11)$. We, therefore, determined in studies of tissues from two additional animals whether the decreased stress generation in fetal systemic arteries was associated with attenuated levels of myosin light chain phosphorylation. At the time of maximum stresses $(\sim \mathrm{min})$ obtained by external umbilical arteries $\left(10^{-5} \mathrm{M}\right.$ serotonin) or adult femoral arteries $\left(10^{-3} \mathrm{M}\right.$ phenylephrine), there was evidence of $45-57 \%$ phosphorylation of the myosin regulatory light chain (Fig 6A and 6B). In contrast, following application of $10^{-3} \mathrm{M}$ phenylephrine to fetal femoral arteries, there was no phosphorylation (Fig 6C) or stress observed. Interestingly, in order to detect regulatory light chain in homogenates of fetal femoral arteries, 5-times the sample volume was required to be loaded as compared to maternal femoral arteries.

\section{Umbilical artery responses}

To determine the contractile responses by ovine umbilical arteries to several agonists, studies were performed comparing responses by external and internal umbilical arteries from near-term fetal sheep using doses reported by White (7). The data have been normalized as a percent of the response to $65 \mathrm{mM} \mathrm{KCl}$, which represents $100 \%$. The external umbilical artery (Fig $7 \mathrm{~A}$ ) constricted in the presence of each agonist examined with the exception of bradykinin. However, only 5-hydroxytryptamine elicited a response that significantly exceeded that seen with $\mathrm{KCl}$, generating 4-fold greater stresses than $\mathrm{KCl}(\mathrm{p}<0.0001$, ANOVA). The internal umbilical artery demonstrated a similar pattern of responses (Fig $7 \mathrm{~B}$ ); but unlike the external umbilical artery it was unresponsive to angiotensin II. 


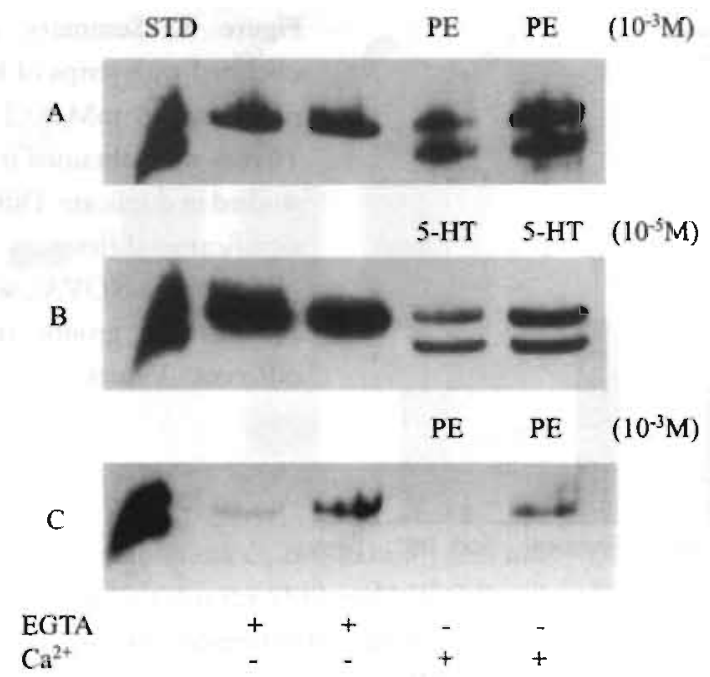

Figure 6. Representative immunoblots of regulatory light chain phosphorylation in adult femoral artery (Row A), external umbilical artery (Row B) and fetal femoral artery (Row C). Tissue homogenates (with STD being bovine tracheal) were subjected to electrophoresis (see Methods) which separates the non-phosphorylated (upper band) from the phosphorylated (lower band) light chain. Lanes 2 and 3 show absence of phosphorylation when vascular strips are at basal tension in the presence of EGTA and the absence of $\mathrm{Ca}^{2+}$ in the baths. Lanes 4 and 5 show $45-57 \%$ phosphorylation at the time of maximum contraction by adult femoral arteries with $10^{-3} \mathrm{M}$ phenylephrine (PE) and by external umbilical arteries with $10^{-5} \mathrm{M}$ 5-hydxroxytryptamine $(5-\mathrm{HT})$. Fetal femoral arteries required 5 -fold greater sample volume to detect regulatory light chain, and phosphorylation was not observed with $10^{-3} \mathrm{M} \mathrm{PE}$. 

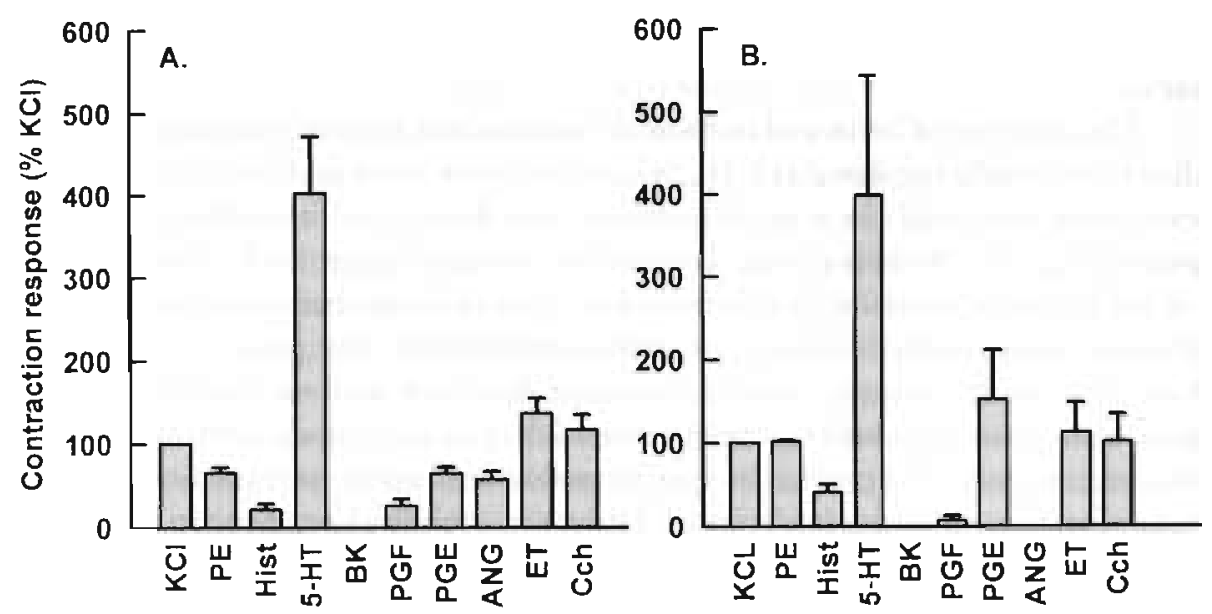

Figure 7. Contraction responses to multiple agonists by strips of external (A) and intraabdominal (B) umbilical arteries obtained from near-term fetal sheep. Responses are presented as the percent of the response observed with $65 \mathrm{mM} \mathrm{KCl}$. Doses and abbreviations are defined in Methods. Arteries from 4 fetal sheep were studied, each in duplicate. Values are means \pm SEM.

\section{DISCUSSION}

In fetal sheep vascular responses to infused vasoconstrictors may be less than those seen in adult animals $(4,34)$. This could reflect differences in the clearance of these agents (3), the absence or immaturity of specific receptors necessary for the transduction of these messages $(28,35)$ or the relative immaturity of fetal VSM as compared to the adult $(12,13,36)$. In addition, significant differences exist between umbilical and systemic responses to vasoconstrictors $(1,3,4)$. For example, in intact fetal sheep with chronically implanted flow probes, the umbilical vascular bed is more sensitive to angiotensin II over a wide range of doses than either the hindlimb vasculature (2) or the systemic vasculature as a whole (4). These dissimilarities, however, are not explained entirely by differences in the receptor subtype expressed in the two vascular beds (2). Thus within the fetal compartment there is increasing evidence of important differences in vascular maturation and function $(1,2,3,4,37,38)$. The expression of contractile proteins in ovine fetal systemic VSM is developmentally regulated and prior to birth a "synthetic" phenotype of VSM is predominant $(12,13)$. However, it is unclear which factors account for the differences in umbilical and systemic vascular responsiveness and what role the expression of VSM contractile proteins might play. To address these queries we examined the expression and contents of key contractile proteins in several systemic arteries from fetal and adult sheep as well 
as the umbilical artery and compared this to their capacity to generate stress in vitro.

The contents of actin and myosin in vascular and visceral smooth muscle are developmentally regulated $(13,16,24)$, and in ovine aorta and bladder values are extremely low until the end of gestation and during the immediate postnatal period $(12,13)$. Whereas actin contents in aorta of term fetal sheep increase -2-fold at term, resulting in values that are half of those seen in the adult, MHC contents have reached values approaching adult levels. The pattern of change in total and soluble protein contents resemble that seen with myosin, i.e., at term gestation values approach that seen in the adult (12). In the present study, contents of actin, myosin, and protein in near-term fetal and adult systemic arteries were similar to those previously observed. However, umbilical artery actin and MHC contents were 2.5- to 3.0-fold greater than those observed in fetal systemic arteries. Further, total myosin content was 2 -fold greater than that measured in adult vessels. The greater contents of actin and $\mathrm{MHC}$ in both umbilical arteries were associated with a greater soluble protein content, suggesting that there is not only more contractile protein in umbilical arteries, but also more smooth muscle, particularly in the external umbilical artery. This conclusion is further supported by histologic comparison of the vessels. The intra-abdominal portion of the umbilical artery was intermediate in this regard and in all other aspects, suggesting it serves as a transitional artery between the fetal systemic and umbilical vasculature, an observation consistent with recent findings regarding angiotensin II receptor subtype expression in fetal sheep (28).

In adult mammals, VSM contains predominately the smooth muscle MHC isoforms, SM1 and SM2, and the SM1 species is the more abundant isoform $(14,30,39)$. Furthermore, SM2 accounts for all or nearly all of the $200 \mathrm{kDa}$ species in adult VSM $(14,40)$. Thus adult VSM consists primarily of the "contractile" smooth muscle phenotype. In contrast, systemic arteries from the developing ovine fetus predominantly express the $200 \mathrm{kDa}$ species, and SM1 does not achieve adult levels until 3-4mon postnatal $(12,13)$. Furthermore, the $200 \mathrm{kDa}$ species in developing systemic VSM consists primarily of the nonmuscle isoform MHC-B until after birth $(12,13)$. This pattern of protein expression reflects the predominance of a "synthetic" smooth muscle phenotype, which has been identified in proliferating smooth muscle cells in culture and within arteriosclerotic neointimas $(24,25,26)$ and is associated with the potential for VSM replication (41). These differences in MHC-isoform expression between fetal and adult systemic VSM were also evident in the present study. In contrast, the umbilical arteries more closely resembled mature adult arteries, i.e., predominantly expressing the SM1 isoform and having no evidence of $\mathrm{MHC}-\mathrm{B}$ expression. Although we have only examined five systemic fetal arteries to date, each has consistently expressed MHC-B, and its expression has decreased with increasing age $(12,13$, unpublished observations). Notably, the bladder is the only other smooth muscle thus far identified in fetal sheep that does not express MHC-B. 
Like the umbilical artery, it too has a predominance of SM1 (12,13). Thus umbilical artery VSM development is precocious within the fetal vascular compartment and unlike systemic VSM, demonstrates only a "contractile" VSM phenotype at term. Advanced differentiation of the ductus arteriosus has also been described recently $(37,38)$; however, MHC-B expression was not examined. Since the umbilical artery and ductus arteriosus constrict at or soon after birth in order to redirect cardiac output, their accelerated maturation of VSM may be unique to the fetal vasculature and related to adaptative alterations necessary following birth.

Responses by vascular strips of fetal femoral artery and aorta were significantly attenuated compared to adult arteries for all agonists examined, including $\mathrm{KCI}$. This is consistent with studies comparing fetal, newborn and adult systemic arteries from sheep, rabbits and rats $(16,42,43,44)$. Although there were quantitative differences in the measured responses to $\mathrm{KCl}$ or other agonists between studies, reflecting the use of strips versus rings, arteries from immature animals were consistently less responsive. In contrast, the external umbilical artery generated stresses comparable to those seen with adult vessels while the internal umbilical artery stresses were intermediate. These results clearly support prior observations that the "synthetic" phenotype of VSM, for which MHC-B serves as a marker, is associated with decreased functional capacity $(45,46)$. Failure of fetal systemic arteries to contract to several agonists may be due to deficits in excitation-contraction coupling. Our finding that supramaximal concentrations of agonist did not elicit myosin light chain phosphorylation in feral femoral arteries suggests these agonists did not elevate intracellular calcium concentrations; however, a more detailed time course will be required to establish if this is the case. In preliminary studies, we have found significant expression of calciumcalmodulin-dependent myosin light chain kinase in fetal arteries at this stige of development. Thus it remains to be determined if the immature VSM phenotype is associated with fewer receptors, channels, or other components required for excitation-contraction coupling. Supporting this notion is our recent observation that only the AT2 subtype of the angiotensin II receptor, which does not couple to contraction (47), is expressed in ovine fetal systemic arteries $(2,29)$. It remains unclear, however, whether differences in contractile protein composition between fetal and adult arteries also contribute to the attenuated stresses. While total MHC contents were similar in fetal and adult systemic arteries, actin contents were less and interestingly, immunoreactive regulatory light chain contents also were substantially lower in fetal VSM. Further, MHC-isoform composition differed, i.e., nonmuscle MHC-B was expressed only in fetal systemic arteries. Direct activation of contractile proteins by elevating calcium in permeabilized muscle fibers will be required to directly assess the contractile capacity of fetal VSM.

Although fetal sheep are extensively used to study cardiovascular development in vivo and have provided important insights into developmental changes, important differences may exist between species. While the human fetus cannot be 
studied in detail, the umbilical artery is readily available after birth, thus its responsiveness to numerous agents has been thoroughly examined $(5,6,7)$. These studies, however, have focused on understanding how the umbilical artery closes at birth. Similar studies of the ovine umbilical arteries are rare (33). We, therefore, determined if the external and internal umbilical arteries responded differently to several agonists, and how these responses compared to those observed with human arteries. Responses by the two segments of ovine umbilical artery were similar, and 5-hydroxytryptamine elicited the greatest contractile responses by both arteries, which is consistent with earlier reports for sheep (33) and the human $(5,6,7)$. Bradykinin, a potent vasoconstrictor in the human umbilical artery $(6,7)$, however, had no effect on either ovine artery. The reason for this disparity is not readily apparent. Angiotensin II also contracted the external umbilical artery, but had no affect on segments of the internal artery. This can be explained by the expression of AT1 receptors in the former and AT2 receptors, which do not couple to contraction, in the latter (29). Comparing these responses with the human is difficult since there may be regional differences in angiotensin II receptor expression (48) and function (6) within the external umbilical artery which will require further evaluation. Nonetheless, evidence exists in both species that the umbilical vasculature is quite sensitive to angiotensin II and several other agonists, further supporting the use of the sheep as a model for studies of cardiovascular development.

In the present studies we have compared for the first time the differences in protein expression and function in fetal systemic and umbilical artery VSM in order to explain previous observations of differences in contractile responses in vivo $(1,2,3,4)$. We have demonstrated that unlike systemic arteries the ovine umbilical artery predominantly expresses the "contractile" phenotype of VSM and there are greater contents of actin and total myosin in the umbilical artery. Moreover, we have shown that the umbilical artery is functionally more like adult arteries, responding to several agonists. Thus umbilical artery smooth muscle development precedes that of the fetal systemic vasculature. Additional studies, however, are needed to determine if the smaller systemic resistance vessels also demonstrate a slower rate of maturation.

\section{Perspectives}

It is now evident that compared to the systemic vasculature as a whole several arteries within the fetal compartment demonstrate precocious development, including the ductus arteriosus and umbilical artery $(2,37,38)$. Thus the maturation of fetal VSM cannot be easily characterized by simply studying a single vessel such as the aorta. It is likely that this differential maturation is associated with local regulatory mechanisms, which in turn are associated with the specific roles of these vessels in ensuring fetal adaptation and well-being prior to and after birth. The present data suggest that the umbilical artery not only actively participates in 
modulating umbilical and placental blood flow, but also may modulate systemic vascular resistance since this vascular bed accounts for $45-50 \%$ of fetal cardiac output. The slower maturation and development of the systemic VSM, therefore, may account for the lower arterial pressure seen in fetal and newborn animals, as well as the prematurely born human neonate. Thus the present observations provide further evidence to support the suggestion that the umbilical vasculature plays a more important role than generally considered in regulating fetal systemic blood pressure and the distribution of cardiac output $(2,49)$.

\section{REFERENCES}

1. Iwamato, H.S. and A.M. Rudolph. Effects of angiotensin II on the blood flow and its distribution in fetal lambs. J. Dev. Physiol. 1: 283-293, 1981.

2. Kaiser, J.R., B.E. Cox, T.A. Roy, and C.R. Rosenfeld. Differential development of umbilical and systemic arteries. I. ANG II receptor subtype expression. Am. J. Physiol. 274 (Regulatory Integrative Comp. Physiol. 43): In press, 1998.

3. Rosenfeld, C.R., A. Gresores, T.A. Roy, and R.R. Magness. Comparison of ANG II in fetal and pregnant sheep: metabolic clearance and vascular reactivity. Am. J. Physiol. 268: E237-E247, 1995.

4. Yoshimura, T., R.R. Magness, and C.R. Rosenfeld. Angiotensin II and $\alpha$-agonist I. Responses of ovine fetoplacental vasculature. Am. J. Physiol. 259: H464-H472, 1990.

5. Bjøro, K. and S. Stray-Pedersen. Effects of vasoactive autacoid on different segments of human umbilicoplacental vessels. Gynecol. Invest. 22: 1-6, 1986.

6. Tulenko, T.N. Regional sensitivity to vasoactive polypeptides in the human umbilicoplacental vasculature. Am. J. Obstet. Gynecol. 135: 629-636, 1979.

7. White, R.P. Pharmacodynamic study of maturation and closure of human umbilical arteries. Am. J. Obstet. Gynecol. 160: 229-237, 1989.

8. North, AJ., M. Gimona, Z. Lando, and J.V. Small. Actin isoform compartments in chicken gizzard smooth muscle cells. J. Cell. Sci. 107: 445-45.5, 1994.

9. Owens, G.K. Regulation of differentiation of vascular smooth muscle cells. Physiol. Rev. 75: 487-517, 1995.

10. Hartshorne, D.J. In: Physiology of the Gastrointestinal Tract; New York; Raven Press; 1987, pp 423-482.

11. Stull, J.T., J.J. Gallagher, B.P. Herring, and K.E. Kamm. Vascular smooth muscle contractile elements. Cellular regulation. Hypertension. 17: 723-732, 1991.

12. Arens, Y.H.J.M., C.R. Rosenfeld, W. Jabbar, K.E. Kamm. Contractile protein and myosin heavy chain isoform expression in vascular smooth muscle during fetal and postnatal life. FASEB J 10: A312 (Abst \#1799), 1996.

13. Chern, J., K.E. Kamm, and C.R. Rosenfeld. Smooth muscle myosin heavy chain isoforms are developmentally regulated in male fetal and neonatal sheep. Pediatr. Res. 38: 697-703, 1995. 
14. Eddinger, T.J. and R.A. Murphy. Developmental changes in actin and myosin heavy chain isoform expression in smooth muscle. Arch. Biochem. Biophys. 284: 232-237, 1991.

15. Giuriato, L., M. Scatena, A. Chiavegato, M. Tonello, G. Scannapieco, P. Pauletto, and S. Sartore. Non-muscle myosin isoforms and cell heterogeneity in developing rabbit vascular smooth muscle. J. Cell. Sci. 101: 233-246, 1992.

16. Seidel C.L. and J.C. Allen. Pharmacologic characteristics and actinomyosin content of aorta from neonatal rats. Am. J. Physiol. 237: C81-C86, 1979.

17. Kawamoto, S. and R. Adelstein. Characterization of myosin heavy chains in cultured aorta smooth muscle cells. J. Biol. Chem. 262: 7282-7288, 1987.

18. Kuro-o, M., R. Nagai, K. Nakahara, H. Katoh, R. Tsai, H. Tsuchimochi, Y. Yazaki, A. Ohkubo, and F. Takaku. cDNA cloning of a myosin heavy chain isoform in embryonic smooth muscle and its expression during vascular development and in arteriosclerosis. J. Biol. Chem. 266: 3768-3773, 1991.

19. Nagai, R., M. Kuro-o, P. Babij, and M. Periasamy. Identification of two types of smooth muscle myosin heavy chain isoforms by cDNA cloning and immunoblot analysis. J. Biol. Chem. 264: 9734-9737, 1989.

20. Nigai, R., D.M. Larson, and M. Periasamy. Characterization of mammalian smooth muscle myosin heavy chain cDNA clone and its expression in various smooth muscle rypes. Proc. Natl. Acid. Sci. USA 85: 1047-1051, 1988.

21. Miano, J.M., P. Cserjesi, K.L. Logan, M. Periasamy, and E.N. Olson. Smooth muscle myosin heavy chain exclusively marks the smooth muscle lineage during mouse embryogenesis. Circ. Res. 75: 803-812, 1994.

22. Aikawa, M., P.N. Sivan, M. Kuro-o, K. Kimura, K. Nakahara, S. Takewaki, M. Ueda, H. Yamaguchi, Y. Yakazi, M. Periasamy, and R. Nagai. Human smoorh muscle myosin heary chain isoforms as molecular marker for vascular development and atherosclerosis. Circ. Res. 73: 1000-1012, 1993.

23. Kuro-o, M., R. Nagai, H. Tsuchimochi, H. Katoh, Y. Yakazi, A. Ohkubo, and F. Takaku. Developmentally regulated expression of vascular smooth muscle myosin heavy chain isoforms. J. Biol. Chem. 264: 18272-18275, 1989.

24. Simons, M., M. Wang, W. McBride, S. Kawamoto, K. Yamakawa, D. Gdula, R.S. Adelstein, and L. Weir. Human nonmuscle myosin heavy chains are encoded by two genes located on different chromosomes. Circ. Res. 69: 530-539, 1991.

25. Reusch, P., H. Wagdy, R. Reusch, E. Wilson, and H.E. Ives. Mechanical strain increases smooth muscle and decreases nonmuscle myosin expression in rat vascular smooth muscle cells. Circ. Res. 79: 1046-1053, 1996.

26. Frid, M.G., O.Y. Printesva, A. Chiavegato, E. Faggin, M. Scatena, V.E. Koteliansky, P. Pauletto, M.A. Glukhova, and S. Sartore S. Myosin heavy-chain isoform composition and distribution in developing and adult human aortic smooth muscle. J. Vasc. Res. 30: 279-292, 1993.

27. Eddinger, T.J. and J.A. Wolf. Expression of four myosin heavy chain isoforms with development in mouse uterus. Cell Motility and the Cytoskeleton 25: 3.58-368, 1993. 
28. Zanellato, A.M.C., A.C. Borrione, L. Giuriato, M. Tonello, G. Sannapieco, P.Pauletto, and S. Sartore. Myosin heavy chain isoforms and cell heterogeneity in vascular smooth muscle. I. Developing and adult bovine aorta. Dev. Biol. 141: 431-446, 1990.

29. Cox, B.E., C.E. Williams, and C.R. Rosenfeld. Ontogeny of Vascular Sinooth Muscle Angiotensin II receptor Subtype Expression in Fetal and Newborn Sheep. Circulation 92: I304 (Abstr \#1446), 1995.

30. Annibale, D.J., C.R. Rosenfeld, and K.E. Kamm. Alterations in vascular smooth muscle contractility during ovine pregnancy. Am. J. Physiol. 25: H1282-H1288, 1989.

31. Annibale, D.J., C.R. Rosenfeld, J.T. Stull, and K.E. Kamm. Protein content and myosin light chain phosphorylation in uterine arteries during pregnancy. Am. J. Physiol. 259: C484-C489, 1990.

32. Ipson, M.A., C.R. Rosenfeld, R.R. Magness, and K.E. Kamm. Alterations in myometrial stress during ovine pregnancy and the puerperium. Am. J. Physiol. 271: R446-R454, 1996.

33. Dyer, D.C. The pharmacology of isolated sheep umbilical cord blood vessels. J. Pharmacol. Exp. Therap. 175: 565-570, 1970.

34. Assali, N.S., L.W. Holm, and N. Sehgal. Regional blood flow and vascular resistance of the fetus in utero. Action of vasoactive drugs. Am. J. Obstet. Gynecol. 83: 809-817, 1962.

35. Grady, E.F., L.A. Sechi, C.A. Griffin, M. Schambelan, and J.E. Kalinyak. Expression of $\mathrm{AT}_{2}$ receptors in the developing rat fetus. J. Clin. Invest. 88: 921-933, 1991.

36. Belik, J. and N.L. Stephens. Developmental differences in vascular smooth muscle mechanics in pulmonary and systemic circulations. J. Appl. Physiol. 74(2): 682-687, 1993.

37. Colbert, M.C., M.L. Kirby, and J. Robbins. Endogenous retinoic acid signaling colocalizes with advanced expression of the adult smooth muscle myosin heavy chain isoform during development of the ductus arteriosus. Circ. Res. 78: 790-798, 1996.

38. Kim, H., M. Aikawa, K. Kimura, M. Kuro-o, K. Nakamura, T. Suzuki, H. Katoh, E. Okamoto, H. Yazaki, and R. Nagai. Ductus arteriosus. Advanced differentiation of smonth muscle cells demonstrated by myosin heavy chain isoform expression in rabbits. Circulation 88: 1804-1810, 1993.

39. Borrione, A.C., A.M.C. Zanellato, G. Scannapieco, P. Pauletto, and S. Sartore. Myosin heavy-chain isoforms in adult and developing rabbit vascular smooth muscle. Eur. J. Biochem. 183: 4132-4137, 1989.

40. Rosenfeld, C.R. and K.E. Kamm. Myosin heavy chain isoforms are regulated differently in myometrium and uterine artery smooth muscle in ovine pregnancy and the puerperium. Biophys. J. 64: A34, 1993.

41. Cook, C.L., M.C.M. Weiser, P.E. Schwartz, C.L. Jones, and R.A. Majack. Developmentally timed expression of an embryonic growth phenotype in vascular smooth muscle cells. Circ. Res. 74: 189-196, 1994.

42. Belik, J., A.J. Halayko, K. Rao, and N.L. Stephens. Pulmonary and systemic vascular smooth muscle mechanical characteristics in newborn sheep. Am. J. Physiol. 263: H881-H886, 1992.

43. Hayashi S., and N. Toda. Age-related changes in the response of rabbit isolated aortae to vasoactive agents. J. Pharmacol. 64: 229-237, 1978. 
44. Nakanishi, T., H.Gu, K. Abe, and K. Momma. Developmental changes in the contractile system of the mesenteric small artery of rabbit. Pediatr. Res. 41: 65-71, 1997.

45. Chamley-Campbell, J., G.R. Campbell, and R. Ross. Smooth muscle cell in culture. Physiol. Rev. 59: 1-61, 1979.

46. Seidel, C.L., D. Rickman, H. Steuckrath, J.C. Allen, and A.M. Kahn. Control and Function of Alterations in Contractile Protein Isoform Expression in Vascular Smooth Muscle. In: Regulation of Smooth Muscle Contraction. New York, Plenum Press, 1991, pp 315-325.

47. Cox, B.E., M.A. Ipson, P.W. Shaul, K.E. Kamm, and C.R. Rosenfeld. Myometrial angiotensin II receptor subtypes change during ovine pregnancy. J. Clin. Invest. 92: 2240-2248, 1993.

48. Kingdom, J.C.P., J. McQueen, J.M.C. Connel, and M.J. Whittle. Fetal angiotensin II levels and vascular (type I) angiotensin receptors in pregnancies complicated by intrauterine growth retardation. Br. J. Obstet. Gynaecol. 100: 476-482, 1993.

49. Dawes, G.S. The umbilical circulation. Am. J. Obstet. Gynecol. 84: 1634-1648, 1962. 
CHAPTER 6

\section{Maturation of ovine uterine smooth muscle during development and the effects of parity}

Yvonne Arens, Kristine E. Kamm, Charles R. Rosenfeld

Departments of Pediatrics and Physiology

University of Texas southwestern medical center, Dallas, Texas

J Soc Gynecol Investig 2000;7:284-290 
A B S T R A C T

To characterize changes in myometrial contractile proteins and myosin heavy chain (MHC) isoforms during ovine fetal and neonatal development and following pregnancy. We hypothesized that ovine myometrium demonstrates progressive cellular differentiation and maturation, which begins in utero and extends into the postnatal period, and that pregnancy causes further cellular alterations.

Myometrium was obtained from female fetal (72-140d gestation, $n=19$; term 145d), postnatal (1d-3mon, $n=25$ ) and parous noncycling nonpregnant $(\mathrm{n}=9)$ sheep to measure total and soluble proteins, actin, MHC and MHC isoforms. Contractile proteins were analyzed by SDS-PAGE and expression of $200 \mathrm{kDa} \mathrm{MHC}$ isoforms determined with Western immunoblots.

The contents of total and soluble proteins and actin and total myosin gradually increase ( $\mathrm{P}=0.003)$ during ovine development. Although the contribution of smooth muscle $204 \mathrm{kDa}$ MHC increases $(\mathrm{P}<0.001)$ from $23 \pm 8 \%$ of total MHC at $<100 \mathrm{~d}$ gestation to $75+2 \% 3-4$ mon postnatal, the $200 \mathrm{kDa}$ species falls proportionately. Before birth MHC-B, a "fetal isoform", is the predominant $200 \mathrm{kDa}$ protein; postnatally, it is replaced by SM2, demonstrating a switch from a "synthetic" to a mature contractile smoorh muscle phenorype. Pregnancy is associated with further increases in actin contents and redistribution of the contents of the $204 \mathrm{kDa}$ and SM2 MHC isoforms.

Although the fetal and postnatal uterus has no known functional demand, ovine myometrial differentiation and maturation begin in the midtrimester and continue throughout the postnatal period. Thus changes in smooth muscle phenotype occur prenatally, as evidenced by a switch from MHC-B to SM2, which may signal completion of organ development and preparation for adult function. Pregnancy results in further modifications in myometrial proteins.

Index terms: Myometrium, Development, Myosin, Ferus, Smooth muscle, Pregnancy. 


\section{INTRODUCTION}

Normal development of the mammalian uterus is essential for the successful propagation of the species. This dictates not only the number of conceptuses that can be supported, but also the subsequent growth and postnatal phenotype of the conceptus $(1,2)$. Uterine development occurs in three stages, organogenesis, cellular differentiation and maturation, and growth. The first begins with fusion of the paramesonephric ducts, which determines species specific morphology and occurs in the ovine fetus between 34 and $55 \mathrm{~d}$ gestation (3). This is followed by the development of two distinct layers of mesenchyme and progressive cytodifferentiation. The inner layer becomes the endometrial epithelium, which has been carefully studied and described in some detail $(1,3,4)$. The outer layer of mesoderm is destined to form both the longitudinal and circular layers of the uterine smooth muscle or myometrium $(1,3)$, and its differentiation, like that of the bladder (5), appears to be dependent upon the endometrium (6). In most mammals this occurs postnatally $(1,7-9)$, whereas in the human and ewe this is observed in utero $(3,10)$. Histological evidence suggests that cellular maturation follows differentiation and proceeds for variable periods of time depending on the species, but always extends into the postnatal period. Organ growth then occurs as the female grows and matures. However, the maturational processes of the developing myometrium are not fully understood, in particular, the characteristics of the smooth muscle phenotype.

Smooth muscle is by far the most abundant tissue in the organs of the urogenital tract, i.e., the uterus and bladder. The phenotypic alterations that occur during smooth muscle development are derived from the sequential and gradual induction of differentiation-specific protein markers (11). Smooth muscle myosin heavy chain (MHC) is exclusively expressed in smooth muscle cells during development and is an indicator of the smooth muscle phenotype (12). The MHC isoforms have traditionally been the subject of investigations defining phenotypic alterations in muscle (13). This derives from the fact that myosin is an essential component of the contractile system and that variations in the myosin structure may underlie differences in muscle contractile properties. Mature smooth muscle primarily expresses the smooth muscle MHC isoforms and to minor extent non-muscle isoforms $(11,14)$. The smooth muscle isoforms are 204 (SM1) and 200 (SM2) kDa, are derived from a single gene through alternative splicing, and differ in their non-helical carboxyterminal tail region $(15,16)$. There are at least two non-muscle MHC isoforms, 200 (MHC-B) and 196 (MHC-A) kDa, which are products of two distinct genes (17). While the former are expressed exclusively in smooth muscle cells, the non-muscle isoforms are expressed in all cell typt's and are involved in actin-based motile functions such as cell locomotion and division (18). Expression of these $4 \mathrm{MHC}$ isoforms is developmentally regulated in a tissue specific manner. For example, during development, $\mathrm{MHC}-\mathrm{B}$ is the predominant $200 \mathrm{kDa}$ protein in vascular smooth muscle, reflecting incomplete maturation, 
and is replaced by SM2 $(11,19)$. In fetal sheep, SM1 is co-expressed with MHC-B in vascular smooth muscle throughout most of gestation; SM2 expression occurs late in gestation and postnatally and is associated with a reciprocal decline in MHC-B $(20,21)$. In contrast, the ovine bladder expresses abundant SM1 and SM2 with little MHC-B at midgestation (21), demonstrating in the developing ovine fetus that these maturational processes are tissue specific. This has not been characterized in the ovine myometrium.

The sheep, because of its long gestation, the size of the fetus, and the ability to alter the hormonal milieu while studying physiological responses in vivo, has been extensively used to study the physiology of pregnancy (22-24) and the fetus (25). Importantly, significant quantities of smooth muscle tissue can be obtained from both fetal and neonatal animals to perform extensive studies of smooth muscle maturation $(20,21,26)$. Therefore, we sought to characterize the normal ontogeny of contractile protein expression in myometrium from fetal and neonatal sheep. In particular, we focused on the patterns of expression of the major contractile proteins: actin, myosin and the $\mathrm{MHC}$ isoforms. We also describe for the first time the effect that having been pregnant has on the expression of these proteins in ovine uterine smooth muscle. We hypothesized that there is progressive cellular differentiation and smooth muscle maturation that begins before birth, and that pregnancy has additional effects on uterine smooth muscle phenotype.

\section{METHODS}

\section{Tissue preparation}

Female fetal ( $72-140 d$ gestation, $n=19$; term $145 d$ ), postnatal ( $1 d-3$ mon, $n=21$ ), and parous noncycling adult $(n=9)$ sheep were euthanized by rapid intravenous injection of pentobarbital sodium $(50 \mathrm{mg} / \mathrm{kg}$ ) to the mother or neonate via the external jugular vein. Ewes in the adult group were $14-30 \mathrm{~d}$ postpartum with suckling lambs. The uterus was quickly removed in block, and generous segments from the uterine body were placed into iced phosphate buffed solution containing (in $\mathrm{mM}$ ): $137.0 \mathrm{NaCl}, 2.7 \mathrm{KCl}, 10 \mathrm{Na}_{2} \mathrm{HPO}_{4}, 1.76 \mathrm{KH}_{2} \mathrm{PO}_{4}, 0.1 \%$ diethyl pyrocarbonate, $\mathrm{pH}$ 7.4. The adventitia and uterine epithelium were removed using sharp dissection. Strips of myometrium were cut, blotted with a cotton swab to remove excess water and capillary blood, frozen in liquid nitrogen, and stored at $-80^{\circ} \mathrm{C}$ until studied. Additional segments were obtained for contraction studies and transported within $30 \mathrm{~min}$ to another laboratory to measure forces as described below. These studies were approved by the Institutional Review Board for Animal Research at UT Southwestern Medical Center at Dallas. 
Samples of frozen tissue (10-20 mg) were weighed and homogenized in 40 volumes of sodium dodecyl sulfate (SDS) buffer as previously reported $(20,21,24,27)$. Homogenates were divided into two aliquots. One was subjected to centrifugation at $10,000 \times \mathrm{g}$ for $2 \mathrm{~min}$, and the supernatant was removed to determine the soluble or cellular protein in each sample. The other sample was nor centrifuged and was used to determine the total homogenate protein content, which includes both soluble and insoluble protein, predominantly extracellular matrix. Aliquots of both samples were analyzed for protein contents by BCA reagent (Pierce, Rockford, III.). Bromophenol blue and 2-mercaptoethanol were added to aliquots of the supernatant, and $20-40 \mu \mathrm{g}$ of soluble protein were then subjected to SDS-polyacrylamide gel electrophoresis (PAGE) using $3-20 \%$ and $4 \%$ polyacrylamide mini-gels to determine the contents of total actin and MHC and the relative amounts of MHC-isoforms, respectively. Gels contained molecular mass standards to confirm relative mobility (Bio-Rad, Hercules, CA) and were subjected to electrophoresis at $200 \mathrm{~V}$ until the dye front reached the bottom of the gel. Gels were stained with Coomassie brilliant blue overnight and appropriately destained to remove background staining. The fractions of Coomassie blue-stained protein accounted for by actin and myosin in 3-20\% gels and MHC isoforms in $4 \%$ gels (Fig 1) were estimated by scanning laser densitometry (Model 2202/2220, LKB Instruments, Inc., Stockholm, Sweden). Lanes were scanned in duplicate. Differences between measurements were $<5 \%$, and values for each band were averaged. The fraction of stained protein accounted for by actin and MHC was converted to micrograms knowing the amount of protein loaded for each sample. Values are expressed as $\mu \mathrm{g} / \mathrm{mg}$ of wet weight.

\section{Western analysis}

Since the $200 \mathrm{kDa}$ MHC may consist of SM2, MHC-B or both, it was necessary to perform western analysis to separate these MHC isoforms. Tissue extracts were subjected to SDS-PAGE in $4 \%$ polyacrylamide mini-gels. Proteins were electrophoretically transferred to nitrocellulose paper at $80 \mathrm{~mA}$ overnight. Blots were incubated overnight with antisera to SM2 (1:4000) and MHC-B $(1: 20,000)$, which were raised in this laboratory against synthetic peptides specific to each isoform and characterized as described previously $(20,21,26)$. Purified bovine brain MHC-B was used as a standard and was the gift of Dr. Barbara Barylko. Following $2 \mathrm{~h}$ incubation with goat anti-rabbit IgG conjugated with horseradish peroxidase $(1: 15,000)$, immunoreactive protein was visualized by chemiluminescence (ECL Amersham). 
A.

B.

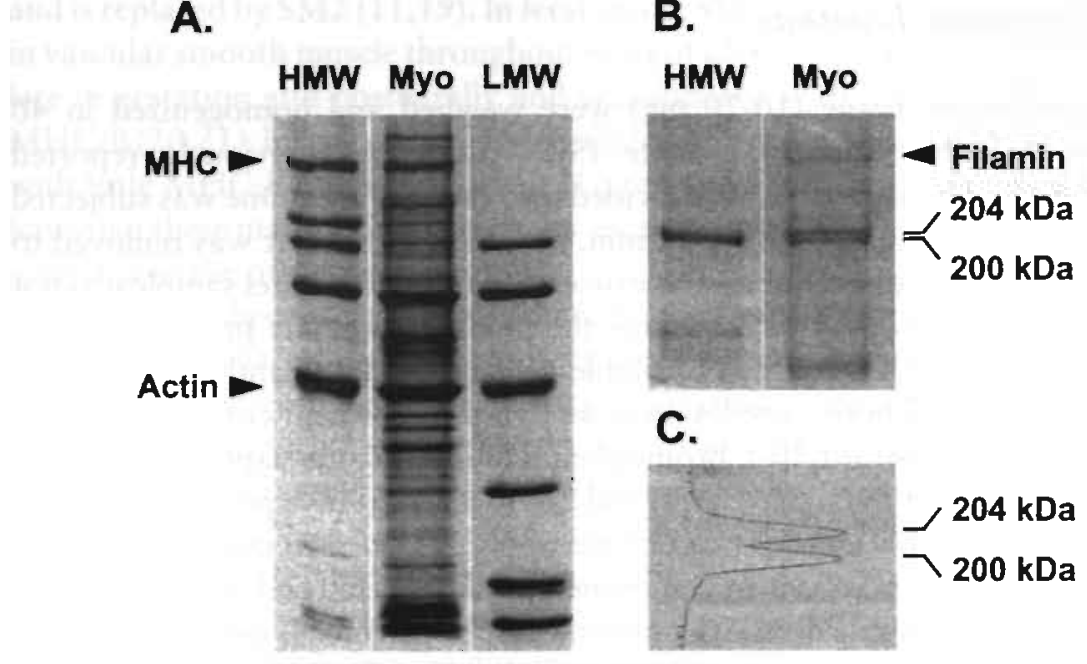

Figure 1. Representative examples of $3-20 \%$ (A) and $4 \%$ (B) polyacrylamide mini-gels stained with Coomassie brilliant blue and then destained to permit scanning laser densitometry (C). The gradient gel (A) demonstrates the separation of protein in a homogenate of myometrium (Myo) obtained from an adult ewe $38 \mathrm{~d}$ postpartum. Myosin heavy chain (MHC; $-200 \mathrm{kDa}$ ) comigrates with $\mathrm{MHC}$ in the high molecular weight (HMW) markers. The actin band is found at $-42 \mathrm{kDa}$, migrating at a position similar to ovalbumin ( $45 \mathrm{kDa}$ ) in both HMW and low molecular weight (LMW) standards. The $4 \%$ gel (B) demonstrates the presence of filamin $(280 \mathrm{kDa})$ as the uppermost band and the myosin heavy chain isoforms a pair of bands at 204 and $200 \mathrm{kDa}$ as noted by the molecular marker containing purified skeletal MHC. Densitometric scans (C) of $\mathrm{MHC}$ isoforms in $4 \%$ gels were used to obtain relative amounts of 204 and 200 $\mathrm{kDa}$ bands in myometrial samples.

\section{Statistics}

Data were analyzed using polynomial regression analysis with protein contents ( $y$-axis) versus gestational age in days ( $x$-axis) to obtain estimates for significance of fit to functions indicating non-zero slope (Sigma Stat 1.0). To further assess changes during development animals were divided into 7 groups: fetal at $<100 \mathrm{~d}$ $(\mathrm{n}=5), 101-130 d(\mathrm{n}=7)$ and $131-145 d(\mathrm{n}=7)$ gestation, and postnatal at $1-7 \mathrm{~d}$ $(n=6), 8-21 d(n=5), 22-30 d(n=3)$ and $>85 d(n=4)$. Significance between groups was assessed by one-way analysis of variance (ANOVA) with Newman-Keuls correction for multiple comparisons to determine when in development signifi- 
cant changes may have occurred. Nonpaired t-test was used where appropriate. Grouped data are reported as means \pm SEM. Significance was taken as $p=0.05$.

\section{RESULTS}

\section{Protein contents}

Both total and soluble protein contents rose in parallel and proportionately throughout development (Fig 2), values gradually increasing from $37 \pm 6$ and $31 \pm 7$ $\mu \mathrm{g} / \mathrm{mg}$ wet weight, respectively, at $<100 \mathrm{~d}$ gestation to $71 \pm 4$ and $65 \pm 2 \mu \mathrm{g} / \mathrm{mg}$ wet weight, respectively, by 1 mon postnatal $(\mathrm{P}=0.001, \mathrm{R}=0.53$ and $\mathrm{P}=0.003$, $\mathrm{R}=0.59$ ). Values were relatively unchanged at $85 \mathrm{~d}$ postnatal, averaging $67 \pm 2$ and $61 \pm 4 \mu \mathrm{g} / \mathrm{mg}$ wet weight. Since the rise in total and soluble protein was proportionate, the soluble:total protein ratio was $\sim 0.84$ until 1 mon postnatal when it rose slightly to 0.91 .

\section{Actin and myosin heavy chain contents}

Actin and $\mathrm{MHC}$ contents in uterine smooth muscle also rose progressively during development (Fig 3). Actin contents increased nearly 12 -fold from $1.6 \pm 0.4 \mu \mathrm{g} / \mathrm{mg}$ wet weight at $<100 \mathrm{~d}$ gestation to $19 \pm 21 \mathrm{mon}$ after birth $(P=0.002, R=0.56)$. Values were similar at $3-4$ mon postnatal. When actin contents in myometrium from nonparous ewes at 3-4mon were compared with those in parous noncycling ewes, levels had increased 2 -fold from $12 \pm 2$ to $24 \pm 2 \mu \mathrm{g} / \mathrm{mg}$ wet weight $(\mathrm{P}=0.003$ ), respectively. $\mathrm{MHC}$ contents followed a similar pattern during development, but rose only $\sim 4$-fold between $<100 \mathrm{~d}$ gestation and 1 mon postnatal (Fig 3), increasing from $0.8 \pm 0.2$ to $2.9 \pm 0.2 \mu \mathrm{g} / \mathrm{mg}$ wet weight $(\mathrm{P}<0.001, \mathrm{R}=0.62$ ). Unlike actin, a significant transition was seen between $100 \mathrm{~d}$ gestation and term, at which time MHC contents rose 2.5 -fold ( $P=0.01$, ANOVA). Also in contrast to that seen with actin, there was no significant change in MHC contents associated with parity, i.e., levels were $3.3 \pm 0.3$ and $3.6 \pm 0.4 \mu \mathrm{g} / \mathrm{mg}$ wet weight in myonetrium trom nonparous and parous ewes, respectively. Since the rise in myosin was not proportionate with that of actin, the actin:myosin ratio, which was -3 before birth, increased to $\sim 6$ at 1 mon postnatal, resembling that seen at 3-4mon postnatal and in the parous adult.

\section{Myosin heavy chain isoforms}

MHC isoforms separated by electrophoresis in gels containing $4 \%$ polyacrylamide yielded two protein species at relative mobilities of 204 and $200 \mathrm{kDa}$ (Fig I). No species of lower mobility $(196 \mathrm{kDa})$ were observed, possibly reflecting rhe care to remove capillary blood prior to freezing. The relative amounts of the 204 and 


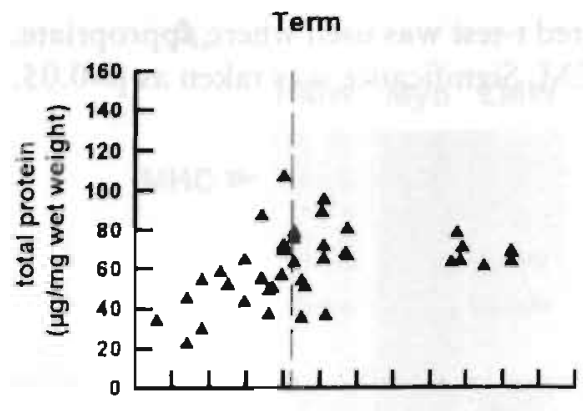

Figure 2. Developmental changes in total and soluble protein contents ( $\mu \mathrm{g} / \mathrm{mg}$ of wet weight) in myometrium from fetal and postnatal sheep. Each point represents a value from an individual animal. Average time of birth $(\sim 145 \mathrm{~d}$ gestation) is indicated by dashed vertical lines.

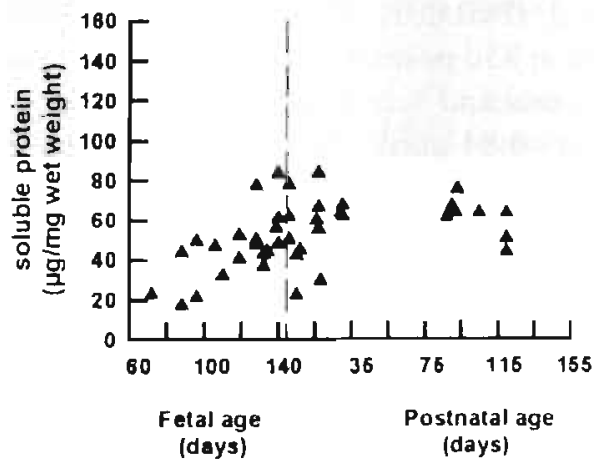

$200 \mathrm{kDa}$ bands were quantified by scanning densitometry and expressed as percent of total MHC. The absolute content was then determined as the product of the measured total myosin content and the percent mass of each isoform. Identification of $\mathrm{MHC}$ isoforms within the $200 \mathrm{kDa}$ species was performed by Western analysis.

The predominant MHC in myometrium from mid-gestation fetal sheep (<100d) was the $200 \mathrm{kDa}$ species, which accounted for $77 \pm 8 \%$ of total MHC (Fig 4). The relative amount of the $200 \mathrm{kDa}$ protein declined rapidly during the latter third of pregnancy and in the immediate postnatal period, accounting for only $25 \pm 2 \%$ of total myosin by 1 mon and $3-4$ mon postnatal $(P<0.001, R=0.87)$. In contrast, the relative amount of the $204 \mathrm{kDa}$ isoform rose in a reciprocal manner $(\mathrm{P}<0.001, \mathrm{R}=0.87)$, increasing from $23 \pm 8 \%$ at $<100 \mathrm{~d}$ gestation to $75 \pm 2 \%$ at 3-4mon after birth (Fig 4). Significant differences in the relative amounts of each isoform were evident at $<100 \mathrm{~d}$ and $>101 \mathrm{~d}$ gestation $(\mathrm{P}<0.001$, ANOVA). In parous noncycling ewes the relative distribution was significantly different $(\mathrm{P}<0.001)$. The 204 and $200 \mathrm{kDa}$ species accounted for $49.9 \pm 2.9$ and $46.6 \pm 2.9 \%$ of total MHC, respectively. Thus the $204: 200 \mathrm{kDa}$ ratio was $\sim 0.3$ at midgestation, 3.3 at 1 mon postnatal, and $\sim 1.0$ after pregnancy. 


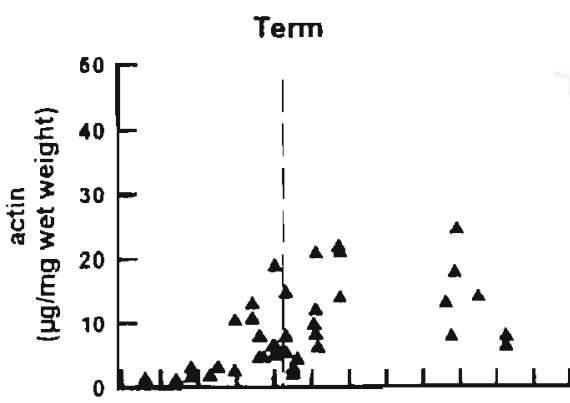

Figure 3. Developmental changes in actin and myosin heavy chain contents $(\mu \mathrm{g} / \mathrm{mg}$ of wet weight) in myometrium from fetal and postnatal sheep. Graph properties are as described in Figure 2.

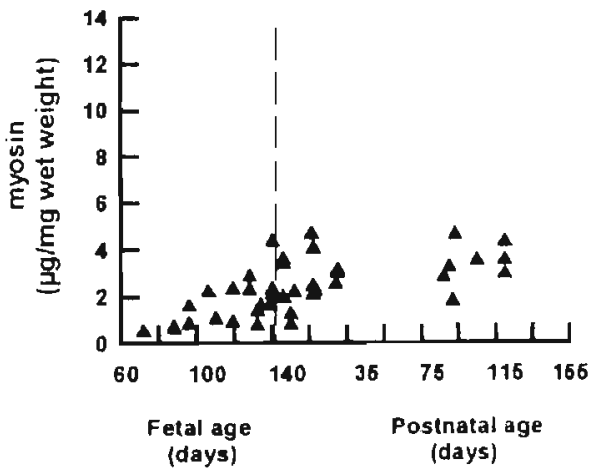

The tissue contents of these MHC species ( $\mu \mathrm{g} / \mathrm{mg}$ of wet weight) were calculated and resulted in a pattern distinctly different from that seen for the relative amounts shown in Figure 4 . Whereas the contents of the $204 \mathrm{kDa}$ isoform increased 7 -fold from $0.3 \pm 0.1$ at $<100 \mathrm{~d}$ gestation to $2.4 \pm 0.2 \mu \mathrm{g} / \mathrm{mg}$ of wet weight by $3-4$ mon postnatal $(\mathrm{P}<0.001, \mathrm{R}=0.65)$, the $200 \mathrm{kDa}$ contents remained quite low and did not differ in the fetus, newborn and nonparous 3-4mon sheep, averaging $0.7 \pm 0.1 \mu \mathrm{g} / \mathrm{mg}$ of wet weight (Fig 5). As with the relative distribution of MHC, parity modified the contents of the 204 and $200 \mathrm{kDa}$ proteins, reflecting the change in distribution. The contents of the $204 \mathrm{kDa}$ protein fell $28 \%$ to $1.73 \pm 0.12 \mu \mathrm{g} / \mathrm{mg}$ of wet weight ( $\mathrm{P}=0.01)$, while the $200 \mathrm{kDa}$ species rose $149 \%$ to $1.74 \pm 0.25(\mathrm{P}=0.02)$; thus the contents of the two isoforms became equal.

Since the $200 \mathrm{kDa}$ species may consist of SM2, MHC-B or both MHC isoforms, we determined the developmental dependence of expression of each by immunoblotting with antibodies specific for SM2 and MHC-B $(20,21,26)$. Each immunoblot was loaded with three standards: sheep platelets as a marker for MHC-A (196 kDa), purified bovine brain myosin as a marker for MHC-B, and adult ovine myometrium as a marker for SM2. Although we never detected a protein species at $196 \mathrm{kDa}$, it is possible that ovine MHC-A may migrate at a 


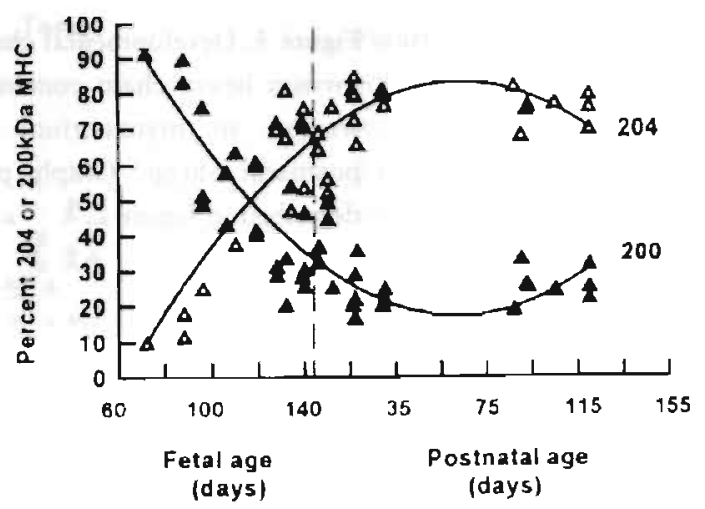

Figure 4. Change in the relative distribution of 204 and $200 \mathrm{kDa} \mathrm{MHC}$ isoforms in myometrium during ovine development. Values were derived by calculating the percent of total staining for $\mathrm{MHC}(200+204$ $\mathrm{kla}$ ) comprised by each isoform on $4 \%$ SDS-PAGE. Polynomial regression curves are shown as solid lines through the data to distinguish the two groups. The open triangles represent the relative amount of 204 $\mathrm{kDa}$ protein and the solid triangles the $200 \mathrm{kDa}$ protein.

different position. We were unable to rule out the presence of MHC-A in these samples because the antibodies against human platelet MHC-A peptide used in these studies did not cross-react with sheep platelet protein and polyclonal antibodies against human platelet $\mathrm{MHC}-\mathrm{A}$ showed cross-reactivity with bovine $\mathrm{MHC}-\mathrm{B}$. The specificities of anti-MHC-B and anti-SM2 are illustrated on representative immunoblots shown in Figure 6. Although the myometrial contents of total $200 \mathrm{kDa} \mathrm{MHC}$ were unchanged during development (Fig 5), the isoform distribution changed dramatically (Fig 6). MHC-B was abundant at midgestation and declined after birth, such that it was not seen in adult tissues. In contrast, SM2, which was barely detected prior to 130 d gestation, demonstrated an increased expression, which was most dramatic after birth. SM2 expression was robust in myometrium from the parous adult ewe and accounted for all of the $200 \mathrm{kDa}$ protein (data not shown). 

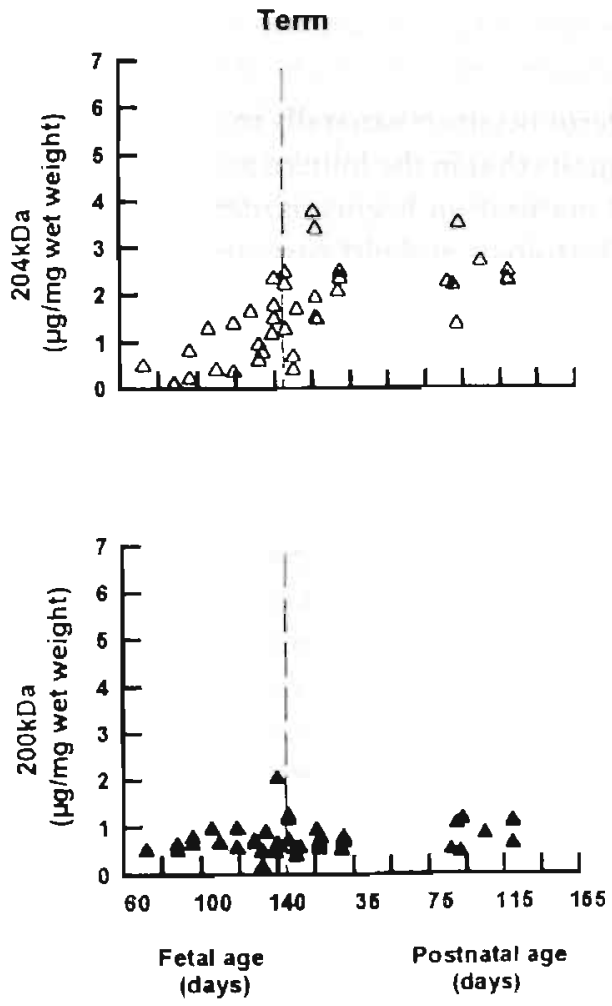

\section{SM2}

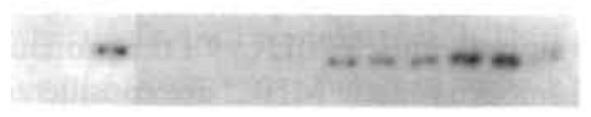
Std Std Std
PH BQ SME Folal

Postnatal

\section{MHC B}

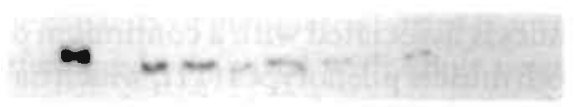

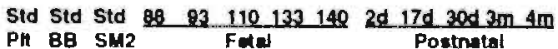

Figure 5. Changes in tissue contents of the 204 and $200 \mathrm{kDa}$ MHC isoforms ( $\mu \mathrm{g} / \mathrm{mg}$ of wet weight) in myometrium during ovine development. Graph properties are as described in Figure 2.
Figure 6. Representative immunoblots illustrating the changes in expression of the 200 $\mathrm{kDa}$ MHC isoforms, SM2 and MHC-B, in myometrium during ovine development. Standards (Std) included sheep platelet lysate (Plt), MHC-B purified from bovine brain $(\mathrm{BB})$, and adult myometrial homogenate (SM2). Numbers represents days following conception (term $-145 \mathrm{~d}$ ). Separating gels were loaded with sufficient protein to yield $200 \mathrm{ng}$ of total MHC per sample, as calculated from $\mathrm{MHC}$ contents assessed above. 


\section{DISCUSSION}

Cytodifferentiation of the developing uterus occurs postnatally in most mammals $(1,7-9)$. However, existing evidence suggests that in the human and ovine species progressive cellular differentiation and maturation begins in utero $(3,4,10)$. By midgestation both species demonstrate histologic and ultrastructural evidence of a definitive smooth muscle layer followed by continuing maturational changes $(4,10)$. Unlike smaller mammals, maturation of ovine uterine smooth muscle has not been defined biochemically, and functional correlates are unclear. In the present study we characterized the biochemical changes that occur in ovine myometrium between $70 \mathrm{~d}$ gestation and 4 mon postnatal. We observed that smooth muscle differentiation occurs early in the midtrimester, reflected by expression of the $204 \mathrm{kDa}$ smooth muscle MHC (SM1), that progressive increases occur in the contents of contractile proteins early in the last third of pregnancy, and that myometrial maturation begins in utero and continues during the first month postnatal as evidenced by decreases in the contents of non-muscle MHC-B and increases in the smooth muscle MHC, SM2. Furthermore, we demonstrate that having been pregnant further modifies the distribution and contents of myometrial contractile proteins. These data, therefore, provide new insights into the developmental and maturational changes that occur in ovine myometrium.

Although uterine morphogenesis occurs in utero in all species, cellular differentiation and maturation are predominately postnatal events in most mammals studied $(1,4,7,8)$. In contrast, Konishi et al (10) and Wiley et al (3), using histologic methods, reported definite cellular differentiation at $20-26 \mathrm{wks}$ in the human female fetus and 90-100d gestation in sheep, and that maturation continues thereafter. Utilizing biochemical markers, we have demonstrated that cellular differentiation of the ovine myometrium occurs as early as $70 \mathrm{~d}$ postconception, as evidenced by the presence of the $204 \mathrm{kDa}$ smooth muscle MHC. Of the proteins characteristic of smooth muscle cells, the smooth muscle MHCs are considered definitive markers of the smooth muscle cell lineage $(11,12)$. Thus the presence of SM1 and its increasing expression during fetal development clearly supports the conclusion that ovine myometrial differentiation begins in utero, probably before $70 \mathrm{~d}$ gestation, and that maturational events proceed throughout the remainder of gestation.

The development of smooth muscle tissues is associated with a continuum of committed but not fully differentiated smooth muscle phenotypes (11), which has been demonstrated in vascular smooth muscle from several species $(21,28,29)$. Evidence is now presented to support this in ovine myometrial development. Although myometrium expressed SM1 early in gestation, it represented $<25 \%$ of total MHC; thus the $200 \mathrm{kDa}$ species was the predominant MHC. Unlike the developing mouse and swine $(28,30)$, the $200 \mathrm{kDa}$ MHC consisted entirely of the non-muscle isoform, MHC-B. The co-expression of MHC-B with SM1 has been considered evidence of a "synthetic" or immature smooth muscle phenotype, 
which has the potential to divide and grow (11). The subsequent decline in myometrial MHC-B late in ovine gestation and during the immediate postnatal period, reflects continuing maturational changes and the development of a mature or "contractile" smooth muscle phenotype by the end of the first month postnatal. This pattern resembles that seen in the developing ovine aorta, but differs from the ovine fetal bladder, in which there is minimal MHC-B expression early in gestation, but abundant SM1 and SM2 (21). It is notable that this was associated with a fully functional bladder in the midtrimester whereas aortic function was greatly attenuated (21). Similar differences in maturational rates between the myometrium and bladder occur histologically in the human fetus (10) and in the mouse postnatally (28). These data, therefore, provide evidence in large mammals that maturation is tissue specific in visceral as well as vascular smooth muscle, and that the timing is species specific.

In addition to the developmentally regulated changes in myometrial MHC isoforms, the tissue contents of total and soluble protein also increased progressively. The principle connective tissue components in smooth muscle tissues are collagen and elastin, which are insoluble in SDS homogenizing buffer due to extensive covalent cross-linking that occurs following secretion of these matrix proteins (31). Protein remaining after sedimentation of homogenates is predominantly cellular. Consistent with this, we found the lowest ratios of soluble to total protein in the elastic ovine aorta: 0.61 , followed by the bladder: 0.82 , and myometrium: 0.90 (21). Although the contents of cellular protein in myometrium increased during development, total protein rose proportionally, and their ratio remained 0.8 to 0.9 . Thus changes in the cellular and matrix components of the myometrium occur in parallel during fetal maturation, resembling that ohserved in the ovine bladder (21). The rise in protein contents was paralleled by even greater increases in actin and myosin contents, values increasing 12- and 4-fold, respectively, by 1 mon postnatal. Thus at term gestation there was evidence not only of a progressive change in smooth muscle phenotype, depicted by the rise in smooth muscle MHC and fall in the non-muscle isoform, but also of a specific increase in the cellular contents of contractile proteins, further demonstrating a continuum of maturation within the myometrium. This too is consistent with observations in vascular smooth muscle $(21,28,29)$. In preliminary studies, these biochemical changes were associated with spontaneous myometrial activity and the capacity of myometrial strips from term sheep to contract, although both were attenuated compared with adult tissues. Thus while fetal myometrium has no known physiologic role, the contractile apparatus appears to be functional, even though SM2 expression was minimal and MHC-B continued to be expressed. Additional studies are needed to address the relationship between protein expression and smooth muscle function.

In previous studies the biochemical and histologic changes occurring in myometrial development were compared with that in nonpregnant, nonparous adults $(3,7-9,28,30)$. It was unclear, however, if additional changes occurred after 
having experienced a pregnancy. In the rabbit, parity increases myometrial cell size and contents of myofilaments, organelles and dense bodies (9). In the rat (32) and monkey (33) the SM1:SM2 ratio is similar in nongravid and gravid animals; postpartum parous animals were not studied. In the ewe, pregnancy increases myometrial actin and myosin contents, which decrease in the postpartum period (24); but there was no comparison with nonparous animals. In each species, however, pregnancy is associated with increased capacity for myometrial contractions. We now report that having been pregnant increases actin but not myosin contents when compared to nonparous animals, and that the relative and absolute contents of SM1 and SM2 also change. That is, the SM1:SM2 ratio falls from 3.3 at $3-4$ mon postnatal, a value similar to that in the nonparous mouse and rat $(28,30)$, to $\sim 1$ in the parous ewe, primarily reflecting an increase in the cellular contents of SM2. Thus pregnancy further alters uterine smooth muscle protein expression which could modify myometrial function at the time of parturition in subsequent pregnancies.

In the present report we have characterized the developmental changes that occur in the uterine smooth muscle of a large mammal, the ewe, demonstrating that the ontogeny of ovine myometrium resembles that seen in the human, but differs from that occurring in smaller mammals. This difference between large and small mammals is largely one of timing, with the latter occurring postnatally. The data also demonstrate that differentiation of ovine myometrium begins early in the middle third of gestation and continues throughout the fetal and neonatal periods, with substantial changes occurring prior to and soon after birth. Moreover, there is tissue/organ specific maturation in both visceral and vascular smooth muscle $(11,20,21,26,28)$, suggesting that local factors, including mechanical stresses, may be involved in the determination of protein expression and the rate of cellular maturation. Additional studies are needed to determine the molecular mechanisms that regulate these varying rates of development and to better characterize the functional changes that occur.

\section{REFERENCES}

1. Bartol, F.F., A.A. Wiley, T.E. Spencer, J.L. Vallet, and R.K. Christenson. Early uterine development in pigs. J. Reprod. Fertil. 48:99-116, 1993.

2. Christenson R.K., K.A. Leymaster, and L.D. Young. Justification of unilateral hysterec: tomy-ovariectomy as a model to evaluate uterine capacity in swine. J. Animal. Sci. $65: 738-744,1987$.

3. Wiley A.A., F.F. Bartol, and D.H. Barron. Histogenesis of the ovine uterus. J. Animal Sci. 64:1262-1269, 1987.

4. Marion G.B., and H.T. Gier. Ovarian and uterine embryogenesis and morphology of the non-pregnant female mammal. J. Animal Sci. 32:24-47, 1971. 
5. Baskin L.S., P. Hayward, P. Young, and G.R. Cunha. Role of mesenchymal-epithelial interactions in normal bladder development. J. Urology 156:1820-1827, 1996.

6. Cunha G.R., P. Young, and J.R. Brody. Role of uterine epithelium in the development of myometrial smooth muscle cells. Biol. Reprod. 40:861-871, 1989.

7. Brody J.R., and G.R. Cunha. Histologic, morphometric, and immunocytochemical analysis of myometrial development in rats and mice: I. Normal development. Am. J. Anat. 186:1-20, 1989.

8. Bal H.S., and R. Getry. Postnatal growth of the swine uterus from birth to six months. Growth 34:15-30, 1970.

9. Yamamoto I. An electron microscope study of development of uterine smooth muscle. J. Electronmicroscopy 10:145-160, 1961.

10. Konishi I., S. Fujii, H. kamura, and T. Mori. Development of smooth muscle in the human fetal uterus: an ultrastructural study. J. Anat. 139:239-252, 1984.

11. Owens G.K. Regulation of differentiation of vascular smooth muscle cells. Physiol. Rev. 75:487-517, 1995.

12. Miano J.M., P. Cserjesi, K.L. Ligon, M. Periasamy, and E.N. Olson. Smooth muscle myosin heavy chain exclusively marks the smooth muscle lineage during mouse embryogenesis. Circ. Res. 75:803-812, 1994.

13. Emerson C.P. Jr, and S.I. Bernstein. Molecular genetics of myosin. Annu. Rev. Biochem. 56:695-726, 1987.

14. Somlyo A.P. Myosin isoforms in smooth muscle: how may they affect function and structure? J. Muscle Res. Cell. Motil. 14:557-563, 1993.

15. Kelley C.A., and R.S. Adelstein. Characterization of isoform diversity in smooth muscle myosin heavy chains. Can. J. Physiol. Pharmacol. 72:1351-1360, 1994.

16. Kuro-o M., R. Nagai, H. Tsuchimochi, H. Katoh, Y. Yazaki, A. Ohkubo, and F. Takaku. Developmentally regulated expression of vascular smooth muscle myosin heavy chain isoforms. J. Biol. Chem. 264:18272-18276, 1989.

17. Simons M., M. Wang, W. McBride, S. Kawamoto, K. Yamakawa, D. Gdula, R.S. Adelstein, and L. Weir. Human nonmuscle myosin heavy chains are encoded by two genes located on different chromosomes. Circ. Res. 69:530-539, 1991.

18. Warrick H.M., and J.A. Spudich. Myosin structure and function in cell motility. Annu. Rev. Cell. Biol. 3:379-421, 1987.

19. Kuro-o M., R. Nagai, K. Nakahara, H. Katoh, R. Tsai, H. Tsuchimochi, Y. Yazaki, A. Ohkubo, and F. Takaku. cDNA cloning of a myosin heavy chain isoform in embryonic smooth muscle and its expression during vascular development and in arteriosclerosis. J. Biol. Chem, 266:3768-3773, 1991.

20. Chern J., K.E. Kamm, and C.R. Rosenfeld. Smooth muscle myosin heavy chain isoforms are developmentally regulated in male fetal and neonatal sheep. Pediatr. Res. 38: 697. 703,1995 .

21. Arens Y.H.J.M., C.R. Rosenfeld, and K.E. Kamm. Maturational differences between vascular and bladder smooth muscle during ovine development. Am. J. Physiol. 278: R1305-R1313, 2000. 
22. Rosenfeld C.R. Distribution of cardiac outpur in ovine pregnancy. Am. J. Physiol. 232:H231-H235, 1977.

23. Rosenfeld C.R., F.H. Morriss, E.L. Makowski, G. Meschia, and F. Battaglia. Circulatory changes in the reproductive tissues of ewes during pregnancy. Gynecol. Invest. 5:252-268, 1974.

24. Ipson M.A., C.R. Rosenfeld, R.R. Magness, and K.E. Kamm. Alterations in myometrial stress during ovine pregnancy and puerperium. Am. J. Physiol. 271:R446-R454, 1996.

25. Nathanielsz. D.W. Animal models in fetal medicine. Ithaca: Perinatology Press, 216, 1984.

26. Arens Y, R.A. Chapados, B.E. Cox, K.E. Kamm, and C.R. Rosenfeld. Differential development of umbilical and systemic arteries. II. Contractile proteins. Am. J. Physiol. 274: R1815-1823, 1998.

27. Annibale D.J., C.R. Rosenfeld, J.T. Stull, and K.E. Kamm. Protein content and myosin light chain phosphorylation in uterine arteries during pregnancy. Am. J. Physiol. 259:C484C489, 1990.

28. Eddinger TJ, and R.A. Murphy. Developmental changes in actin and myosin heavy chain isoform expression in smooth muscle. Arch. Biochem. Biophys. 284:232-237, 1991.

29. Seidel CL, and R.A. Murphy. Changes in rat aortic actomyosin content with maturation. Blood Vessels 16:98-108, 1979.

30. Eddinger T.J., and J.A. Wolf. Expression of four myosin heavy chain isoforms with development in mouse uterus. Cell. Motility Cytoskeleton 25:358-368, 1993.

31. Jones A.W. Vascular Smooth Muscle. In: Bohr DF, Somlyo AP and Sparks, Jr, HV eds. Handbook of Physiology. Bethesda:Am. Physiol. Soc., 253-299, 1980.

32. Sparrow M.P., M.A. Mohammad, A. Arner, Hellstrand, and J.C. Ruegg. Myosin composition and functional properties of smooth muscle from the uterus of pregnant and non-pregnant rats. Pflugers Arch. 412:624-633, 1988.

33. Cavaille F., C. Janmot, S. Ropert, and A. d'Albis. Isoforms of myosin and actin in human, monkey and rat myometrium. Comparison of pregnant and non-pregnant uterus proteins. Eur. J. Biochem. 160:507-513, 1986. 
CHAPTER 7

\section{Cytoskeletal proteins in aortic and bladder smooth muscle during ovine development}

Yvonne Arens, Desiree van den Bogaard, Charles R. Rosenfeld, Kristine E. Kamm

Departments of Physiology and Pediatrics

University of Texas southwestern medical center, Dallas, Texas 


\section{A B S T R ACT}

Maturation of cytoskeletal proteins in vascular and visceral smooth muscle was studied during ovine fetal and postnatal development by measures of atin-binding proteins caldesmon, calponin and filamin, and the intermediate filament proteins. Proteins were assessed by SDS-PAGE and western analysis with specific antibodies in abdominal aorta and bladder from fetal 172-145d gestation; term $145 \pm 5 \mathrm{~d}$ ), postnatal (1d-3mon) and adult sheep. In aorta, both h-caldesmon and calponin increased progressively from about $20 \%$ adult values at $100 \mathrm{~d}$ gestation to adult values at $1-4$ weeks after birth ( $p=0.001$, ANOVA). In contrast, in bladder smooth muscle both caldesmon and calponin were expressed at values comparable to adult as early as $100 \mathrm{~d}$ gestation. Similarly, filamin increased in aorta from $0.9 \pm 0.3 \mu \mathrm{g} / \mathrm{mg}$ wet weight to $1.9 \pm 0.2$ at 3 mon ( $p=0.003$, ANOVA), whereas it was unchanged in bladder, averaging $2.4 \pm 0.2 \mu \mathrm{g} / \mathrm{mg}$ wet weight. A different pattern was seen with the intermediate filament proteins which were unchanged in aorta $(1.7 \pm 0.1 \mu \mathrm{g} / \mathrm{mg})$, but in bladder increased from $2.0 \pm 0.5$ at $100 \mathrm{~d}$ gestation to $6.0 \pm 1.0$ by $140 \mathrm{~d}$ gestation, remaining stable thereafter $(p=0.002, A N O V A)$. The expression of cytoskeletal proteins in developing smooth muscle is coordinately regulated. However, expression of the actin-binding proteins appears to be regulated in a manner distinct from the intermediate filament proteins. These results also demonstrate that smooth muscle of the bladder matures during prenatal development, well before birth, whereas that of the aorta matures more slowly over the entire course of the prenatal and postnatal periods.

Keywords: caldesmon, calponin, filamin, intermediate filaments 


\section{INTRODUCTION}

Smooth muscle plays an important role in the function of several organ systems essential to normal growth, development and adaptation of the fetus and newborn. In the cardiovascular system smooth muscle modulates arterial pressure and mediates vascular responses to numerous endogenous stimuli, where in the urinary tract it is essential for normal bladder filling and micturition. Delineation of the normal course of vascular and visceral smooth muscle maturation will be critical to understanding congenital defects occurring in vascular and visceral development $(1,2)$. We previously showed in the sheep that aortic smooth muscle attains a mature contractile phenotype only after birth, whereas bladder smooth muscle matures early during prenatal development $(3,4)$. Contractile phenotype was assessed by comparing the temporal changes in actin, myosin heavy chain (MHC), and total protein contents, as well as stress generating capacity during the last trimester of gestation and during postnatal development. In those studies, aortic actin contents were found to rise gradually between $115 \mathrm{~d}$ gestation (term is $145 \mathrm{~d}$ ) and 3 mon postnatal, attaining adult values in the postnatal period. In contrast, bladder actin contents rose abruptly after $100 \mathrm{~d}$ gestation, achieving adult values well before term. Accompanying changes in actin-binding proteins that may have an effect on contractile capacity have not been described.

Actin is a highly abundant cytoskeletal protein involved in a wide variety of cellular structures, the geometry and stability of which depend upon actin-binding proteins. In mature smooth muscle tissues, actin, in the form of thin filaments, supports myosin-dependent force development and shortening. In adult animals, the actin-binding proteins calponin and h-caldesmon are expressed exclusively in smooth muscle and are implicated in the regulation of actomyosin interactions and therefore contraction $(5,6,7,8)$. Calponin and $\mathrm{h}$-caldesmon have been localized in myosin-containing contractile domains of smooth muscle cells $(9,10)$. The onset of expression of these proteins has been shown in vascular smooth muscle to occur after detection of the smooth muscle isoform $\alpha$-actin, but before smooth muscle isoforms of myosin heavy chain (MHC), thus they have served as markers of smooth muscle maturation during development and after birth $(1,2,11,12,13,14)$. The onset of h-caldesmon expression is also accompanied by down-regulation of the non-muscle isoform 1 -caldesmon $(1,2,12,13,14)$. In addition to supporting contraction, actin also provides structural stability in cytoskeletal regions of mature smooth muscle cells where thin filaments are cross-linked into a three-dimensional network by the potent actin-binding protein filamin $(9,15,16)$. Filamin, although not smooth-muscle specific, is found in abundance in smooth muscle and in proliferating tissues $(17,18)$. The cytoskeleton of smooth muscle also contains structural filaments of the intermediate $(10 \mathrm{~nm})$ class that are composed primarily of desmin and vimentin $(19,20,21,22)$, with desmin being a muscle-specific form (19). Immunohistochemical staining of avian embryos suggests that both filamin and desmin 
expression precede that of calponin and h-caldesmon in vascular, as well as visceral, smooth muscles during development (11).

In the present study, we tested the hypothesis that the actin-binding proteins $\mathrm{h}$-caldesmon, calponin and filamin are expressed in coordination with actin during development in aorta and bladder smooth muscles. In addition, alterations in amounts of the cytoskeletal intermediate filament proteins were assessed. We found in aorta that the actin-binding proteins $\mathrm{h}$-caldesmon, calponin and filamin did not achieve adult values until after birth, consistent with the gradual maturation observed for actin and MHC contents, as well as isoforms of MHC in this tissue. In contrast, in bladder muscle the contents of all three actin-binding proteins at any time during maturation were not different from those in adult tissues, consistent with early maturation in this tissue. Interestingly, the opposite pattern was observed for intermediate filament proteins, indicating that thin and intermediate classes of filamentous cytoskeletal proteins are subject to different regulatory schemes during growth and maturation.

\section{METHODS}

\section{Tissue preparation}

Female fetal ( $72-140$ d of gestation, $n=19$; term $~ 145 d$ ), postnatal ( $1-120 d, n=25$ ) and adult $(\mathrm{n}=5)$ sheep were killed by rapid intravenous injection of pentobarbital sodium $(50 \mathrm{mg} / \mathrm{kg})$ to the mother or neonate via the external jugular vein. Segments of abdominal a orta and bladder were quickly removed from all animals and placed into iced physiological buffed solution containing (in $\mathrm{mM}$ ): 137.0 $\mathrm{NaCl}, 2.7 \mathrm{KCl}, 10 \mathrm{Na}_{2} \mathrm{HPO}_{4}, 1.76 \mathrm{KH}_{2} \mathrm{PO}_{4} .0 .1 \%$ diethyl pyrocarbonate, $\mathrm{pH}$ 7.4. Aortic endothelium and adventitia and bladder epithelium were removed with a soft cotton swab and sharp dissection, respectively. Strips of tissue were cut, gently blotted to remove excess water and capillary blood, frozen in liquid nitrogen, and stored at -80 ? C until studied. Protocols for the use of sheep were approved by the Institutional Animal Care and Reseach Advisory Committee.

\section{Protein analysis and contents}

Sodium dodecyl sulfate (SDS) homogenates were prepared from $10-20 \mathrm{mg}$ samples of frozen tissue as previously described (4). Homogenates were subjected to centrifugation at $10,000 \times \mathrm{g}$ for $2 \mathrm{~min}$, and the supernatant was removed to determine the soluble or cellular protein in each sample. Protein concentration was determined by BCA reagent (Pierce, Rockford, IL). Aliquots of the supernatant containing bromphenol blue and 2-mercaptoethanol were subjected to SDS-PAGE in 3-20\% polyacrylamide gels to determine the contents of filamin and desmin. For each tissue, gels were loaded with $20 \mu \mathrm{g}$ of soluble protein and a 
molecular weight standard and subjected to electrophoresis at $200 \mathrm{~V}$ until the dye front ran off the bottom of the gel. Gels were stained with Coomassie Brilliant Blue overnight and appropriately destained to remove background staining (Fig 1A). Gels were scanned, each lane in duplicate, with a laser densitometer (LKB Instruments, Inc., Stockholm, Sweden) to estimate the fraction of total stained protein occupied by filamin ( 280 kDa) and intermediate filament (IF) proteins (53-55 $\mathrm{kDa})$. The band corresponding to filamin was previously identified by immunoblotting (23). IF proteins in smooth muscle can be estimated from whole muscle preparations owing to their relative abundance $(20,21)$. In addition, we confirmed by immunoblotting that this band contained desmin in both aortic and bladder samples. Values for each band were averaged, and the fractional content of filamin or IF protein was converted to micrograms using the total protein quantified by BCA reagent. Values are expressed as $\mu \mathrm{g} / \mathrm{mg}$ of tissue wet weight.

\section{Western analysis}

To examine expression of $\mathrm{h}$ - and $\mathrm{l}$-caldesmon and calponin, tissue extracts $(2.5 \mu \mathrm{g}$ of soluble protein) were subjected to electrophoresis in $3-20 \%$ gradient polyacrylamide gels. Proteins were electrophoretically transferred to nitrocellulose paper at $100 \mathrm{~V}$ for $1 \mathrm{~h}$. The membranes were cut according to molecular weight markers. The top half of these blots, molecular weights $>47 \mathrm{kDa}$, were incubated overnight with antiserum against caldesmon $(1: 10,000)$ that detects both h-caldesmon $(\sim 140 \mathrm{kDa})$ and I-caldesmon $(\sim 80 \mathrm{kDa})$ isoforms (24). The bottom half of the membranes, molecular weights $<47 \mathrm{kDa}$, were incubated overnight with an antibody (Sigma; 1:10,000) against calponin $(\sim 34 \mathrm{kDa})$. The following morning blots were incubated with horseradish peroxidase-conjugated goat anti-rabbit IgG or goat anti-mouse IgG $(1: 15,000)$ respectively. Immunoreactive protein was then visualized by enhanced chemiluminescence (ECL, Amersham). Each immunoblor contained samples obtained across development plus tissue from adult ewes (Fig 1B). Blots were subjected to densitometric analysis and values normalized to the adult sample for both proteins.

\section{STATISTICAL ANALYSIS}

Grouped data are reported as means \pm SEM. Groups were defined as follows: 1 ) midgestation $(<100 \mathrm{~d} ; n=6), 2)$ the fetal period of rapid growth preceding increases in estrogen and cortisol $(101-130 \mathrm{~d} ; \mathrm{n}=8), 3)$ preparation for parturition (131-145d gestation; $n=6), 4)$ adaptation immediately following birth $(1-7 \mathrm{~d} ; n=8)$, 5) postnatal adaptation ( $8 \mathrm{~d}-1$ mon;n=7), 6) 3-4mon or late postnatal ( $n=9)$, and 7) adult. Groups contained from 6-9 samples. Data were analyzed using Student's $\mathrm{t}$-test and one-way analysis of variance (ANOVA) with Newman-Keuls correc- 
A.

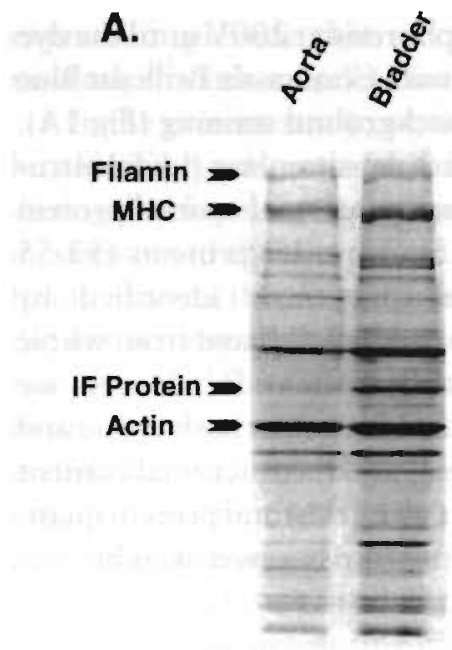

B.

h-Caldesmon

Figure 1. Representative images of Coomassie Blue-stained 3-20\% polyacrylamide gel (A) and immunoblots (B). A. 20 ug of soluble protein were loaded in each lane. Positions of filamin, myosin heavy chain (MHC), intermediate filament (IF) protein and actin bands are indicated. B. 2.5 ug of soluble protein from aortic tissues collected at the indicated times during development were loaded in each lane. Proteins were detected with specific antibodies as described in Methods.

tion for multiple comparisons. Significance was taken as $p=0.05$. Values presented are means \pm SEM.

\section{RESULTS}

\section{Caldesmon and calponin expression}

The h-caldesmon contents in aortic smooth muscle demonstrated a progressive rise during development ( $\mathrm{p}=0.001$, ANOVA), increasing 4-fold from $100 \mathrm{~d}$ to term, and achieving adult values by 1 mon postnatal (Fig 1B and 2). Although l-caldesmon was present throughout development, its content was unchanged (data not shown) and did not differ from that in adult. Thus the ratio of 1 - to h-caldesmon fell from 11.8 to 0.75 at 1 mon postnatal. In the bladder a different pattern was observed. Both h-caldesmon and l-caldesmon were present during development; but expression of $h$-caldesmon at $<100 \mathrm{~d}$ gestation resembled that in adult tissues (Fig 2). Furthermore, the ratio of 1 - to h-caldesmon in bladder was unchanged and averaged 0.28 .

Calponin was present before $100 \mathrm{~d}$ gestation in aurtic smooth muscle (Fig 1B) and progressively increased from $22 \pm 8 \%$ of adult expression to $74 \pm 10 \%$ at 

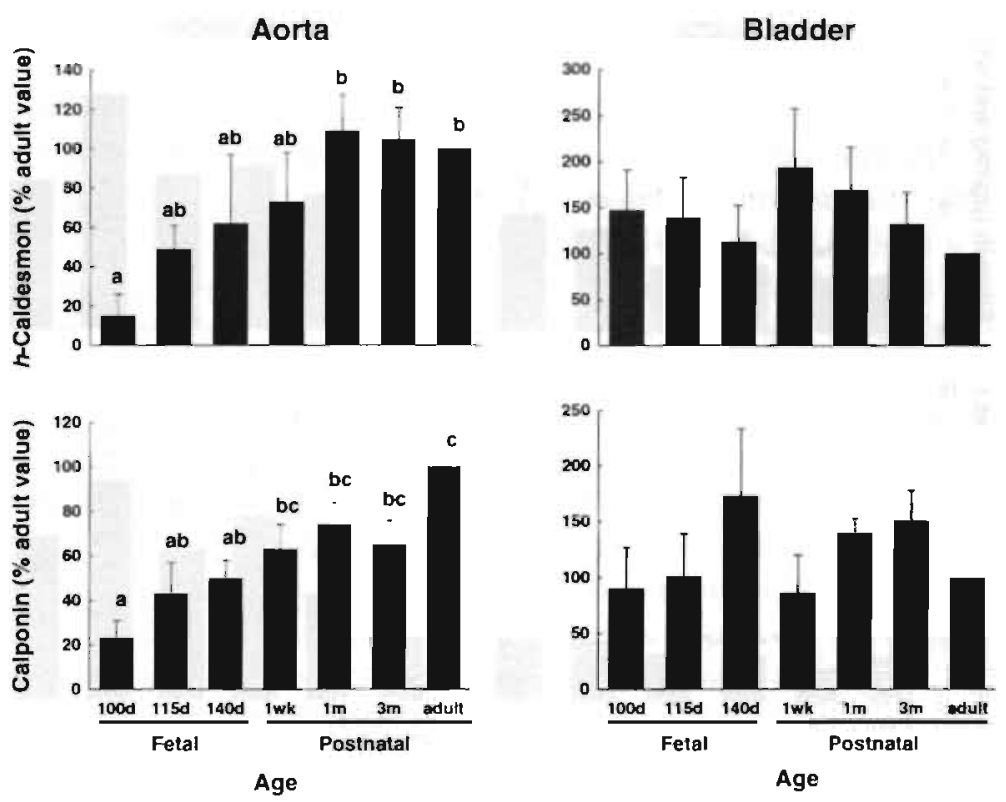

Figure 2. Patterns of h-caldesmon and calponin expression in aorta and bladder smooth muscle during ovine development. Values were derived from densitometric scans of immunoblots and normalized to those in adult tissues, represented as $100 \%$. Groups are as follows: $100 \mathrm{~d},<100 \mathrm{~d}$ gestation; $115 \mathrm{~d}$, 101-130d gestation; 140d, 131-145d gestation; $1 \mathrm{wk}, 0-7 \mathrm{~d}$ postnatal; $1 \mathrm{~m}$, $8 \mathrm{~d}-1 \mathrm{~m}$ postnatal; $3-4 \mathrm{~m}, 3-4 \mathrm{~m}$ postnatal; and adult. Values are means $\pm S E M$. Different letters denote significant differences at $p<0.05$ among age groups by ANOVA, whereas groups not significantly different from each other are denoted by the same letters.

3-4mon postnatal, at which time expression was not different from that in adult tissues ( $\mathrm{p}=0.0007$, ANOVA) (Fig 2). In contrast, calponin expression in bladder smooth muscle did not change significantly during development, always resembling that in adult bladder smooth muscle.

\section{Filamin and intermediate filament protein contents}

Quantitative analysis of filamin protein contents in aortic and bladder smooth muscle was carried out by densitometric analysis of tissue protein subjected to electrophoresis in 3-20\% gradient gels (Fig 1). Although the content of filamin in aortic smooth muscle increased from $0.9 \pm 0.1 \mu \mathrm{g} / \mathrm{mg}$ wet weight at $<100 \mathrm{~d}$ gestation to $1.9 \pm 0.2 \mu \mathrm{g} / \mathrm{mg}$ wet weight at $3-4$ mon postnatal (ANOVA, $\mathrm{p}=0.003$ ), this was not significant until $1 \mathrm{mon}$ after birth (Fig 3). Filamin contents in bladder 

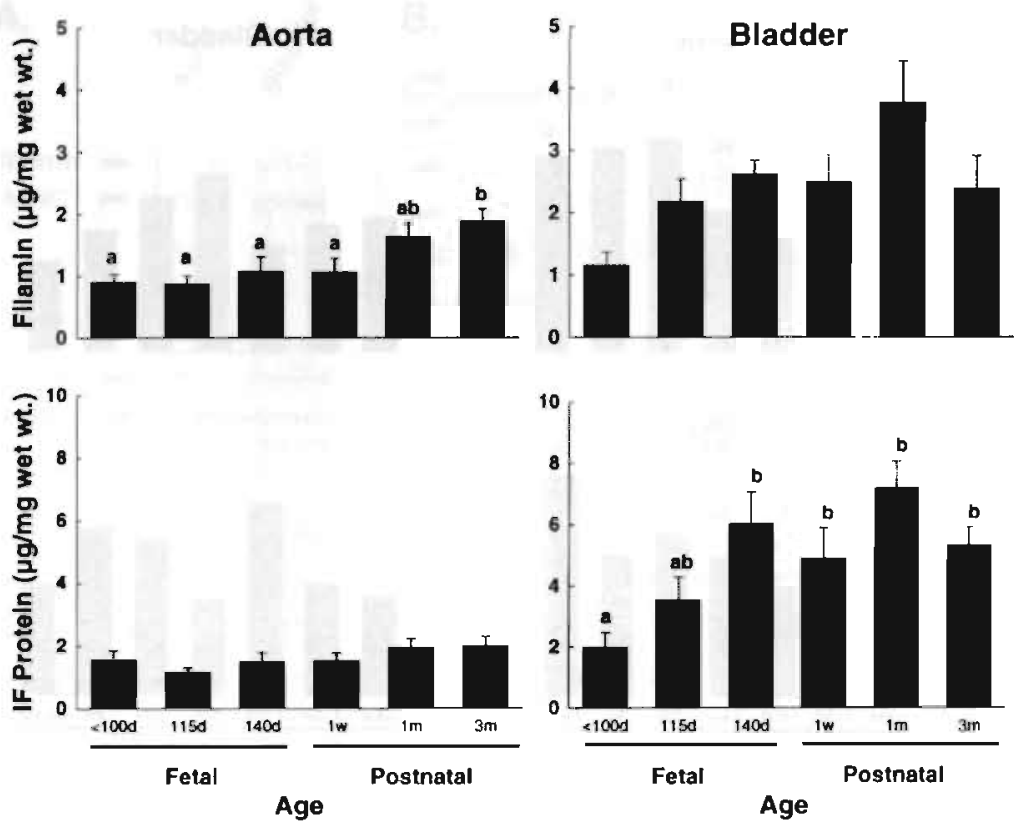

Figure 3. Filamin contents ( $\mu \mathrm{g} / \mathrm{mg}$ of wet weight) in aorta and bladder smooth muscle during ovine development. Values were derived from densitometric scans of 3-20\% polyacrylamide gels. Groups are as defined in Fig. 2. Values are means \pm SEM. Different letters denote significant differences at $\mathrm{p}<0.05$ among age groups by ANOVA, whercis groups not significantly different from each other are denoted by the same letters.

smooth muscle showed high variation, thus, unlike the aorta, no change was detected when the entire period was analysed (Fig 3). Values averaged $2.4 \pm 0.2$ $\mu \mathrm{g} / \mathrm{mg}$ wet weight.

In contrast to the pattern of gradual increases of actin-binding proteins observed in the aorta, contents of the intermediate filament proteins were unchanged in aorta throughout the period of development studied (Fig 3), values averaging $1.7 \pm 0.1 \mu \mathrm{g} / \mathrm{mg}$ wet weight. As observed for most smooth muscle proteins (3), the bladder tissue contents of intermediate filament proteins exceeded that in aorta during late fetal and postnatal development. Furthermore, there was a rapid, progressive increase in IF protein contents during the last month of pregnancy, contents increasing $\sim 3$-fold from $2.0 \pm 0.5$ to $6.0 \pm 1.0 \mu \mathrm{g} / \mathrm{mg}$ wet weight by $140 \mathrm{~d}$ gestation (ANOVA, $\mathrm{p}=0.002$ ), following which values remained stable (Fig 3). 


\section{DISCUSSION}

Results of the present study are consistent with our previous observations that smooth muscle of the bladder matures during prenatal development and well before term gestation, whereas aortic smooth muscle matures more slowly over the entire course of the prenatal and postnatal periods $(3,4)$. The smooth muscle-specific, actin-binding proteins h-caldesmon and calponin, as well as the more ubiquitous filamin, were present in amounts comparable to adult in bladder tissues from all stages studied, indicating that this tissue exhibits early "accelerated" maturation. In contrast, each of these proteins in aortic smooth muscle exhibited a gradual rise during fetal and postnatal development with tissues from midgestation containing a fraction the amount in adult. This pattern is very similar to that seen with total actin contents in the aorta (3). We hypothesized that the actin-binding proteins, h-caldesmon, calponin and filamin, would be expressed in coordination with actin. Whereas this appears to hold for aorta, a different conclusion is drawn for bladder, where content of these proteins remains stable while actin and myosin heavy chain contents increase about 3 -fold during the late stages of fetal development (3). In bladder, this is associated with a six-fold increase in stress generating capacity (3). As both caldesmon and calponin inhibit the actin-activated MgATPase activity of myosin $(5,6,7,8)$, we might speculate that the apparent decrease in their proportion to total actin may contribute to enhanced stress generation previously observed.

In addition to the gradual and sequential onset of various smooth musclespecific protein markers, smooth muscle development is also accompanied by the down-regulation of non-muscle isoforms that are expressed in immature muscle $(1,2)$. For example, in the ovine aorta the non-muscle MHC-B was gradually replaced by the smooth muscle SM-2; however, no MHC-B was found in bladder muscle as early as $70 \mathrm{~d}$ gestation (3). This pattern has also been observed for the alternatively spliced isoforms of caldesmon in chick $(12)$ and human $(13,14)$ smooth muscle development, where expression of $h$-caldesmon increases progressively and l-caldesmon decreases to minor levels. Surprisingly, l-caldesmon is present in sheep aortic as well as bladder smooth muscle throughout development. Because of the significant increase in h-caldesmon in aortic muscle, there was a substantial decline in the proportion of total caldesmon comprised of the l-form with maturity. In contrast, bladder muscle retained a lower, but constant proportion of I-caldesmon throughout. We speculate that any changes in the proportions of these isoforms, as well as the contents of calponin and filamin in bladder precede mid-gestation and may coincide with the period $(60-90 \mathrm{~d}$ gestarion) when bladder function is increasing $(25,26)$.

The smooth muscle cytoskeleton is a three-dimensional array of filaments (actin-containing thin filaments, desmin- and/or vimentin-containing, intermediate filaments, and tubulin-containing microtubules) that provides structural integrity and functional support for many cellular processes. Thin and interme- 
diate filaments comprise the bulk of the cytoskeleton in mature smooth muscle and have been proposed to exist in subcellular domains referred to as "contractile," including $\alpha$-actin, myosin, caldesmon and calponin, and "cytoskeletal," including desmin/vimentin, $\beta$-actin, filamin, and calponin $(9,10)$. A comparison of patterns of intermediate filament protein expression with those previously obtained for actin (3) shows that these two classes of protein increase in parallel in the ovine bladder, reaching adult values during the last third of fetal development. In contrast, actin contents in aorta increase gradually during fetal and post-natal development, while IF protein remains unchanged. These results may suggest that the development of subcellular domains exhibits tissue specificity, and that these domains need nor augment in parallel. In adult sheep, bladder IF protein content exceeds that in aorta, while there is no difference in actin content, resulting in a ratio of IF protein to actin of 0.30 in bladder and 0.13 in aorta. A lower ratio of IF protein to actin in vascular compared to visceral muscle has also been observed in adult porcine tissues (21), again indicating tissue-specific regulation of cytoskeletal domains. Further investigations will be required to evaluate whether there is a conversion of IF proteins from vimentin to desmin during ovine smooth muscle maturation as reported for smooth muscle types in the rat lung (27), and whether these developmental patterns differ between vascular and visceral muscle (22).

We can conclude from this study that the onset of expression of actin-binding proteins h-caldesmon, calponin and filamin, as well as the intermediate filament proteins occurs before mid-gestation in the sheep. However, the patterns of expression show marked tissue specificity when comparing aorta and bladder smooth muscle. By using a large animal model, quantitative changes in cytoskeletal proteins could be studied over a prolonged period of time not only during neonatal life, but also in fetal and adult stages of life. These results also provide a continuum with other studies done in our laboratory using the same animals as used in our contractile protein studies and functional contraction studies $(3,4)$. The advanced maturation and growth of bladder smooth muscle as compared to aortic points to the early demands for function of the bladder $(25,26)$ and relatively minor roles of aortic and systemic arterial contraction in fetal cardiovascular homeostasis $(28,29)$. Both environmental factors and intracellular elements involved in regulating the coordinated patterns of protein expression in developing smooth muscles remain to be explored.

\section{REFERENCES}

1. Sartore S., R. Fanch, M. Roelofs, A. Chiavegato. Molecular and cellular phenotypes and their regulation in smooth muscle. Rev. Physiol. Biochem. Pharmacol. 134:235-320,1999.

2. Owens G.K. Regulation of differentiation of vascular smooth muscle cells. Physiol. Rev. $7 \$: 487-517,1995$. 
3. Arens Y., C.R. Rosenfeld, K.E. Kamm. Maturational differences between vascular and bladder smooth muscle during ovine develpment. Am. J. Physiol.: Regulatory Integrative Comp Physiol 278:R1305-R1313,2000.

4. Chern J., K.E. Kamm, C.R. Rosenfeld. Smooth muscle myosin heavy chain isoforms are developmentally regulated in male fetal and neonatal sheep. Pediatr. Res. 38:697-703, 1995.

5. Winder S.J. and M.P. Walsh. Smooth muscle calponin: Inhibition of actomyosin MgATPase and regulation by phosphorylation. J. Biol. Chem. 265:10148-10155,1990.

6. Abe M., K. Takahashi, K. Hiwada. Effect of calponin on actin-activated myosin ATPase activity. J. Biol. Chem. 108:835-838,1990.

7. Sobue K., and J.R. Sellers. Caldesmon, a novel regulatory protein in smooth muscle and non-muscle acromyosin systems. J. Biol. Chem. 266:12115-12118,1991.

8. Nagai P.K., and M.P. Walsh. Inhibition of smooth muscle actin activated $\mathrm{Mg}^{2+}$ ATPase activity by caldesmon. J. Biol. Chem. 259:13656-13659,1984.

9. North A.J., M. Gimona, Z. Lando, J.V. Small JV. Actin isoform compartments in chicken gizzard smooth muscle cells. J. Cell. Sci. 107:445-455,1994.

10. North A.J., M. Gimona, R.A. Cross, J.V. Small. Calponin is localised in both the contractile apparatus and the cytoskeleton of smooth muscle cells. J. Cell. Sci. 107: 437-444,1994.

11. Duband J.L., M. Gimona, M. Scatena, S. Sartore, J.V. Small. Calponin and SM22 as differentiation markers of smooth muscle: spatiotemporal distribution during avian embryonic development. Differentiation 55:1-11,1993.

12. Ueki N., K. Sobue, K. Kanda, T. Hada, K. Higashino. Expression of high and low molecular weight caldesmons during phenotypic modulation of smooth muscle cells. Proc. Natl. Acad. Sci USA 84:9049-9053,1987.

13. Frid M.G., B.V. Shekhonin, V.E. Koteliansky, M.A. Glukhova. Phenotypic changes of human smooth muscle cells during development: late expression of heavy caldesmon and calponin. Dev. Biol. 153:185-193, 1992.

14. Glukhova M.A., M.G. Frid, V.E. Koteliansky. Developmental changes in expression of contractile and cytoskeletal proteins in human aortic smooth muscle. J. Biol. Chem. 265:13042-13046,1990.

15. Small J.V., D.O. Fürst, J. De Mey. Localization of filamin in smooth muscle. J. Cell. Biol. 102:210-220,1986.

16. Hartwig J.H., and D.J. Kwiatowski. Actin-binding protcins. Curr. ('pin. Cell. Biol. $3: 87-97,1991$

17. Wang, K., J.F. Ash, S.J. Singer. Filamin, a new high-molecular weight protein found in smoorh muscle and non-muscle cells. Proc. Nar. Acad. Sci. USA 72:4483-4486,1975.

18. Sparrow M.P., and H.W. Mitchell. Contraction of smooth muscle of pig airway tissues before birth to maturity. J. Appl. Physiol. 68:468-477, 1990.

19. Lazarides E. Intermediate filaments: a chemically heterogeneous, developmentally regulated class of proteins. Annu. Rev. Biochem. 51:219-250, 1982.

20. Malmquist U., A. Arner, B. Uvelius. Contractile and cytoskeletal proteins in smoorh muscle during hypertrophy and its reversal. Am. J. Physiol. 260:C1085-C1093,1991. 
21. Small J.V., A. Sobieszek. Studies on the function and composition of the $10 \mathrm{~nm}$ (100 A) filaments of vertebrate smooth muscle. J. Cell. Sci. 23:243-268,1977.

22. Gabbiani G., E. Schmid, S. Winter, C. Chaponnier, C. de Chastonay, J. Vandekerchove, K. Weber, W.W. Franke. Vasuclar smooth muscle cells differ from other smooth muscle cells: Predominance of vimentin filaments and specific $\alpha$-type acrin. Proc. Natl. Acad. Sci. USA 78:298-302,1981.

23. Persechini A., K.E. Kamm, J.T. Stull. Different phosphorylated forms of myosin in contracting tracheal smooth muscle. J. Biol. Chem. 261:6293-6299,1986.

24. Word R.A., J.T. Stull, M.L. Casey, K.E. Kamm. Contractile elements and myosin light chain phosphorylation in myometrial rissue from nonpregnant and pregnant women. J. Clin. Invest. 92:29-37,1993.

25. Ohel G., S. Haddad, A. Samueloff. Fetal Urine Production and micturition and fetal behavioral state. Am. J. Perinatol. 12:91-92,1995.

26. Kogan B.A., H.S. Iwamoto. Lower urinary tract function in the sheep fetus: studies of autonomic control and pharmacologic responses of the fetal bladder. J. Urol. 141:1019$1024,1989$.

27. Mitchell J.J., S.E. Reynolds, K.O. Leslie, R.B. Low, J. Woodcock-Mitchell. Smooth muscle cell markers in developing rat lung. Am. J. Respir. Cell. Mol. Biol. 3:515-523,1990.

28. Kaiser J.R., B.E. Cox, T.A. Roy, C.R. Rosenfeld. Differential development of umbilical and systemic arteries. I. ANG II receptor subtype expression. Am. J. Physiol. Regulatory Integrative Comp. Physiol. 274: R797-R807,1998.

29. Arens Y., R.A. Chapados, B.E. Cox, K.E. Kamm, C.R. Rosenfeld. Differential development of umbilical and systemic arteries. II. Contractile proteins. Am. J. Physiol. Regulatory Integrative Comp. Physiol. 275: R1815-R1823,1998. 
CHAPTER 8

\section{Altered pulmonary artery smooth muscle proteins in postnatal sheep with high flow pulmonary hypertension}

S. Chamnanvanakij, Y. Arens, L. van der Steeg,

J. Fineman, K.E. Kamm, V.H. Reddy, C.R. Rosenfeld

Departments of pediatrics, physiology and surgery

UT southwestern medical school, Dallas, Texas

University of California San Francisco, California 


\section{A B S T R A C T}

Large left to right shunts in infants with congenital heart disease may result in development of PAH. Prenatal placement of aortopulmonary shunts in fetal sheep mimics this condition, resulting in increased PBF and PAH by $4 \mathrm{wks}$ postnatal. Whereas cardiovascular changes and pulmonary artery (PA) morphology are described in PAH, alterations of SM contractile proteins and cell phenotype are unknown. To address this, we obtained 3 rd-4th generations of PA and femoral arteries from twin lambs at 1 mon postnatal, one with an aortopulmonary shunt $(n=8)$ and the other without $(n=7)$. We measured SM contents of total and soluble protein, actin, myosin, desmin, filamin and MHC-isoforms using SDS-PAGE with 3-20\% and 4\% polyacrylamide gels. $200 \mathrm{kDa}$ MHC-isoforms, calponin and caldesmon were measured by Western immunoblott analysis. While PA total protein was unaltered, soluble protein and soluble to total protein ratios in $\mathrm{PAH}$ were decreased $35 \%$ and $25 \%$, respectively. Although PA actin was unchanged, MHC contents were decreased $51 \%(6.54 \pm 0.81$ to $3.23 \pm 0.43 \mu \mathrm{g} / \mathrm{mg}$ of wet weight, $\mathrm{p}<0.01)$ and actin to myosin ratios were increased $58 \%$ in PAH. PAH also caused 204 and $200 \mathrm{kDa}$ MHC-isoforms to decrease from $4.64 \pm 0.56$ and $1.90 \pm 0.25$ to $2.18 \pm 0.29$ and $1.05 \pm 0.15 \mu \mathrm{g} / \mathrm{mg}$ of wet weight, respectively. Interfilament protein (Desmin) contents in PAH were unchanged, whereas filamin content was $63 \%$ lower. By Western immunoblot, PAH was associated with a $96 \%$ greater expression of MHC-B; SM2 was unaltered. Although calponin and caldesmon expressions were unaffected, the l- to h-caldesmon ratio was $55 \%$ greater in PAH, suggesting predominance of the immature isoform. In contrast, femoral artery SM protein contents were unaffected by PAH. Increases in PBF in postnatal sheep with aortopulmonary shunts result in persistence of an immature phenotype in PA SM, which may reflect the ongoing $S \mathrm{M}$ growth associated with vascular remodeling and possibly vascular dysfunction.

Key words: pulmonary hypertension, smooth muscle 


\section{INTRODUCTION}

The hemodynamic adaptation to extrauterine life (abruptly decreased PAP and PVR) results in remodeling of pulmonary vasculature to establish gas exchange $(1,2)$. Any disturbance of this process leads to abnormal pathology changes in pulmonary vascular bed and eventually life threatening disease (3). While congenital heart disease with left to right shunts results in pulmonary vascular disease in infancy and childhood $(4,5)$, PPHN causes a high mortality in the early neonatal period. To understand the mechanisms of these diseases, several experimental models were developed. In utero placement of aortopulmonary shunts in fetal sheep which resulted in a tremendous increase in PBF and slowly decreased PVR mimicked congenital heart disease in human infants such as ventricular septal defect, atrioventricular canal or truncus arteriosus (6). The other adaptive failure, PPHN, was represented by the models of chronic hypoxia in newborn calves at high altitude $(7,8)$ and prenatal ductus ligation in fetal lambs $(9-11)$, where PAP and PVR remained high postnatally while PBF diminished $(9,10)$. Although the hemodynamic findings were not completely uniform, the link between these models was the persistence of high PAP resulting in consistent pathologic features, which included an abnormal extension of SM into small or intra-acinar arteries and an increased percent medial thickness in PA $(6-8,12,13)$.

Since PA SM is substantially involved in PAH, the SM proteins are most likely affected during this abnormal vascular remodeling. SM is composed of a contractile domain and a cytoskeletal channel (14). In the contractile domain, actin and myosin are the major proteins in the thin and thick filament, respectively. Myosin is a large protein made of 6 polypeptide chains, 2 identical myosin heavy chains (MHC) and two pairs of light chains (15). $\mathrm{MHC}$ in human aorta has, at least, 3 major isoforms: SM, (204 kDa), SM2 (200 kDa), and MHC-B (200 kDa) (16). While $S M 1$ and $S M 2$ are considered to be mature isoforms expressed as a contractile phenotype, $\mathrm{MHC}-\mathrm{B}$ is a nonmuscle isoform associated with a synthetic phenorype conducting a role in SM cell growth and cell division (16-19). The expressions of these SM proteins are developmentally regulated. While SM1 is expressed throughout development, SM2 is upregulated during late fetal and postnatal period. In contrast, $\mathrm{MHC}-\mathrm{B}$ is the predominant $\mathrm{MHCl}$ in the fetus and its level decreases significantly after birth (16-19).

The cytoskeletal channel consists of many specific proteins providing support for the contractile machinery $(14,9,20)$. The interfilament proteins and filamin can be electrophoretically separated by SDS-PAGE on a gradient gel and are also reported to be increased in a parallel manner with the progressive development of the contractile domain (19-21).

Calponin and caldesmon are actin-binding proteins in the contractile domain involved in the regulation of SM contraction through an inhibitory effect on ATPase activity of the actomyosin complex $(19,22)$. The proportions of caldesmon variants are altered during development. l-Caldesmon, the low molec- 
ular weight form of caldesmon $(70 \mathrm{kDa})$, is detected in early fetal life and is replaced by h-caldesmon the high molecular weight form $(150 \mathrm{kDa})$, which increases in mature SM (19,22-24). Calponin and h-caldesmon are considered markers of SM maturation (24).

In PAH, the regulation of SM protein production and differentiation are changed. We reported that in prenatal ductal ligation, the expression of MHC-isoforms is altered. There is an increase in MHC-B and decrease in SM2 (25). The conversion of MHC-isoforms from a contractile to synthetic phenotype was presumably associated with a decreased capacity for stress generation (25). Regarding the integrated molecular structures in SM cells, other regulatory and cytoskeletal proteins may be affected in concert with alterations of MHCI in response to PAH. Although the alterations of SM proteins and MHC-isoforms are previously described, they have not been performed in this model of congenital heart disease. Therefore, we studied smooth muscle alterations in PA to determine the expression of contractile and cytoskeletal proteins in newborn lambs with high PAP and PBF.

\section{METHODS}

\section{Tissue preparation}

Eight pregnant mixed-breed western ewes with twin gestations were operated upon at the University of California, San Francisco at $\sim 1.40 \mathrm{~d}$ of gestation under sterilc condition with epidural anesthesia and intravenous sedation. One twin fetus $(\mathbf{n}=8)$ was partially exposed through a hysterotomy, and a thoracotomy was performed as previously described (6). Briefly, the arterial truck and the main pulmonary artery were dissected, and an aortotomy and pulmonary arteriotomy were performed. Between these two arteries, an $8.0-\mathrm{mm}$ expanded polytetrafluoroethylene vascular graft ( $2 \mathrm{~mm}$ length) (Gore-tex; W.L. Gore and Assoc) was placed to provide an aortopulmonary shunt. The other twin $(n=7)$ served as a control and was not operated upon. The thoracotomy incision was closed, and the fetus was returned into the uterus. Amniotic fluid was replaced by warm saline before closure of the uterine incision. Postoperatively, the ewes recovered and the fetuses were allowed to deliver spontaneously at term. Following delivery, lambs were maintained in a holding area until one month of age when they were killed with lethal doses of intravenous pentobarbital sodium, and tissue was collected. These protocols were approved by the Committee on Animal Research of the University of California, San Francisco.

The lungs were removed in block and third and fourth generations of PA and femoral arteries were collected. Adventitia and adjacent lung tissue were removed by blunt dissection and endothelium was removed with a soft cotton swab. Strips of arteries were cut, frozen in liquid nitrogen, and stored at $-80^{\circ} \mathrm{C}$ until studied. 


\section{Protein analysis}

SDS homogenates were prepared from $15-20 \mathrm{mg}$ of frozen tissue and divided into 2 aliquots. One aliquot was centrifuged at $10,000 \mathrm{xg}$ for $2 \mathrm{~min}$, and the supernatant was removed for determination of soluble or cellular protein and subsequent gel electrophoresis. The other aliquot was not centrifuged and was used to measure total homogenate protein (sum of cellular and extracellular fractions). Total and soluble protein contents were analyzed using BCA reagent (Pierce, Rockford, IL); bovine serum albumin (BSA) (Pierce, Rockford, IL) was used to construct a standard curve between the optical density and protein content. Another aliquot of the supernatant was mixed with $0.2 \%$ bromphenol blue and Bis-mercaptoethanol, and $20 \mu \mathrm{g}$ of soluble protein was subjected to SDS-PAGE, using 3-20\% polyacrylamide gels, to determine the contents of actin, $\mathrm{MHC}$, desmin, and filamin. Electrophoresis was run at $200 \mathrm{~V}$ until the dye front ran of the gel. Each gel also contained lanes for high and low molecular weight standards (Biorad laboratories, Hercules, CA) to determine the molecular mass of protein bands. Gels were stained overnight with Coomassie Brilliant Blue, and background staining was then removed with appropriate destaining solutions. The protein bands were scanned in duplicate with a laser densitometer (model 2202, LKB instruments, Inc., Stockholm, Sweden) and the absorbance recorded by a $2220 \mathrm{LKB}$ recording integrator. The amounts of each protein were calculated by using the average values of the areas under peaks. These values were converted to micrograms using the total protein measured by BCA reagent in each sample and were expressed as $\mu \mathrm{g} / \mathrm{mg}$ of wet weight. The amounts of $204 \mathrm{kDa}$ and $200 \mathrm{kl}$ ) a MHC-isoforms were determined by loading one microgram of myosin on $4 \%$ polyacrylamide gels.

\section{Antibody production}

Two peptides of 9 amino acids were synthesized based on the specific amino acid sequence of the $200 \mathrm{kDa} \mathrm{MHC}$ from bovine brain (MHC-B) and adult rabbit aorta (SM2) and then conjugated to tuberculin purified protein derivative. The antisera were produced by immunization these proteins in rabbits by the Animal Resources Center, UT Southwestern Medical Center. The specificity of these antisera was illustrated by Western immunoblot using purified bovine myosin (gift of Barbara Barylko) for MHC-B and adult myometrium for SM2 (26).

The purified caldesmon was prepared from chicken gizzards and injected into rabbits to produce the polyclonal anti-caldesmon by the Animal Resources Center, UT Southwestern Medical Center (27). 


\section{Western analysis}

To determine the expression of $200 \mathrm{kDa}$ MHC-isoforms, MHC-B and SM2, 400 ng of myosin were loaded and separated on $4 \%$ polyacrylamide gels. Each gel also contained $200 \mathrm{ng}$ of purified bovine brain myosin and adult myometrium myosin to serve as controls for MHC-B and SM2, respectively. Proteins were transferred by electrophoresis to nitrocellulose paper at $100 \mathrm{~V}$ for $1.5 \mathrm{~h}$. Blots were blocked in the buffer contained powdered milk $(0.3 \% \mathrm{wt} / \mathrm{vol})$ for $2 \mathrm{~h}$ and incubated overnight with blocking buffer containing antisera $(1: 10,000)$ against MHC-B or antisera $(1: 4,000)$ against SM2. Two percent of sodium azide $(1: 2,000)$ was added to prevent bacterial contamination. The blots then were incubated with goat anti-rabbit IgG conjugated with horseradish peroxidase (HRP) $(1: 15,000)$ (BioRad Laboratories, Hercules, CA) for $1 \mathrm{~h} 45 \mathrm{~min}$. Afterwards, the blots were placed in Enhanced Chemiluminescence (ECL) for $1 \mathrm{~min}$ and exposed on ECL film in a dark room. The bands of MHC-B and SM2 were visualized on the films and were scianned on an Arcus II scanner (Agfa) with software, FotoLook 95 V.2.08Standa lone. The relative volumes of these bands were determined by densitometry using a Molecular analyst software V.1.3 (Bio-Rad laboratories, Hercules, CA).

Calponin and caldesmon expression was determined by loading 2 and $0.5 \mu \mathrm{g}$ of soluble protein, respectively, on 3-20\% polyacrylamide gels, and separated by SDS-PAGF. Western immunoblots were performed for each protein as described above. The blots for calponin were blocked and incubated with monoclonal antisera $(1: 10,000)$ against calponin prepared from human uterus smooth muscle extract (Sigma, St Louis, MO) and then with goat anti-mouse Ig G-HRP conjugate (1:15,000 Bio-Rad Laboratories, Hercules, CA). The blots for caldesmon were incubated with antisera $(1: 20,000)$ against caldesmon and goat anti-rabbit IgG-HRP conjugate $(1: 15,000)$. The relative volumes of calponin and I- and h-caldesmon were determined by densitometry using methods described above.

\section{STATISTICS}

The data from each study group was analyzed by descriptive statistics and presented as the mean $\pm S E M$. The unpaired student $t$-test was used to determine the differences between groups. Significance was observed at $\mathrm{p}=0.05$.

\section{RESULTS}

\section{Pulmonary Artery Protein, Actin and Myosin contents}

Total protein contents were not significantly different between control and shunted animals (Fig 1A). In contrast, contents of soluble protein were $35 \%$ less 
$(\mathrm{p}=0.039)$ in PA from shunted lambs (Fig 1B). Therefore, the ratio of soluble to total protein was $25 \%$ less $(\mathrm{p}=0.015)$ in shunted animals, $0.49 \pm 0.05$ versus $0.65 \pm 0.03$.

Actin contents in PA from shunted animals were decreased $23 \%$ compared to the other twin, but this difference was not significant (Fig 2A). In contrast, the myosin content was $51 \%$ less in the lambs with $\mathrm{PAH}(\mathrm{p}=0.002)$ (Fig $2 \mathrm{~B})$, resulting in an increase of $58 \%$ in the actin to myosin ratio in the shunted lambs, $3.08 \pm 0.21$ versus $1.95 \pm 0.14(\mathrm{p}=0.001)$.

\section{Pulmonary Artery $\mathrm{MHC}$-isoforms}

In concert with the decreased contents of total MHC in PA from shunted animals, there was a $53 \%(p=0.001)$ and $45 \%(p=0.010)$ decrease in the content of the 204 and $200 \mathrm{kDa}$ isoforms respectively (Fig $3 \mathrm{~A}$ and 3B). Since the $200 \mathrm{kDa} \mathrm{MHC}$ isoform represented as MHC-B or SM2 in PA SM, they were separated by Western immunoblot analysis using specific antisera (see methods), and the differences were analyzed by densitometric analysis. Although there was no difference detected in the SM2 expression, MHC-B expression was $96 \%$ greater in PA from shunted animals (Fig 4).

\section{Pulmonary Artery Interfilament protein and Filamin}

These proteins represent the cytoskeletal domain of SM cells and can be measured on $3-20 \%$ polyacrylamide gels with SDS-PAGE. Interfilament protein contents were $38 \%$ less in PA from shunted lambs with PAH, however, this was not significant (Fig 5A). The filamin content, however, was significantly less in PA from shunted animals, $0.75 \pm 0.15$ versus $2.02 \pm 0.39 \mathrm{pg} / \mathrm{mg}$ of wet weight in the other twin ( $\mathrm{p}=0.007$ ) (Fig 5B).

\section{Pulmonary Artery Calponin and Caldesmon}

Although the protein expression of total calponin and caldesmon was unaffected by $\mathrm{PAH}$, the ratio of low and high molecular weight caldesmon was significantly greater in PA of animals with PAH 0.53 \pm 0.07 versus $0.34 \pm 0.03$ ( $p=0.044$ ) (Fig 6). Therefore, there is a predominance of the low molecular weight isoform.

\section{Femoral Arteries Protein Expression}

There was no significant difference in SM protein expression in femoral arteries of shunted and control lambs (data not shown), except for a modest decrease in the calponin expression $(\mathrm{p}=0.05)$ in shunted animals. 

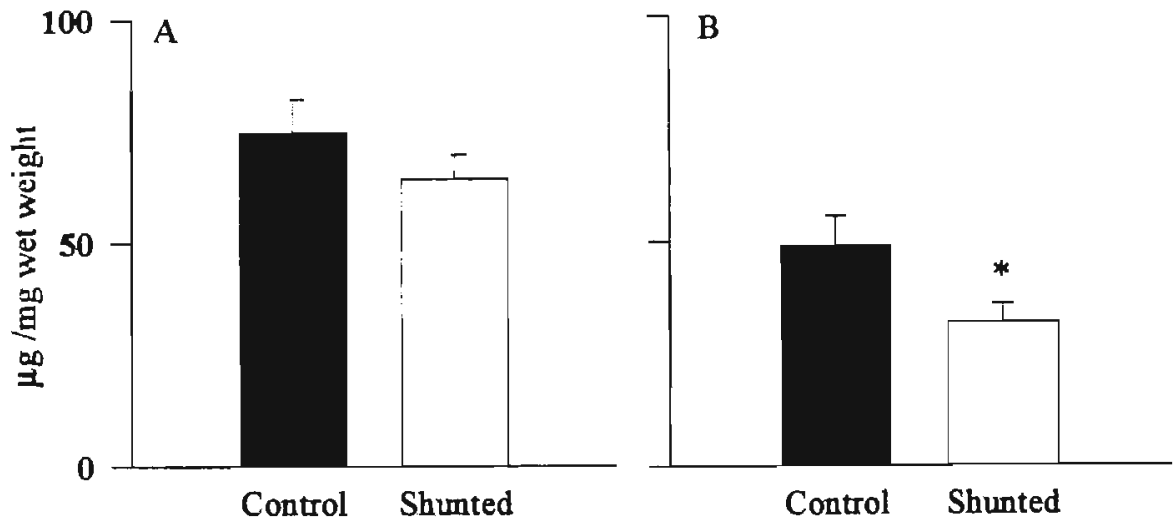

Figure 1. Contents of total $(A)$ and soluble $(B)$ protein in pulmonary arteries from control and shunted posmatal sheep. Values are means \pm SF.M. ${ }^{*} \mathrm{p}=0.0 .39$.
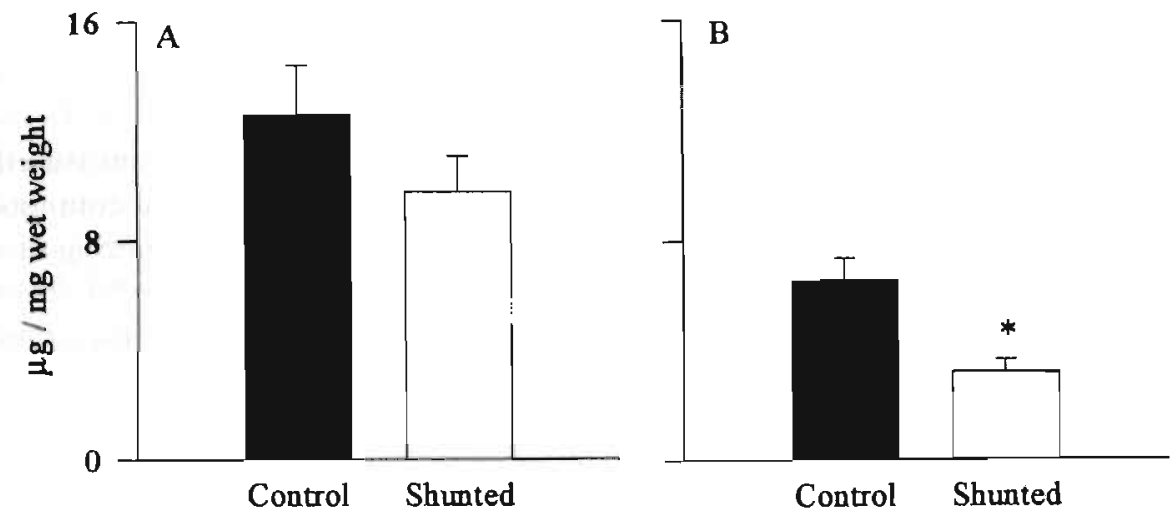

Figure 2. Contents of actin (A) and myosin (B) in pulmonary arteries from control and shunted postnatal sheep. Values are means \pm SEM. ${ }^{*} p=0.002$. 

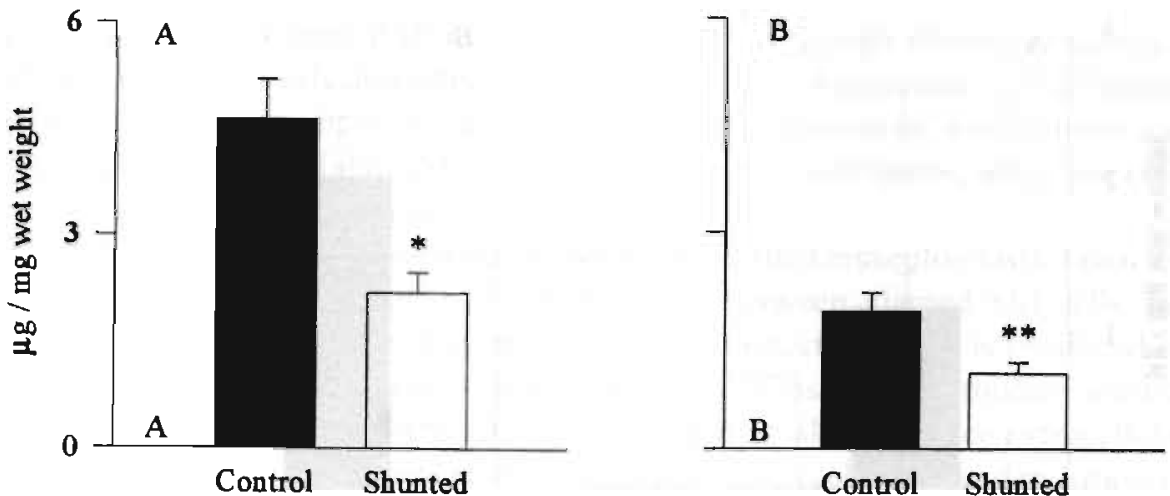

Figure 3. Contents of 204 (A) and 200 (B) kDa myosin heavy chain isoforms in pulmonary arteries from control and shunted postnatal sheep.Values are means \pm SEM. " $p=0.001$, $* \mathrm{p}=0.01$.

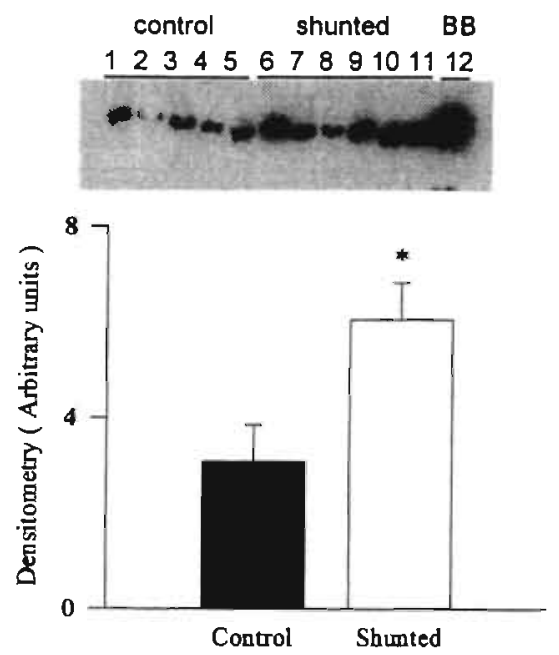

Figure 4. A representative Western immunoblot demonstrating the expression of the 200 $\mathrm{kDa}$ MHC- $\mathrm{B}$ in pulmonary arteries from control (Lane 1 to 5) and shunted (Lane 6-11) postnatal sheep. Lane 12 is purified bovine brain myosin. The results of volumetric densitometry (sec methods) are shows in the lower half of the figure from control $(n=7)$ and shunted $(n=8)$ animals. Values are means \pm SFM. ${ }^{*} \mathrm{p}=0.017$. 

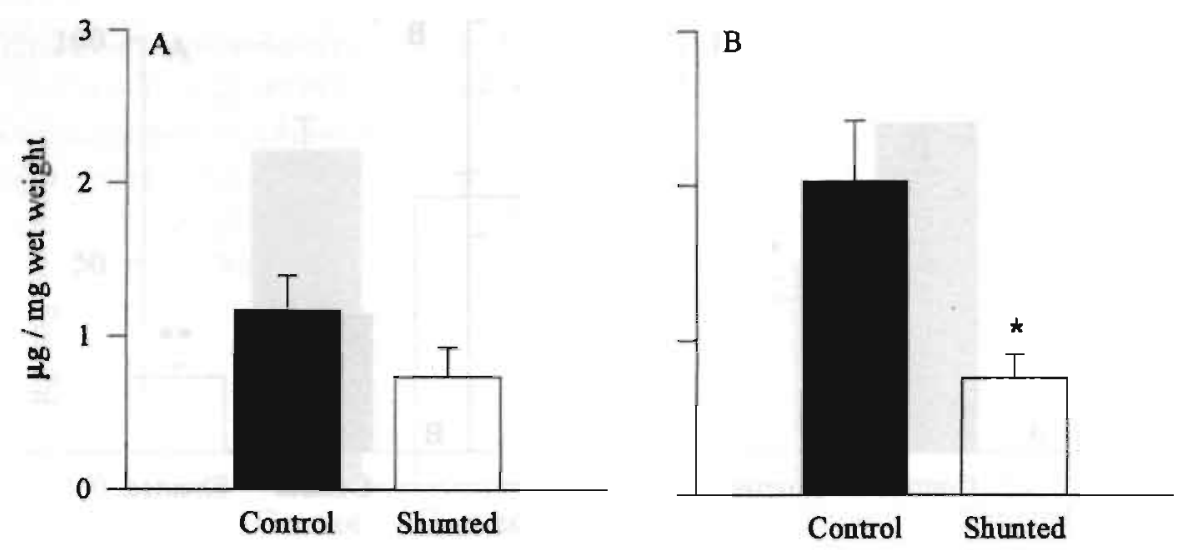

Figure 5. Contents of desmin (A) and filamin (B) in pulmonary arteries from control and shunted postnatal sheep. Values are means \pm SEM. ${ }^{*} p=0.007$.

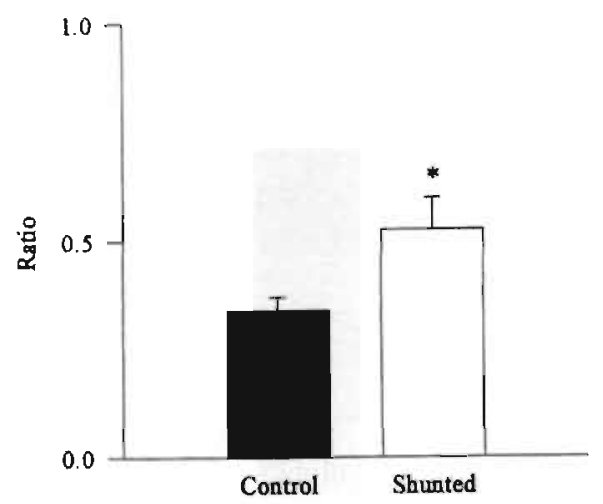

Figure 6 . The ratio of 1 - to h-caldesmon in pulmonary arteries from control and shunted postnatal sheep. Values are means \pm SEM. ${ }^{*} \mathrm{p}=0.044$.

\section{DISCUSSION}

The abnormal hemodynamic status in 1 month old lambs with systemic-topulmonary communications results in structural changes, which possibly represented an early adaptation of congenital heart disease with high PBF in human infants (3-6). The increase in percent medial thickness in PA from shunted lambs was similar to that observed in other animal reflecting the postnatal response of 
PA to persistently high PAP models $(7,8,12,13)$. Although this morphological change was previously described as a result of SM cells hyperplasia and/or hypertrophy in response to hemodynamic stress $(28,29)$, in this study, we demonstrated a decrease in intracellular SM protein content in shunted lambs, while the total protein contents remains unchanged.

The arterial media is organized into lamellar units called musculo-elastic fascicles, which consist of elastic fibers forming layers between aligned SM cells and collagen fibers (30). In developing vessels, this connective tissue is produced by SM cells and consequently constitutes a significant mass of the pulmonary arterial wall $(1,2,31)$. Since newborns have a greater potential to produce extracellular matrix $(30,31)$, hypoxic newborn calves with PAH accelerate the deposition of elastin and collagen in both adventitial and medial layers $(7,8,33,34)$. Correspondingly, in infants with pulmonary hypertensive heart disease, the proportion of medial connective tissue to SM cells in the wall of small PA was greatest in the youngest age group, 2-6 month old (32). The soluble protein contents in PA calculated per tissue wet weight were relatively decreased in shunted lambs when extracellular matrix proteins were addirionally increased.

The major cellular proteins in vascular SM capable of contractions, actin and myosin, are affected in PAH. While actin was the only SM contractile protein shown to be transiently increased in intra-acinar arteries from infants with pulmonary hypertensive heart disease at 2 months of age (35), actin and myosin expression was inconsistently described to either increase (11) or to stay stabile in animal models with PAH (25). In contrast, we demonstrate a decrease in both contractile proteins in 1 month old sheep with aortopulmonary shunts. Since myosin contents have decreased significantly more than actin content, the actin to myosin ratio was subsequently increased. The variations of the SM protein expression are probably due to the differences in experimental models, time and severity between animal and human diseases.

We previously reported the unchanged myosin contents but converted proportions of $\mathrm{MHC}$-isoforms in prenatal ductus ligation model (25). In the present study we observed significantly decreased amounts of 200 and $204 \mathrm{kDa}$ MHC-isoforms in a parallel pattern with the decreased myosin in shunted lambs, although the proportions were not changed. Accordingly, we postulated that the total myosin and also MHC-isoforms in PA SM declined in response to increalsed PAP and possibly associated with SM functional changes.

In addition to $\mathrm{MHC}$, the PA SM cytoskeletal channel, which normally develops in parallel with the contractile domain (19-21), may be concurrently involved in the abnormal remodeling process. Although they were not exclusively studied, the alterations of SM cytoskeletal proteins were shown to be selective to specific subpopulations and possibly time-dependent expression. While the interfilament protein vimentin was transiently increased in infants with pulmonary hypertensive heart disease during 2 to 8 month of age (35), PA SM proliferation in newborn calves with hypoxic PAH was shown to occur almost exclusively 
in metavinculin-negative SM subpopulation (36). We studied different SM proteins and demonstrated an unchanged interfilament desmin content, but a significant decrease in filamin content in shunted lambs versus control. SM cytoskeletal protein is selectively affected in $\mathrm{PAH}$ and filamin protein expression is decreased in concert with the contractile proteins, which altogether contributes to the decrease of cellular protein contents in PA SM in animals with PAH.

$200 \mathrm{kDa}$ MHC is represented as two isoforms. While SM2 is a smooth muscle isoform expressed in the mature contractile phenotype, MHC-B is an immature isoform related to $S M$ cell replication (16-19). In response to $\mathrm{PAH}, \mathrm{SM}$ changes its protein expression from a contractile to synthetic phenotype (31), which enhances tissue growth and repair. On the other hand, the accelerated cell growth results in thickening of arterial wall and a subsequent decrease in the diameter of vascular lumen. The conversion of $\mathrm{MHC}$-isoforms was consistently demonstrated in the models of prenatal ductus ligation $(11,25)$. While Belik showed an increased percentage of unspecified nonmuscle MHC-isoform (11), Chapados established an increased in $\mathrm{MHC},-\mathrm{B}$ and a decrease in $\mathrm{SMMHCI},(25)$. We found an increase in MHC-B expression in PA SM from shunted lambs compared to control, while SM2 did not differ. In this regard, we determined that the predominance of the synthetic phenotype, MHC-B, enabled the PA SM to proliferate resulting in the increased medial thickness in PA.

The regulatory proteins in SM contractile domain, calponin and caldesmon are probably involved together with the alterations of the contractile proteins. Opposite to normal development, we reported a significant increase of $l$ - to h-caldesmon ratio in PA SM from shunted lambs with PAH, although the relative amount of caldesmon and calponin are unaltered. Therefore, the conversion of caldesmon corresponds with the alterations of $\mathrm{MHC}$ isoforms suggesting that the immature isoforms in PA SM are significantly expressed in PAH. Since immature isoforms are expressed as synthetic rather than the contractile phenotype, these alterations of SM proteins may have a consequent effect on PA vascular functions. The increase of SM immature isoforms in 2nd to 4th generations PA from newborn lambs with PAH resulted in a decreased capacity of stress generation in response to variant stimuli $(11,25)$. This circumstantial evidence suggests that $P A$ SM is not responsible for the PA hyper-reactivity or increased vascular tone in $\mathrm{PAH}$. The reactivity of PA to vasoactive stimuli in infants with congenital heart disease or PPHN may be modified by other factors. The increases of vasoconstrictors, endothelin-1 and thromboxane A2, but impairment of endothelium-dependent PA relaxation have been reported in infants with PAH (37-40), these vasoactive products might play a potential role in pulmonary vasoregulation $(37-42)$. In addition, the smaller PA distal to the 4th generation and pulmonary veins might also conduct vasoconstriction and participate in maintaining vascular tone in $\mathrm{PAH}$.

Although the mechanism responsible for controlling vascular remodeling and SM protein expression are unknown, there is some evidence that 
high-pressure-induced vascular injury may expose medial and adventitial cells to peptide mitogens and differentiation factors $(42,43)$. Subsequently, these factors such as insulin-like growth factor 1 (IGF-1), transforming growth factor- $\beta 1$ (TGF- $\beta 1$ ) may have an effect on vascular remodeling and alterations of the phenotype of SM cells (43-4.5).

Since femoral artery SM proteins, except calponin, did not differ hetween shunted and control animals, it suggests a specificity for $S M$ protein alterations in response to $\mathrm{PAH}$ to pulmonary vasculature.

We conclude that in the animal model of congenital heart disease with high $\mathrm{PBF}, \mathrm{SM}$ proteins in PA are altered with vascular remodeling. At 1 month of age, PA contractile and cytoskeletal SM proteins are selectively decreased in response: to high PAP. The PA SM proteins are changed to immature isoforms reflecting the ongoing vascular growth and possibly attenuated contractile capability. The mechanisms controlling this alterations and modifying vascular reactivity need further investigation to be elucidated, which might have implications in treatment strategies.

\section{REFERENCES}

1. Allen K., and S.G. Haworth. Human postnatal pulmonary arterial remodeling: ultrastructural studies of smooth muscle cell and connective tissue maturation. Lab. Invest. 59:702-709, 1988.

2. Hall S.M., and S.G. Haworth. Normal adaptation of pulmonary arterial intima to extrauterine life in the pig: ultrastructural studies. J. Pathol. 149:55-56, 1986.

3. Haworth S.G. Pulmonary vascular remodeling in neonatal pulmonary hypertension. Chest 93:133S-138S, 1988.

4. Rabinovitch M., S.G. Haworth, A.R. Castaneda, A.S. Nadas, and L.M. Reid. Lung biopsy in congenital heart disease: a morphometric approach to pulmonary vascular disease. Circulation 58:1107-1121, 1978.

5. Haworth S.G. Pulmonary vascular disease in different rypes of congenital heart disease: implications for interpretation of lung biopsy findings in early childhood. Br. Heart J. 52:557-571, 1984.

6. Reddy V.M., B. Meyrick, J. Wong, A. Khoor, J.R. Liddicoat, F.L. Hanley, and J.R. Fineman. In utero placement of aortopulmonary shunts: a model of postnatal pulmonary hypertension with increased pulmonary blood flow in lambs. Circulation 92:606-613, 1995 .

7. Stenmark K.B., J. Fasules, D.M. Hyde, N.F. Voelkel, J. Henson, A. Tucker, H. Wilson, and J.T. Reeves. Severe pulmonary hypertension and arterial adventitial changes in newborn calves at 4,300 m. J. Appl. Physiol. 62:821-830, 1987.

8. Durmowicz A.G., E.C. Orton, and K.R. Stenmark. Progressive loss of vasodilator responsive component of pulmonary hypertension in neonatal calves exposed to $4,570 \mathrm{~m}$. Am J Physiol 265:H2175-H2183, 1993. 
9. Morin III F.C., E.A. Egan. The effect of closing the ductus arteriosus on the pulmonary circulation of the fetal sheep. J. Develop. Physiol. 11:283-287, 1989.

10. Morin III F.C. Ligating the ductus arteriosus before birth causes persistent pulmonary hypertension in the newborn lamb. Pediatr. Res. 25:245-250, 1989.

11. Belik J., A.J. Halayko, K. Rao, and N.L. Stephens. Fetal ductus arteriosus ligation: pulmonary vascular smooth muscle biochemical and mechanical changes. Circ. Res. 72:588-596, 1993.

12. Wild L.M., P.A. Nickerson, and F.C. Morin III. Ligation the ductus arteriosus before birth remodels the pulmonary vasculature of the lamb. Pediatr. Res. 25:251-257, 1989.

13. Belik J., F.W. Keeley, F. Baldwin, and M. Rabinovitch. Pulmonary hypertension and vascular remodeling in fetal sheep. Am. J. Physiol. 266:H2303-2309, 1994.

14. North A.J., M. Gimona, R.A. Cross, and J.V. Small. Calponin is localised in both the contractile apparatus and the cytoskeleton of smooth muscle cells. J. Cell. Sci. 107: 437-444, 1994.

15. Stryer L. Molecular motors. In:Stryer L. (eds) Biochemistry. W.H. Freeman and Company, New York, pp391-416, 1995.

16. Aikawa M., P.N. Sivam, M. Kuro-o, K. Kimura, K. Nakahara, S. Takewaki, M. Ueda, H. Yamaguchi, Y. Yazaki, M. Periasamy, and R. Nagai. Human smooth muscle myosin heavy chain isoforms as molecular markers for vascular development and arterosclerusis. Circ. Res. 73:1000-1012, 1993.

17. Kuro-o M., R. Nagai, H. Tsuchimochi, H. Katoh, Y. Yazakfi, A. Ohkubo, and F. Takaku. Developmentally regulated expression of vascular smooth muscle myosin heavy chain isuforms. J. Biol. Chem. 264:18272-18275, 1989.

18. Kuro-o M., R. Nagai, K. Nakahara, K. Hirohisa, R. Tsai, H. Tsuchimoch, Y. Yazaki, A. Ohkubo, and F. Takaku. CDNA cloning of a myosin heavy chain isoform in embryonic smooth muscle and its expression during vascular development and in arteriosclerosis. J. Biol. Chem. 266:3768-3773, 1991.

19. Owens G.K. Regulation of differentiation of vascular smoorh muscle cells. Physiol. Rev. $75: 487-517,1995$.

20. Gordin J., and J. Hartwig. Actin and associated proteins. In: Kreis T, Vale R (eds) Guidebook to the cytoskeletal and motor proteins. Oxford University Press Inc., New York pp 18-20, 1993.

21. Kocher O., O. Skalli, D. Cerutti, F. Gabbiani, and G. Gabbiani. Cytoskeletal features of rat aortic cells during development: an electron microscopic, immunohistnchemical, and biochemical study. Circ. Res. 56:829-838, 1985.

22. Sobue K., J.R. Sellers. Caldesmon, a novel regularory prutein in smooth muscle and nonmuscle actomyosin systems. J. Biol. Chem. 266:12115-12118, 1991.

23. Glukhova M.A., M.G. Frid, V.E. Koteliansky. Developmental changes in expression of contractile and cytoskeletal proteins in human aortic smooth muscle. J. Biol. Chem. 265:1304213046, 1990.

24. Frid M.G., B.V. Shekhonin, V.E. Koteliansky, and M.A. Glukhova. Phenotypic changes of human smooth muscle cells during development: late expression of heavy caldesmon and calponin. Dev Biol 153:185-193, 1992. 
25. Chapados R.A., R. Steinhorn, K.E. Kamm, F.C. Morin III, and C.R. Rosenfeld. Increased pulmonary artery (PA) myosin heavy chain (MHC)-B expression and decreased force generation occur in persistent pulmonary hypertension (PPH). Pediatr. Res. 37:389A (abstr), 1995.

26. Chern J., K.E. Kamm, and C.R. Rosenfeld. Smooth muscle myosin heavy chain isoforms are developmentally regulated in male fetal and neonatal sheep. Pediatr. Res. 38:697-703, 1995.

27. Word R.A., J.T. Stull, M.L. Casey, and K.E. Kamm. Contractile elements and myosin light chain phosphorylation in myometrial tissue from nonpregnant and pregnant women. J Clin Invest 92:29-37, 1993.

28. Owens G.K. Control of hypertrophic versus hyperplastic growth of vascular smooth muscle cells. Am. J. Physiol. 257:H1755-H1765, 1989.

29. Orton E.C., S.M. LaRue, B. Ensley, and K. Stenmark. Bromodeoxyuridine labeling and DNA content of pulmonary arterial medial cells from hypoxia-exposed and nonexposed healthy calves. Am. J. Vet. Res. 53:1925-1930, 1992.

30. Mecham R.P., K.R. Stenmark, and W.C. Parks. Connective tissue production by vascular smooth muscle in development and discase. Chest 99:43S-47S, 1991.

31. Morin III F.C., and K.R. Stenmark. Persistent pulmonary hypertension of the newborn. Am. J. Respir. Crit. Care Med. 151:2010-2032, 1995.

32. Hall S.M., and S.G. Haworth. Onset and evolurion of pulmonary vascular disease in young children: abnormal postnatal remodeling studied in lung biopsies. J. Pathol. 166:183-193, 1992.

33. Mecham R.P., L.A. Whitehouse, D.S. Wrenn, W.C. Parks, G.L. Griffin, R.M. Senior, E.C. Crouch, K.R. Stenmark, and N.F. Voelkel. Smooth muscle-mediated connective tissue remodeling in pulmonary hypertension. Science 237:423-426, 1987.

34. Stenmark K.R., A.A. Idashev, E.C. Orton, A.G. Durmowicz, D.B. Badesch, W.C. Parks, R.P. Mecham, N.F. Voelkel, and J.T. Reeves. Cellular adaptation during chronic neonatal hypoxic pulmonary hypertension. Am. J. Physiol. Suppl. 261:97-104, 1991.

35. Allen K.M., and S.G. Haworth. Cytoskeletal features of immature pulmonary vascular smooth muscle cells: the influence of pulmonary hypertension on normal development. J. Pathol. 158:311-317, 1989.

36. Wohrley J.D., M.G. Frid, E.P. Moisecva, E.C. Orton, J.K. Belknap, and K.R. Stenmark. Hypoxia selectively induces proliferation in a specific subpopulation of smooth muscle cells in the bovine neonatal pulmonary arterial media. J. Clin. Invest. 96:273-281, 1995.

37. Rosenberg A.A., J. Kennaugh, S.L. Koppenhafer, M. Loonris, B.A. Chatfield, S.H. Abman. Elevated immunoreactive endothelin-1 levels in newborn infants with persistent pulmonary hypertension. J. Pediatr. 123:109-114, 1993.

38. Adatia I., S.E. Barrow, P.D. Stratton, V.M. Miall-Allen, J.M. Ritter, and S.G. Haworth. Thromboxane A2 and prostacyclin biosynthesis in children and adolescents with pulmonary vascular disease. Circulation 88:2117-2122, 1993.

39. Celermajer D.S., S. Cullen, and J.E. Deanfield. Impairment of endothelium-dependent pulmonary artery relaxation in children with congenital heart disease and abnormal pulmonary hemodynamics. Circulation 87:440-446, 1993. 
40. Haworth S.G. Pathophysiological and metabolic manifestations of pulmonary vascular disease in children. Herz 17:254-261, 1992.

41. Abman S.H., D.D. Ivy, J.W. Ziegler, and J.P. Kinsella. Mechanisms of abnormal vasoreactivity in persistent pulmonary hypertension of the newborn infant. J. Perinatol. 16:S 18-523, 1996.

42. Stenmark K.R., E.C. Orton, J.T. Reeves, N.F. Voelkel, E.C. Crouch, W.C. Parks, and R.P. Mecham RP 1988 Vascular remodeling in neonatal pulmonary hypertension: role of the smooth muscle cell. Chest 93:1275-1325, 1988.

43. Ross R., E.W. Raines, and D.F. Bowen-Pope. The biology of platelet-derived growth factor. Cell 46:155-169, 1986.

44. Perkett E.A., D.B. Badesch, M.K. Roessler, K.B. Stenmark, and B. Meyriek. Insulin-like growth factor 1 and pulmonary hypertension induced by continuous air embolization in sheep. Am. J. Respir. Cell. Mol. Biol. 6:82-87, 1992.

45. Botney M.D., W.C. Parks, E.C. Crouch, I.C. Stenmark, and R.P. Mecham. Transforming growth factor- $\beta$, is decreased in remodeling hypertensive bovine pulmonary arteries. J Clin Invest 89:1629-1635, 1992. 


\section{General discussion}

An understanding of the normal regulation of smooth muscle differentiation and maturation is critical to our understanding of congenital defects in vascular and visceral development, as well as vascular development in tumors or arteriosclerosis.

It has been emphasized by Owens (1) that there is a continuum of differentiated phenotypes that exists between the committed, but undifferentiated smooth muscle cell in one end of the spectrum and the contractile mature smooth muscle cell on the other. Specific marker proteins are induced sequentially during differentiation and are documented most extensively in vascular smooth muscle. The expression of contractile proteins is developmentally regulated, and prior to birth a synthetic smooth muscle phenotype is predominant in systemic vasculature $(2,3)$. During smooth muscle development it is important to determine which of the smooth muscle cell phenotypes is being studied. Furthermore, marker proteins and their cellular function are to be identified in smooth muscle. Their phenotypic state of these marker proteins and their pattern of expression are to be characterized. The protein isoform expression patterns of the major contractile proteins have been evaluated extensively as qualitative indices of maturation, although quantitative increases in contractile proteins have received scant attention. There are few studies available focusing on late fetal or postnatal maturation $(4,5,6)$.

\section{Developmentally regulated contractile proteins}

We examined vascular and visceral smooth muscle tissues from feral and neonatal sheep. Sheep have been used to study various aspects of fetal physiology $(7,8,9)$. The large size of the fetus permits instrumentation and studies in utero. The relatively long duration of gestation, $145 \pm 5$ days, allows the study of specific time points during development more easily than in smaller species like rodents, whose gestation is $\sim 20 \mathrm{~d}(10,11)$. Moreover, the hormonal milieu or time of parturition can be modified to study cardiovascular development in fetal sheep.

In the present studies we demonstrated that maturation of vascular and visceral smooth muscle tissues, as assessed by increases in contractile protein contents, occurs continuously from mid-gestation through the first month of life. Distinct differences were observed between tissues, leading to the conclusion that smooth muscle maturation is tissue specific. For example, bladder smooth muscle matures far in advance of another visceral muscle, the myometrium, as well as the 
vascular smooth muscle in the aorta. The expression of contractile proteins during development is carefully orchestrated, yet patterns of expression differ in a tissue specific manner.

\section{Smooth muscle myosin isoform expression}

Smooth muscle replication plays a central role in the pathogenesis of atherosclerosis (12). It has been demonstrated that non-muscle MHC-B isoform of myosin is re-expressed in smooth muscle cells of neointimas. These cells express SM1, but little SM2. This MHC isoform profile in the smooth muscle of neointimas suggests a dedifferentiation of smooth muscle towards the embryonic phenotype and involvement in the cellular mechanism of the development of atherosclerosis (12). There is a marked contrast of MHC expression in neointimal and medial smooth muscle cells.

The role of the different myosin isoforms remains unclear. SM1 and SM2 are clearly associated with a mature contractile phenotype, whereas MHC-B expression in smooth muscle is associated with growth either during development, disease or in cell culture $(12,13,14)$. Variation of the C-terminal of SM-myosin has little effect on the ability of isolated myosin to translocate actin in vitro motility assays (15); however, studies in permeabilized fibers suggest that the unique nonhelical tail region of SM1 may modulate contractility through an interaction with adjacent myosin molecules in the thick filament (16). Others have suggested that SM1 and SM2 may have different effects on the filament stability and thereby stress generation (17). While different smooth muscle tissues exhibit characteristic ratios of SM1 and SM2, a distinct population of cells can exist within a tissue $(18,19)$. The ultimate effect of cellular heterogeneity remains to be determined. Non-muscle myosin exhibits different patterns of staining in tissues and isolated cells, suggesting that they serve different functions $(20,21)$. These and other results favor the notion that expression of non-muscle myosin in smooth muscle supports proliferation and other non-contractile functions during development (22). Our finding that little or no MHC-B is expressed in bladder muscle during fetal maturation may indicate that this muscle has a fully expanded population of smooth muscle cells at an early stage, as compared to aorta and myometrium. This remains to be determined. The data do not explain how this tissue specificity is regulated.

\section{Role of proteins and stresses}

We also examined the possibility that early maturation of bladder protein expression would be associated with early onset of contractile capacity. Developmental increases in contractile content should be the foundation for increasing contractile capacity during maturation $(5,6)$. We compared contractions elicited by aorta, bladder and myometrium from near-term fetal and adult sheep. Whereas fetal 
bladder exhibited spontaneous activity and gave robust contractile responses to depolarization by $\mathrm{KCl}$ and carbochol, aorta was refractory to all stimuli tested. Fetal myometrium, on the other hand, exhibited spontaneous activity, but contractile forces were a small fraction of those seen by maternal myometrium. The results were consistent with the notion that bladder muscle growth and maturation is initiated early in development and proceeds rapidly thereafter. The pattern of myosin heavy chain species was very similar for aorta and myometrium, yet strikingly different from those in the bladder. The advanced maturation and growth of bladder smooth muscle as compared to aorta and myometrium probably reflects their functional differences during development. The uterus has no known function until reproductive age is achieved, and the aorta is exposed to relatively low arterial pressures until after birth (23). Thus the need for rapid maturation changes in these tissues may be minimal. In contrast, the bladder is functional early in development, excreting urine at a rate of $\sim 7-10 \mathrm{ml} / \mathrm{kg} \cdot \mathrm{h}$ as early as $24 \mathrm{wk}$ gestation in the human $(24,25,26)$. Since fetal growth is logarithmic after $100 \mathrm{~d}$, weight increases $\sim 4$-fold by term. The urine production also increases $\sim 4 \mathrm{ml} / \mathrm{h}$ to $\sim 30 \mathrm{ml} / \mathrm{h}$. The intraluminal pressures and volumes must rise accordingly, which may play a fundamental role in early maturation observed in bladder smooth muscle.

\section{Umbilical-placental circulation}

The umbilical-placental circulation is crucial for fetal growth and well being. After observing the differences in tissue maturation we decided to compare the systemic circulation to the umbilical circulation, unique and only present during fetal life. The responsiveness of the fetal peripheral vascular bed is known to be less responsive to some vasoconstrictors, especially angiotensin II, compared to the umbilical circulation $(27,28,29)$. One explanation is that the contractile protein composition and therefore the contractile capacity of vascular smooth muscle in umbilical and systemic arteries differ. This observation is consistent with the expression of the angiotensin receptor subtype expression in fetal sheep (30).

Umbilical artery, like bladder, therefore demonstrates precocious maturation not only in this early onset of contractility, but in achieving high (2-fold greater than aorta or femoral artery) contents of actin and myosin in the absence of MHC-B expression.

Significant differences exist between the umbilical and systemic responses to vasoconstrictors $(27,31,32)$.

\section{Impact on development}

These findings raise provocative questions of the role of smooth muscle in cardiovascular function during development. Dawes suggested in 1968 that the 
umbilicoplacental bed might be important in regulating total peripheral resistance, because it accounts for $40 \%$ of fetal cardiac output. Our group $(28,30,31)$ and others $(27,33)$ reported this bed is very sensitive to angiotensin II. The major response was seen in the umbilical artery and minimal responses were reported in the fetal umbilical vein. The umbilical artery expresses the angiotensin 1 receptor AT1R, which mediates contraction in the adult. In contrast, the fetal arteries express only the angiotensin 2 receptor (AT2R) $(28,30)$, whose function is not known, but does not appear to be directly related to contraction (28). Ovine umbilical responses exceed those of the systemic vasculature $(27,28,32)$. The mechanism for this is not known. It was noted that the hindlimb was less sensitive to angiotensin II. Furthermore, there is evidence that there is autoregulation in the hindlimb, which suggests peripheral responses to angiotensin might be due to the myogenic response. This is supported by the results of Iwamoto and Rudolph (27), who reported that relative to the umbilical circulation, the peripheral organ and tissue blood flow was maintained during angiotensin II mediated increases in arterial pressure. A possible explanation is that the contractile protein expression in the fetal systemic vasculature is immature compared to the umbilical circulation as is assessed by an abundance of nonmuscle MHC-B and decreased contents of actin, myosin and smooth muscle MHC isoforms compared with the adult and postnatal animal $(2,3)$. When the umbilical and fetal systemic artery protein expression was compared with adult vessels, only the umbilical artery resembles the adult artery (34). If the AT2R is the predominant receptor in systemic arteries prenatally and the expression of contractile proteins is immature, it is unclear how the pressor responses are elicited. In the fetus, this may occur by constricting the umbilicoplacental bed, which accounts for $40 \%$ of cardiac output.

We have shown that both fetal aorta and fetal femoral artery are refractory to all stimuli, including $\mathrm{KCl}$; however, umbilical artery generated significant stress in response to a number of agonist (34). The umbilical artery smooth muscle development is precocious within the fetal vasculature. Advanced maturation has also been described in the ductus arteriosus (20). The accelerated maturation of the umbilical artery and ductus arteriosus appear to be unique to the fetal vasculature, resembling adult vascular smooth muscle in both protein expression and capacity to contract. Because the umbilical artery and ductus arteriosus constrict in term infants soon after birth to redirect cardiac output, these differences may relate to adaptive alterations necessary after birth.

Smooth muscle differentiation is a complex process that involves sequential activation of genes encoding smooth muscle specific proteins. Whether this maturation is determined by the embryonic origins of smooth muscle cells or by paracrine, hormonal or mechanical factors remains to be investigated. This study illustrates that maturation of the contractile protein phenotype is associated with maturation of contractile function. Further studics will be required to determine threshold conditions leading to contractile function, as well as specific queues promoting maturation during development. 


\section{REFERENCES}

1. Owens G.K. Regulation of differentiation of vascular smooth muscle cells. Physiol. Rev. $75: 487-517,1995$.

2. Chern J., K.E. Kamm, and C.R. Rosenfeld. Smooth muscle myosin heavy chain isoforms are developmentally regulated in male fetal and neonatal sheep. Pediatr. Res. 38:697-703, 1995.

3. Arens Y., K.E. Kamm, and C.R. Rosenfeld. 1999. Maturational differences between vascular and bladder smooth muscle during ovine development. Am. J. Physiol. 278: R1305-R1313, 2000.

4. Belik J., A. Halayako, K. Rao, and N. Stephens. Pulmonary vascular smooth muscle: Biochemical and mechanical developmental changes. Am. J. Physiol. 71: 1129-1135, 1991.

5. Seidel C.L. and J.C.Allen. Pharmacological characteristics and actomyosin content of aorta from neonatal rats. Am. J. Physiol. 237:C81-C86, 1979.

6. Tomomasa T, Y. Xie, A. Morikawa, T. Kuroume, and P.E. Hyman. Postnatal changes in size and actomyosin content of rabbit gastric myocytes. Reprod. Fert. Dev. 7:1305-1310, 1995.

7. Brace R.A. Amniotic fluid volume and its relationship to fetal fluid balance: review of experimental data. Sem. Perinatol. 10:103-112, 1986.

8. Andujo O, H. Nielsen, C.R. Rosenfeld, J.M. Snyder. Failure to detect a stimulatory effect of estradiol-17 $\beta$ on fetal lung maturation. Pediatr. Res. 22:145-149A, 1987.

9. France J.T., R.R. Magness, B.A. Murray, C.R. Rosenfeld, J.I. Mason. The regulation of ovine placental steroid 17ß-hydroxylase and aromatase by glucocorticoid. Mol. Endocrinol. 2:193-199, 1988.

10. Kuro-o M., R. Nagai, H. Tsuchimochi, H. Katoh, Y. Yazaki, A. Ohkubo, and F. Takaku. Developmentally regulated expression of vascular smoorh muscle myosin heavy chain isoforms. J. Biol. Chem. 264:18272-18276, 1989.

11. Eddinger T.J., R.A. Murphy. Developmental changes in actin and myosin heavy chain isoform expression in smooth muscle. Arch. Biochem. Biophys. 284:2232-2237, 1991.

12. Kuro-o M. R. Nagai, K. Nakahara, H. Katoh, R. Tsai, H. Tsuchimochi, Y. Yazaki, A. Ohkubo, and F. Takaku. cDNA cloning of a myosin heavy chain isoform in embryonic smooth muscle and its expression during vascular development and in arteriosclerosis. J. Biol. Chem. 266:3768-3773, 1991.

13. Chamley-Campbell J., G.R. Campbell, and R. Ross. Smooth muscle cell in culture. Physiol. Rev. 59:1-61, 1979.

14. Simons M., M. Wang, W. Mc.Bride, S. Kawamoto, K. Yamakawa, D. Gdula, R.S. Adelstein, and L. Weir. Human nonmuscle myosin heavy chains are encoded by two genes located on different chromosomes. Circ. Res. 69:530-539, 1991.

15. Kelley C.A., R.S. Adelstein. Characterization of isoform diversity in smooth muscle myosin heavy chains. Can. J. Physiol. Pharmacol. 72:1351-1360, 1994.

16. Shuang C., D.G. Ferguson, A.F. Martin, and R.J. Paul. Smooth muscle contractility is modulated by myosin tail-S2-L.MM hinge region interaction. Am. J. Physiol. 269:C1126C1132, 1995.

17. Somlyo A.P. Myosin isoforms in smooth muscle: how may they affect function and structure? J. Muscle Res. Cell Motil. 14:557-563, 1993. 
18. Frid M.G., E.P. Moiseeva, and K. Stenmark. Multiple phenotypically distinct smooth muscie cell populations exist in the adult and developing bovine pulmonary arterial media. in vivo. Circ. Res. 75:669-681, 1994.

19. Meer D.P. and T.J. Eddinger. Heterogeneity of smooth muscle myosin heary chain expression at the single cell level. Am. J. Physiol. 270:C1819-C1824, 1996.

20. Giuriato L., M. Scatena, A. Chiavegato, M. Tonello, G. Scannapieco, P. Pauletto, and S. Sartore. Non-muscle myosin isoforms and cell heterogeneity in developing rabbit vascular smooth muscle. J. cell Sci. 101:233-246, 1992.

21. Kelly C.A., J.R. Sellers, D.L. Gard, D. Bui, R. Adelstein, and I.C. Baines. Xenopus nonmuscle myosin heavy chain isoforms have different subcellular localizations and enzymatic activities. J. Cell Biol. 134:675-687, 1996.

22. Warrick H.M. and J.A. Spudich. Myosin structure and function in cell motility. Annu. Rev. Cell Biol. 3:379-421, 1987.

23. Dawes G.S. Feral and neonatal Physiology. Chicago: Year book Medical Publishers, Inc. 1968 p. $97-99,177-179$.

24. Kulhanek J.F., G. Meschia, E.L. Makowski, and F.C. Battaglia. Changes in DNA content and urea permeability of the sheep placenca. Am. J. Physiol. 226:1257-1263, 1974.

25. Takeuchi H., T. Koyanagi, T. Takashima, S. Satoh, and H. Nakano. Fetal urine production is different gestational ages: Correlation to various compromised fetuses in utero. Early Hum. Dev. 40:1-11, 1994.

26. Van Otterlo L.C., J.W. Wlaimiroff, and H.C.S. Wellenburg. Relationship between fetal urine production and amnioric fluid volume in normal pregnancy and pregnancy complicated by diabetes. Br. Obstet. Gynecol. 84:205-209, 1977.

27. Iwamoto H.S. and A.M. Rudolf. Effects of angiotensin II on the blood flow and its distribution in fetal lambs. J. Dev. Physiol. 1:283-293, 1981.

28. Kaiser J.R., B.E. Cox, T.A. Roy, and C.R. Rosenfeld. Differential development of umbilical and systemic arteries. I. ANG II receptor subtype expression. Am. J. Physiol. 274:R797R807, 1998.

29. White R.P. Pharmadynamic study of maturation and closure of human umbilical arteries. Am. J. Obstet. Gynecol. 160:229-237, 1989.

30. Cox B.E. and C.R. Rosenfeld. Ontogeny of vascular angiotensin II receptor subtype expression in ovine development. Pediatr. Res. 45:414-424, 1999.

31. Yoshimura T., R.R. Magness, and C.R. Rosenfeld. Angiotensin II and alpha-agonist. I. Responses of ovine fetoplacental vasculature. Am. J. Physiol. 259:H464-472, 1990.

32. Rosenfeld C.R., A. Gresores, T.A. Roy, and R.R. Magness. Comparison of ANG II in fetal and pregnant sheep: metabolic clearance and vascular sensitivity. Am. J. Physiol. 268: E237-247, 1995.

33 Adamson S.L., R.J. Morrow, S.B. Bull, and B.L. Langtille. Vasomotor responses of the umbilical circulation in fetal sheep. Am. J. Physiol. 256:R1056-R1062, 1989.

34. Arens, Y, R.A. Chapados, B.E. Cox, K.E. Kamm, and C.R. Rosenfeld. Differential development of umbilical and systemic arteries. II. Contractile proteins. Am. J. Physiol. 274: R1815-1823, 1998. 


\section{Summary}

During ovine development there are substantial tissue specific alterations that occur in the expression and contents of several important contractile proteins and the nonmuscle $\mathrm{MHC}$ isoforms in smooth muscle of a number of arteries and visceral tissues. We studied animals before 80 days of gestation and after 3 months postnatally, which had not been done before. Furthermore it had not been studied in detail how the smooth muscle proteins are associated with the development of smooth muscle cytoskeleton, e.g. $\alpha$-actin, desmin, filamin and calponin, nor have the other contractile protein expression been extensively studied. The contractile proteins are believed to play an important role in the contractile properties of smooth muscle cells and possibly their maturation, e.g. caldesmon, $\alpha$-actin, myosin, calponin, and myosin light chain kinase.

Chapter 1 is a review of the literature regarding the physiology of smooth muscle contraction. In this chapter the contractile and cytoskeletal domain, the contraction pathway, the regulatory factors and necessary stimulation of smooth muscle contraction are discussed.

Chapter 2 describes the developmental aspect of smooth muscle as described in the literature. It discusses the differentiation and maturation of smooth muscle. Furthermore, it gives a review about markers of maturation. The major contractile and cytoskeletal proteins, which are studied in the rest of the thesis during ovine development: actin, myosin, caldesmon, calponin, filamin, desmin, the regulatory light chains and the enzyme myosin light chain kinase are reviewed.

Chapter 3 gives a short summary of the material and methods used in this study.

Chapter 4 in this study the hypothesis is tested that smooth muscle maturation is dictated by functional requirements. Amounts and patterns of actin and myosin isoform expression as well as stress generating capacity are compared between the bladder, and the aorta. The present results of this study indicate that bladder smooth muscle undergoes accelerated maturation of the contractile phenotype accompanied by the early onset of force development as compared to the vascular smooth muscle of the aorta.

Chapter 5 in this study the hypothesis is tested that differences in vascular responsiveness could reflect dissimilarities in the vascular smooth muscle phenotype during development. Actin, myosin, myosin isoforms, and active stresses were compared in femoral and aortic sınooth muscle in near-term and adult sheep to external and internal umbilical arteries. We concluded that compared with the umbilical and adult circulation, the fetal systemic vascular smooth muscle is biochemically and functionally immature. Thus umbilical vascular smooth 
muscle demonstrates precocious maturation resembling adult vascular smooth muscle in protein expression and function.

Chapter 6 this chapter focuses on the patterns of expression of the major contractile proteins in the developing myometrium and the myometrium during its reproductive cycle. Although no direct functional demand is known for the fetal uterus, the smooth muscle development in the myometrium at the end of gestation expresses the contractile phenotype and is capable of force generation, unlike the systemic fetal vasculature.

Chapter 7 in this chapter the proteins examined are caldesmon, calponin, desmin and filamin during an extended period of development. Distinct groups of proteins appear to exist, whose expression is regulated differently. The results indicate a time course of maturation in visceral smooth muscle, which is different compared to vascular smooth muscle in both the cytoskeleton and contractile domain.

Chapter 8 Large left to right shunts in fetuses with congenital heart disease may result in development of pulmonary hypertension. In a sheep model of this form of PAH the expression of contractile and cytoskeletal proteins is examined in comparison with control animals. The conclusion of this study was that PAH resulted in persistence of the immature phenotype in the pulmonary artery.

In conclusion the studies in this thesis show, as discussed in Chapter 9, that the expression of contractile proteins during development are carefully orchestrated, yet patterns of expression differ in a tissue specific manner. The fetal systemic vascular smooth muscle in near-term fetal sheep is functionally immature as assessed by MHC-B expression and attenuated stress generation. The umbilical smooth muscle appears to be unique to the fetal vasculature, resembling adult vascular smooth muscle in both protein expression and capacity to contract. Bladder smooth muscle undergoes accelerated maturation compared to vascular tissues during development. Maturation of the contractile phenotype is associated with maturation of contractile function. 


\section{Samenvatting}

Gedurende de foetale ontwikkeling gebeuren er substantiële weefsel specifieke veranderingen in de expressie van de verschillende contractiele eiwitten in glad spierweefsel van vaten en holle organen. Wij bestudeerden in dit proefschrift schapen vanaf 80 dagen gestatie tot 3 maanden na de geboorte en volwassen schapen. Het was niet bekend hoe de glad spierweefsel eiwitten zijn geassocieerd met de ontwikkeling van het cytoskelet. Gekeken werd naar de rol van de eiwitten actin, desmin, filamin en calponin. Tevens waren de eiwitten, die geassocieerd worden met het contractile domein niet volledig onderzocht. Deze contractile eiwitten spelen een belangrijke rol in de contractile eigenschappen van de glad spierweefsel cel: actin, myosin, caldesmon, calponin en myosin light chain kinase.

Hoofdstuk 1 geeft een overzicht van de literatuur over de fysiologie van glad spierweefsel contractiliteit. In dit hoofdstuk worden het contractiele domein en het cytoskelet, de contractie pathway en de regulatie en stimulatie van glad spierweefsel besproken.

Hoofdstuk 2 beschrijft een literatuurstudie van de ontwikkeling van glad spierweefsel. Differentiatie en maturatie worden besproken. De belangrijkste contractiele en cytoskelet eiwitten worden samengevat, te weten actin, myosin, caldesmon, calponin, desmin, filamin, regulerende light chains en het enzym myosin light chain kinase.

Hoofdstuk 3 geeft een korte samenvatting van de gebruikte materialen en methoden.

Hoofdstuk 4 beschrijft de hypothese of glad spierweefsel maturatie samengaat met functie. De hoeveelheid en expressie patronen van actin en myosin, als ook het vermogen tot stress generatie worden vergeleken in twee weefsels: blaas en aorta. De resultaten wijzen erop dat glad spierweefsel in de blaas een versnelde maturatie ondergaat naar het contractiele fenotype, wat samengaat met een vroege aanzet tot het vermogen tot krachtontwikkeling vergeleken met de aorta.

Hoofdstuk 5 licht de hypothese in deze studie toe, namelijk dat er verschil is in vasculaire respons in verschillend vasculair glad spierweefsel tijdens foetale en postnatale ontwikkeling. Actin, myosin, myosine isovormen en actieve stress worden vergeleken in foetale aorta en arteria femoralis, externe cn internc irteria umbilicalis en volwassen aorta en arteria femoralis. Uit dere studie konden wij concluderen, dat vergeleken met de umbilicale en volwassen circulatie, het foctale vaatstelsel immatuur is, zowel biochemisch als functioneel. De umbilicale circulatie lijkt in eiwit opmaak en functie op volwassen glad spierweefsel.

Hoofdstuk 6 beschrijft het patroon van contractiele eiwit expressie in het foetale en neonatale myometrium en het myometrium tijdens de reproductieve cyclus. 
Ofschoon er geen functie bekend is voor de foetale uterus tijdens ontwikkeling, heeft het glad spierweefsel aan het einde van gestatie het contactiele fenotype en is in staat tot stress generatie. Dit in tegenstelling tot het systemische foetale vaatstelsel.

Hoofdstuk 7 bestudeert de eiwitten caldesmin, calponin, desmin en filamin tijdens de ontwikkeling. Er lijken verscheidene groepen te bestaan, waarvan de expressie verschillend wordt gereguleerd. De resultaten wijzen op een patroon van maturatie van visceraal gladspierweefsel, wat anders is dan vasculair glad spierweefsel, zowel in het contractiele domein als in het cytoskelet.

Hoofdstuk 8 een grote links/rechts shunt in foetusen met een congenitale hartafwijking kan resulteren in pulmonale hypertensie. In het diermodel voor deze vorm van pulmonale hypertensie wordt de expressie van contractiele eiwitten en de eiwitten van het cytoskelet bestudeerd en vergeleken met controle dieren. De conclusie was, dat deze vorm van pulmonale hypertensie resulteert in continuering van het immature fenotype in de arteria pulmonalis.

Hoofdstuk 9 bevat de conclusie van de studies in dit proefschrift en de discussie daaromtrent. De expressie van contractile eiwitten tijdens foetale ontwikkeling is zorgvuldig georkestreerd en het patroon is anders in de diverse bestudeerde weefsels. Het foetale systemische vaatstelsel is immatuur, wat blijkt uit de expressie van MHC-B en het verlate vermogen tot stress generatie. Het umbilicale systeem is uniek in het foetale vaatstelsel. Het is te vergelijken met het volwassen vaatstelsel in eiwit expressie en het vermogen tot contractie. De blaas ondergaat een versnelde, mogelijk aan functie gerelateerde maturatie tijdens de foetale ontwikkeling. De maturatie van het contractile fenotype is geassocieerd met contractile functie. 


\section{Curriculum vitae}

5 november 1969 geboren te 's-Hertogenbosch

1981-1988 Gymnasium, Stedelijk Gymnasium 's-Hertogenbosch

1988-1993 Doctoraal Geneeskunde Rijksuniversiteit Limburg Maastricht

1993-1995 Arts-examen Geneeskunde Rijksuniversiteit Limburg Maastricht

1995-1998 Promotieonderzoek, Division of Neonatal-Perinatal Medicine, Southwestern Medical Center, Dallas, Texas, USA

1997 ECFMG examen

1998 Arts-assistent geneeskundige niet in opleiding, afdeling Obstetrie-Gynaecologie, St Anna ziekenhuis Oss

1999 Arts-assistent geneeskundige niet in opleiding, afdeling Klinische Genetica, Universiteit Maastricht

Start opleiding tot klinisch geneticus in augustus 2000 


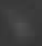

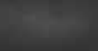

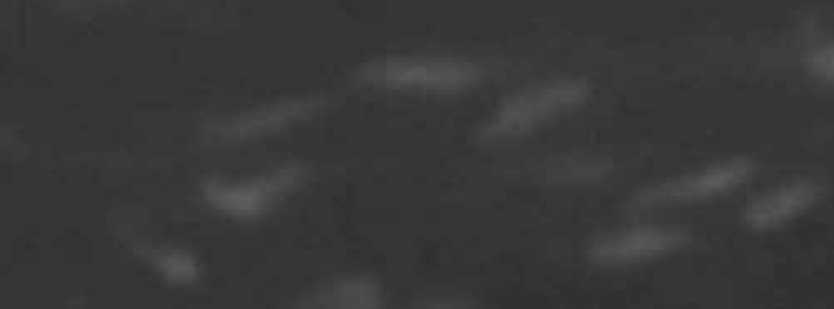

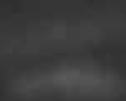

(2)

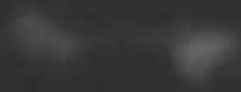

\section{cosise}

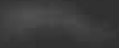

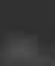

(2)

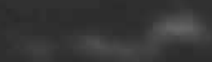

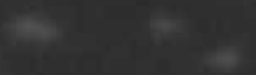

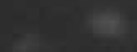

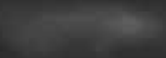

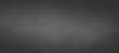

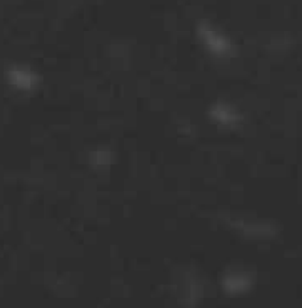

$x_{x}$

(2)

6.

a

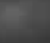

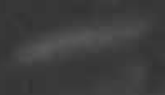

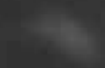

37

(4)

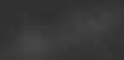

$3 x^{2}$

\section{-}
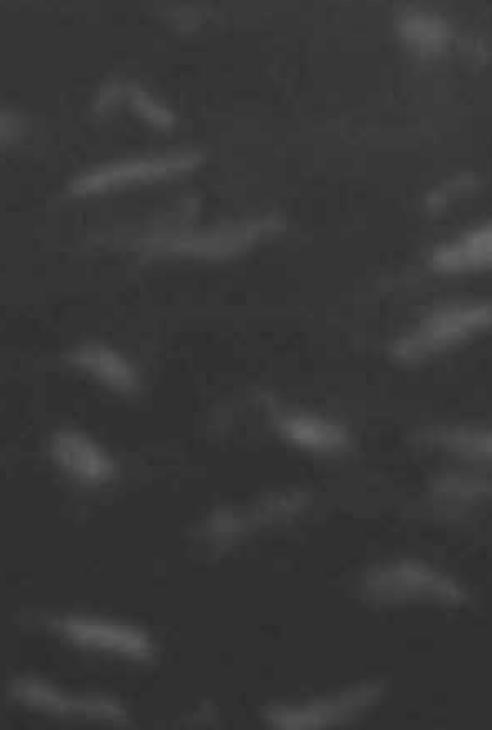